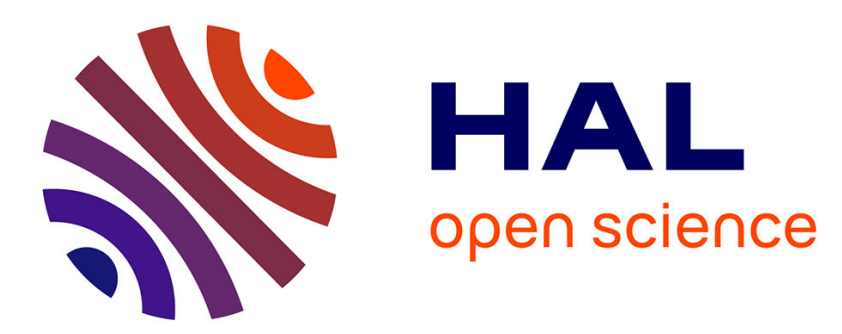

\title{
Science and Technology in East Asia. The Legacy of Joseph Needham:
}

\author{
Alain Arrault, Catherine Jami
}

\section{To cite this version:}

Alain Arrault, Catherine Jami (Dir.). Science and Technology in East Asia. The Legacy of Joseph Needham:. Brepols, pp.152, 2001, Proceedings of the XXth International Congress of History of Science (Liège, 20-26 July 1997) Vol. IX, 2-503-51268-2. 10.1484/M.DDA-EB.5.106663 . hal-03120526

\section{HAL Id: hal-03120526 \\ https://hal.science/hal-03120526}

Submitted on 9 Jan 2022

HAL is a multi-disciplinary open access archive for the deposit and dissemination of scientific research documents, whether they are published or not. The documents may come from teaching and research institutions in France or abroad, or from public or private research centers.
L'archive ouverte pluridisciplinaire HAL, est destinée au dépôt et à la diffusion de documents scientifiques de niveau recherche, publiés ou non, émanant des établissements d'enseignement et de recherche français ou étrangers, des laboratoires publics ou privés. 



\title{
SCIENCE AND TECHNOLOGY IN EAST ASIA
}

\author{
The Legacy of JosePH NeEDHAM
}




\section{DE DIVERSIS ARTIBUS}

COLLECTION DE TRAVAUX

DE L'ACADÉMIE INTERNATIONALE

D'HISTOIRE DES SCIENCES
COLLECTION OF STUDIES

FROM THE INTERNATIONAL ACADEMY OF THE HISTORY OF SCIENCE

\section{DIRECTION \\ EDTTORS}

\section{EMMANUEL ROBERT}

POULLE HALLEUX

TOME 51 (N.S. 14)

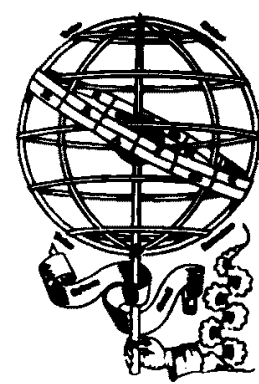

BREPOLS 
iij PROCEEDINGS OF THE XX ${ }^{\text {th }}$ INTERNATIONAL CONGRESS OF HISTORY OF SCIENCE (Liège, 20-26 July 1997)

VOLUME IX

\section{SCIENCE AND \\ TECHNOLOGY \\ IN EAST ASIA \\ THE LEGACY OF JOSEPH NEEDHAM}

Edited by

Alain ARRAULT and Catherine JAMI

BREPOLS 
The $\mathrm{XX}^{\text {th }}$ International Congress of History of Science was organized by the Belgian National Committee for Logic, History and Philosophy of Science with the support of :

ICSU

Ministère de la Politique scientifique

Académie Royale de Belgique

Koninklijke Academie van België

FNRS

FWO

Communauté française de Belgique

Région Wallonne

Service des Affaires culturelles de la Ville de Liège

Service de l'Enseignement de la Ville de Liège

Université de Liège

Comité Sluse asbl

Fédération du Tourisme de la Province de Liège

Collège Saint-Louis

Institut d'Enseignement supérieur "Les Rivageois"

Academic Press

Agora-Béranger

APRIL

Banque Nationale de Belgique

Carlson Wagonlit Travel Incentive Travel House
Chambre de Commerce et d'Industrie de la Ville de Liège

Club liégeois des Exportateurs

Cockerill Sambre Group

Crédit Communal

Derouaux Ordina sprl

Disteel Cold s.a.

Etilux s.a.

Fabrimétal Liège - Luxembourg

Generale Bank n.v. -

Générale de Banque s.a.

Interbrew

L'Espérance Commerciale

Maison de la Métallurgie et de l'Industrie de Liège

Office des Produits wallons

Peeters

Peket dè Houyeu

Petrofina

Rescolié

Sabena

SNCB

Société chimique Prayon Rupel

SPE Zone Sud

TEC Liège - Verviers

Vulcain Industries

(C) 2001 Brepols Publishers n.v., Turnhout, Belgium

All rights reserved. No part of this publication may be reproduced, stored in a retrieval system, or transmitted, in any form or by any means, electronic, mechanical, photocopying, recording, or otherwise, without the prior permission of the publisher.

$\mathrm{D} / 2001 / 0095 / 51$

ISBN 2-503-51268-2

Printed in the E.U. on acid-free paper 


\section{TABLE OF CONTENTS}

Introduction : Science and Technology in East Asia

Catherine JAMI

Joseph Needham, Heterodox Marxism, and Chinese Science.

Gregory BLUE

Joseph Needham's Grand Question and How to Make it Productive for our Understanding of the Scientific Revolution

H. Floris COHEN

Needham's Vision of the Encounter of China and Europe : The Case of the History of Botany

Georges MÉTAILIÉ

Technological Illustration in China : A Post-Needham Perspective

Peter J. Golas

Influence of Islamic Astronomy in Song and Yuan China -

Some Facts and Discussions.

SUN Xiaochun, Jacob KISTEMAKER

Some Reflections on the Western Scientific Traditions from the East Asian Perspective

Yung Sik KIM

Needham's Impact on Japanese History of Science

Togo TsUKaHARA, Keizo Hashimoto, Noriaki MatsUMURA

Cognitive Homologies in the Studies of Science in Indian Antiquity :

A Historiographic Axis of the Indian Journal of History of Science.

Dhruv RAINA

Why The Classic of Mountains and Seas (the Shan hai jing) contains Topographically Inaccurate Data

Véra DOROFEEVA-LICHTMANN 
Pensée corrélative et arithmologie en Chine.

Le cas de Shao Yong (1012-1077)

Alain ARRAULT

The Argument Between Right-rotation Theory and Left-rotation

Theory of the Sun, the Moon and the Five Planets in Ancient China....... 139 CHEN Meidong

The Acceptance of Proportional Expression in Japan 145

Ken'ichi SaTo

Contributors 153 


\title{
INTRODUCTION
}

\author{
SCIENCE AND TeChNOLOGY IN EAST Asia
}

Catherine JAMI

The $\mathrm{XX}^{\mathrm{th}}$ International Congress of History of Science was the first to be held after Joseph Needham (1900-1995) passed away. It was during this Congress, that the International Society for the History of East Asian Science, Technology, and Medicine (ISHEASTM), became the East Asia Commission of IUPHS's Division of History of Science. It therefore seemed most appropriate that ISHEASTM should hold a symposium dedicated to Needham's memory on this occasion. The many tributes that had been paid to him had mainly highlighted - quite rightly - his immense and pioneering work, mostly published in Science and Civilisation in China (hereafter SCC)'. In contrast, we chose to focus on some aspects of the history of "NonWestern " science, on which an impressive amount of literature has appeared since the first volume of $S C C$ was published. Besides bringing to light a " dark continent", this literature raises fundamental methodological and historiographical issues that could and should inform the work of the majority of historians of science, who study the "West". We thus intended to enlarge upon Needham's contribution to the construction of a new history of science, which strives to take into account its multifaceted development in all civilisations. Such was the meaning of the symposium's title, "Global History of Science : A Symposium Dedicated to Joseph Needham ". This Symposium was jointly organised by Sun Xiaochun (Chinese Academy of Sci- 
ences, then Vice-president, ISHEASTM), Togo Tsukahara (Tôkai University, then Secretary, ISHEASTM), and myself (then President ISHE-ASTM).

The first two papers contribute to a better understanding of Needham's work in the context of the historiography of science. Gregory Blue shows the significance of Needham's own choices within the debates among Marxist historians from the 1930s to the 1960s, concerning China's historical development. H. Floris Cohen, on the other hand, draws inspiration from the "Needham Question" for his reflection on the Scientific Revolution; his essay is a fine example of how Needham's work nourished the reflection on the history of European science.

Next, two of the scholars who are contributing to the ongoing publication of $S C C$, in botany and in mining technology respectively, give their own further reflections on questions that have been discussed by Needham. This gives a fine illustration of how in his own lifetime, he saw the field maturing from and beyond his own standpoint. Both Georges Métailié and Peter Golas question Needham's assertion that "modern ecumenical science was [the] common end of ancient and mediaeval systems of knowledge". Métailié argues that what we refer to as "botany" did not exist per se in the Chinese tradition, where the knowledge of plants emphasised the relationship between humans and their environment. Golas seeks explanation of the discrepancy between China and Europe as regards technical illustration. In a very Needhamian way, he points to possible technological, as well as cultural and social factors to account for this difference, pointing to the complexity of the context in which a book's illustrations should be assessed.

Sun Xiaochun and Jacob Kistemaker address the issue of transmission, which Needham discussed at length. Sharing his view that the Eurasian continent should be considered as a whole, rather than as a juxtaposition of mutually impermeable cultures, they differ from him in that, instead of once more emphasising Chinese contributions that circulated westward, they bring to light the important part played by Arabic astronomy in Yuan China. Such an approach is all the more welcome as it goes against an all too common tendency to mimic Needham's great regard for China without understanding his internationalist stand, which results in caricatural accounts of China's " firsts". Indeed one issue on which Needham's own work contributed to make his own approach outdated in his lifetime is that of the search for priority.

Yung Sik Kim proposes an unusual perspective on comparison - another major theme running through $S C C$. He discusses how Confucian scholars might have assessed some notions and issues that were deemed central in European intellectual history, and suggests how this can throw new light on 
long debated issues such as the relation between science and religion. This is an interesting way of breaking away from Eurocentric assessments of East Asian science.

In their joint paper, Togo Tsukahara, Keizo Hashimoto and Noriaki Matsumura assess the reception of Needham's work in Japan. When his work became known there, Japan, unlike Europe and America, already had a wellestablished tradition of research in the history of Chinese science, mainly the scholarship the "Kyoto school", under the aegis of Prof. Yabuuti Kiyosi (1906-). The political as well as institutional settings of this research explain that, during and after the Cold War, continued exchanges between Needham and Japanese historians of science and technology resulted in his work being widely known and accepted in Japan.

An indication that Needham's work is relevant far beyond the study of China, or the comparison between China and Europe, is the debates it has given rise to in, among other countries, India ${ }^{2}$. By analysing the contents in the Indian Journal of History of Science up to 1994, Dhruv Raina brings out features of the historiography of Indian science that parallel some which characterise Needham's approach, while showing that British colonial science and the break from its dominant discourse raised peculiar problems in the setting up of the field in India.

These papers, each in their own way, contributed towards the aim of the symposium, which was to open a dialogue on some of the issues discussed above, and to assess the ways in which these issues can reshape history of science seen in a global perspective. It is our hope that the publication of these proceedings will contribute to involve more scholars in that dialogue.

Besides the proceedings of this Symposium, four other papers read at the Congress are included in this volume. They give an idea of the diversity and sophistication of the ongoing research on East-Asian science. Véra Dorofeeva-Lichtmann and Alain Arrault's contributions, on Shanhai jing and on Shao Yong's arithmology respectively, represent what we might call a postNeedhamian approach: China's contribution to human knowledge once acknowledged, recent scholarship has turned to study more specifically the patterns in which this knowledge made sense in, and formed an integral part of, the world-view of those who produced it. The last two papers, on the other hand, follow the historical evolution of a particular topic: Chen Meidong's account of the debates on the sense of rotation of the Sun, Moon and Five Planets in imperial China shows that their history is no mere linear

2. See e g. S.I Habib and D Raina (eds), Situatıng the History of Scrence Dialogues with Joseph Needham. New Delhi. 1999 
evolution from error to truth, whereas Ken'ichi Sato's analysis of the proportional expressions used by mathematicians in Edo Japan points to the dependence of their choices on the purposes for which they used proportions; these in turn were related to their positions in the communities in which mathematics was then practiced. 


\title{
JosePh NeEdHAM, HeTERodoX MARXISM AND CHINESE SCIENCE'
}

\author{
Gregory BLUE
}

In 1967, the BBC produced a series of radio lectures to mark the centenary of the publication of Karl Marx's Das Kapital. Included among the eminent speakers was classicist M.I. Finley, who began his talk ${ }^{2}$ with a story of how he had been castigated for "vulgar Marxism" after mentioning in a recent book review the "fierce class-bias" in Josephus's account of the Masada revolt. His point was to illustrate that rather than being treated as a source of more or less fruitful analytical ideas, "Marxism" was often reduced in the West to an epithet, with the implication that anyone with a responsible attitude towards existing Communist states would detest Marxist thinking in whatever field it might be found. "To be sure", he went on, " no serious writer puts the argument explicitly in this crude way". In fact he was being somewhat disingenuous, for he knew that some prominent writers did put it precisely that way.

1. This paper is part of a project on Joseph Needham undertaken with support from the Social Sciences and Humanities Research Council of Canada The author is grateful to the late Joseph Needham for having granted permission to use his private papers and would like to acknowledge the generosity of the Cambridge University Library and the Needham Research Institute in making those his papers accessible. Gregory Blue worked as Needham's assistant and research associate from 1977 to 1990.

2. M.I. Finley, Mimeograph of script for radio lecture in the BBC series " A Centenary of Das Kapital" broadcast on $1^{\text {st }}$ August 1967. (Annotated mimeograph in Joseph Needham's SCC project files, Needham Research Institute Cambridge), 1967. 
Along with the many early appreciations of Joseph Needham's Science and Civilisation in China series [hereafter SCC], there were a number of assessments which rejected it out of hand on the grounds that it was permeated with Marxism. One of the harshest critics was the ex-Communist sinologist K.A. Wittfogel ${ }^{3}$, who castigated Needham's notion of " bureaucratic feudalism" as a betrayal of Marx's theory of an "Asiatic" mode of production and as toadying to official historiography in the People's Republic of China. Another well known American sociologist of China, Marion J. Levy of Princeton, twisted the sinological knife when he commented that Needham seemed to have learned his Marxism by rote, like his Chinese characters ${ }^{4}$. Levy also invoked the historian of Western science Charles Gillispie, who had described SCC as " shot through with Marxism" and who judged Needham's externalist reading of the history of science to be an " abject betrayal of the autonomy of science" ". In short, Needham's work was born in the Cold War, and these reviewers' political perspectives can be said to have shaped their reception of it. In hindsight, one might think that they missed some stimulating aspects of his enterprise, including his creative relation to Marxist theory ${ }^{6}$.

As it happened, Needham too was asked to contribute to the BBC series commemorating the centenary of Das Kapital. In the end he declined the invitation. As he wrote to the producer, he did so for two reasons ${ }^{7}$. The first was tactical : he wanted to avoid the risk that $S C C$ would again be dismissed as "Marxist". The second was that he was not certain himself how useful Marxist theory actually was for solving the problem that most concerned him, namely: Why, after surpassing other parts of the world in technical innovation for centuries, had traditional Chinese society not been the first to give rise to specifically " modern" science? Yet he stated, "I do indeed believe, in accordance with 'historical materialism', that the fundamental factors which could prevented the rise of modern science in China (and India) were sociological and economic...".

3. K.A. Wittfogel, " Review of J. Needham, Science and Civilisation in China", American Anthropologist, vol. 2, 60 (1958), 398-400.

4. M.J. Levy, "Some Light on the Far East", Joint review of K.A. Wittogel, Oriental Despotism, J. Needham, Science and Civilisation in China, vols. 1 and 2], World Politics, 10, 3 (1958), 470.

5. C.C. Gillispie, "Perspectives" [Essay review of J. Needham, Science and Civilisation in China, vol. 2], American Scientist (1957), 173-176.

6. J. Needham, Within the Four Seas, London.

7. J. Needham, (unpublsshed). Letter to Helen Rapp, 6 October $1967 \mathrm{~b}$. 
He then went on to situate his hesitation about stating his relationship to Marxism in the framework of broader historiographical concerns, particularly his opposition to the " internalist" and "Spenglerian " interpretations of the history of science. On the one hand, he was not yet satisfied that he had proved his case about the social determination of scientific change, so that trying to say what role Marxism would finally play in answering his central problem was awkward. He also noted that in several recent articles on the nature and dynamics of traditional Chinese society he had criticised " internalist" readings of the history of science in telling fashion without confining himself to specifically Marxist arguments. On the other hand, he felt that a clear response was needed against what he saw as neo-Spenglerian forms of cultural relativism emerging in the history of science, but he was not yet ready to give one. For these reasons he declared himself " very inhibited" about publicly weighing up his relationship with Marxism. As he put it ${ }^{8}$, "The only way to let the situation work itself out properly is to wait until I can write the socio-economic chapters of Vol. 7 of Science and Civilisation in China in full - then people will be able to see round all sides of the question, and they can amuse themselves if they want to by calculating just how Marxist I have been. For some it will doubtless be too much, but for others not nearly enough".

Before declining the BBC invitation, however, he did draft part of a talk on his relationship to Marxism. This fragment" was an amplification of what he had written in the essay "Science and Society in East and West" ${ }^{\circ}$. Successively addressing the three main dimensions - political, philosophical and historical - in which Marxism influenced his thinking, this text not only summarises what he thought at that time, but also indicates the independentmindedness of his appropriation of Marxism.

On the political front, he observed that he had been an "equalitarian socialist" long before reading the works of Marx and Engels. While noting that he had found their analysis of politics and history in terms of class struggle " deeply illuminating", he re-affirmed (as he did until the end of his life) that he still adhered to the Christian Socialism of his youth, though in a version influenced between the wars by friends like Louis Rapkine and Liljana

8. J. Needham, (unpublished). Letter to Helen Rapp, op. $c t$.

9. J. Needham, (unpublished). Untitled draft written following invitation to partucipate in BBC series "A Century of Das Kapital", Handwritten draft located in SCC files, Needham Research Institute, Cambridge, 1967a, 2-3 [Referred to in text as Needham Kapital Centenary Draft].

10. J. Needham. "Science and Society in East and West ", Science and Society, 4, 1964, 385-408. References above are to the reprint in Needham 1969a. 
Lubinska, Marxists of an "undogmatic and unorthodox" sort, raised in Jewish and anticlerical traditions".

Of dialectical materialism he observed that he had " never found it of much methodological use in detailed research planning ", though he recognised it as valuable in other important ways. In the work of Marxist biochemical colleagues - J.B.S. Haldane and Vladimir Engelhardt - he saw it as helping "greatly in general thinking", and as giving " a special subtlety to scientific insights and hypotheses" 12 . More revealingly for his own outlook, he suggested that dialectical materialism " as a general world view" was " another way of expressing the fact of emergent evolution, i.e. the principle that social evolution should be understood as the continuation of biological evolution, part of the rise in organisational level that has happened throughout the development of our world "13.

The personal, non-exclusive character of Needham's thinking comes out in another passage in this draft, where he recounts that early in his career he had sought to work out " a world view or faith ", to which he could " wholeheartedly subscribe". He wrote: "This I did in a series of four volumes of essays, essentially synthetic and syncretistic in character, in which I combine Marxist thought with the revolutionary Christianity of Conrad Noel, the philosophy of religion of Rudolf Otto and R.G. Collingwood, and the emergent evolutionism of Lloyd Morgan and Samuel Alexander. Teilhard de Chardin I came to know and admire only after the second world war $" 14$.

Thus, what Needham said of his relation to the political and philosophical aspects of Marxism in his's draft supports two conclusions : (1) that he considered Marxism an essential source for his personal world-view; and (2) that he appropriated Marxist ideas which he saw as consistent with his experience and with other theories he thought fruitful.

Needham claimed however that what was most important to him personally in the legacy of Marx and Engels was their " principle of historical materialism ", i.e. the view that " the mainsprings of history were to be found, not in the wills and actions of a succession of great men ", "nor in indelible racial or genetic characteristics", " nor in pure chance", but " in the relations of man with the productive processes in which he engages, i.e. with the

11. J. Needham, (unpublished). Untitled draft written following invitatıon to participate in BBC series " A Century of Das Kapital ", op. cit., 1-2.

12. Ibid., 2-3.

13. Ibid., 3-3a.

14. Ibid., 2.

15. Idem. 
changing conditions of the social and economic life of his societies" 16 . This was an appreciation of Marxism which Needham repeated throughout his later years.

If one turns now to his published works, his historiographical engagement with Marxism can be traced more clearly. Numerous passages show that he recognised Marxism as a component part of the personal world-view he elaborated from the 1920s, and the influence of historical materialism on him in the 1930s is seen, e.g. in his critique of Spencer and his studies of English social history ${ }^{17}$. Yet, despite Marx and Engels' considerable scientific interests, they gave no systematic treatment of the history of the natural sciences in the works which by the 1930s had become the classics of the socialdemocratic and communist movements. In the 1920s Joseph and Dorothy Needham's formation in the history of science, with the encouragement of Charles and Dorothea Singer, was on a different track from their socialism. These interests began to converge only with the Second International Congress on the History of Science held in London in 1931, when the papers given by the Soviet delegation led by N.I. Bukharin showed the possibilities of understanding the history of science in the context of major changes in society and of integrating the history of science into the theoretical structure of Marxism. Particularly important for Needham's later historiography of science, as for that of other British Left intellectuals, was Boris Hessen's paper on Newton's Principia. In his introduction to the 1971 reprint of the Russian papers to the 1931 conference $^{18}$, Needham affirmed his continuing respect for the vision they enunciated ${ }^{19}$, a sentiment he expressed more prominently in his opening address at the $15^{\text {th }}$ International Congress of the History of Science held in Edinburgh in $1977^{20}$. Marxism was thus part of his

16. Ibid., 4-5.

17. J. Needham, "Laud, the Levellers, and the Virtuosi ", in J. Lewıs, K. Polanyı and D.K. Kitchin (eds), Christianity and the Social Revolution, London, 1935, 163-179; J. Needham, Integrative Levels : a Revolution of the Idea of Progress, Oxford, 1937 ; reproduced in revised form in Needham 1943.

18. N.I. Bukharin, "Science at the Cross Roads", Papers presented to the International Congress of the History of Science and Technology held in London from June $29^{\text {th }}$ to July $3^{\text {rd }}$ 1931 by the Delegates of the U.S.S.R. (With a new foreword by Joseph Needham, and a new introduction by P.G. Werskey), London, 1971, ix-x.

19. J. Needham. "Address to the Opening Session of the $15^{\text {th }}$ International Congress of the History of Science. Edinburgh. 11 August 1977 ". British Journal for the History of Sclence, 11 (38) (1978). 103-113.

20. K. Wittfogel, Wirtschaft und Gesellschaft Chinas. Versuch der wissenschaftlichen Analyse einer grossen asiatischen Agrargesellschaft, Erster teIl : Productivkrafte, Produktions- und Zirkulationsprozess, Leipzig. 1931. 
outlook on the history of science well before he became involved in the study of China in 1937.

The Russian participants in the 1931 Congress remind one immediately of the shifting nature of who and what was "orthodox" in the world of official, state-approved Marxist theory. In 1931 Bukharin was traversing a brief moment of official approbation that was poised precariously between two condemnations, with the second entailing his execution. Hessen's fate is not so precisely known, as Needham observed in 1971, but after 1931 he disappeared, presumably a victim of the 1930 s purges. Despite their personal disappearance their ideas about the history of science continued essentially to be accepted in Soviet academic circles. While Needham remained devoted to those ideas about the importance of understanding science in social context, his consistent avowals during the Cold War of a debt to Bukharin set him apart from official historiography in the Soviet block and China.

The sporadic character of what the Marxist classics had to say about the history of science was more than matched by the scantiness of their remarks on traditional Chinese society. It was only in the years after the First World War that China became the object of intense theoretical and political analysis by Marxist thinkers. One can discern three lines of analysis which emerged then in the Comintern. One of these, formulated in the mid-1920s by Karl Radek, rector of Sun Yatsen University in Moscow, asserted that China had at some earlier time embarked on a capitalist phase of development. Another line was developed by Bukharin, who drew on Max Weber; he argued that China was an example of a bureaucratic feudalism. A third school relied on Marx's notion of an " Asiatic" mode of production. Inside the Soviet Union this was line was associated with the name of Ludwig Mad'iar. In the West, the most prominent Communist theorist of the Asiatic mode of production was Karl Wittfogel, who made his case in his Wirtschaft und Gesellschaft Chinas $^{21}$ and several subsequent articles, works which influenced significantly Needham.

In 1931, the year Bukharin attended the Second International Congress on History of Science, a crucial conference was held in Leningrad to debate whether the notion of the Asiatic mode of production was a valid Marxist category for analysing Chinese ancient society. The conference was one of a series of debates held between 1928 and 1934 on the Marxist theory of social formations. Not only were these crucial for the development of orthodox " 5stages "Stalinist historiography, which greatly restricted the range of acceptable Marxist analyses of social history ; but these debates also soon led to the 
sub-sumption of Chinese history into the model of five universal stages ${ }^{22}$. Following Stalin's intervention in 1931 the notion of the "Asiatic mode of production " was expelled from the orthodox Soviet Marxist canon, only to resurface explicitly again in the Soviet Union in the $1960 \mathrm{~s}^{23}$. In 1977 Needham supposed that the notion had been suppressed because the Soviet government did not want to be tarred with the "Oriental despotism" brush ${ }^{24}$. For an understanding of his persistent interest in what one might call the " heterodox" Marxist notion of the "Asiatic" mode, it is important to appreciate that he came to Marxism prior to the dissemination of the Stalinist historical model and approached Marxism with the attitude of an intellectual not only committed to synthesising insights from various schools of thought. Another important factor lies in the fact that during his World War II years in China, he was reinforced in his commitment to the notion of the "Asiatic mode" through contact with the Chinese historians Chi Ch'ao-Ting, Wang Ya-Nan and Wu T'a-Kun.

In SCC as well as in various essays, Needham employed the notion of " bureaucratic feudalism " as his central organising category for interpreting imperial Chinese society. The characteristics he emphasised in that notion were always close to those associated with the Marxian "Asiatic" mode of production. For Needham these categories filled two important functions. On the one hand, they served as integrative mechanisms that permitted him to elucidate his vision of Chinese society as an organic whole, in which various components were related systematically to one another, from water and soil conditions, to specific forms of agriculture, to the centralised state managed by a non-aristocratic elite, to a philosophical propensity to organicism ${ }^{25}$. On the other hand, perhaps more importantly, these categories played a crucial role in Needham's answer to the general problem of explaining differential scientific development. As he put it in a 1964 essay, "For the purposes of the historian of science, therefore, we have to be on the watch for some essential differences between the aristocratic feudalism of Europe, out of the womb of which mercantile and industrial capitalism, together with the Renaissance and Reformation, could be born ; and those other kinds of feudalism (if that is what it really was) which were characteristic of medieval Asia. From the point of view of the history of science we must have something

22. G. Blue, "China and Western Social Thought in the Modern Period", in T. Brock and G. Blue (eds), China and Historical Capitalism, Cambridge, 1999.

23. S.P. Dunn, The Fall and Rise of the Asiatic Mode of Production, London, 1982.

24. Joseph Needham to G. Blue, 21 March 1977.

25. SCC, vol. 4 , pt. 3,378 . 
sufficiently different from what existed in Europe to help us solve our problem $" 26$.

In this essay, "Science and Society in East and West", Needham considered his attitude toward various categories of Marxist historical analysis. Having stated his desire to establish differences between China and the West sufficient to explain their differential scientific development, he declared himself unsympathetic to the orthodox Marxist notion of universal stages of development. In accord with mainline Western scholarship, he also opposed the idea that China had gone through a stage in which chattel slavery was the defining component of the economy. With both of these points he set himself apart from the respective orthodoxies of the Soviet Union and the People's Republic of China. He then turned to the notion of the Asiatic mode of production. In addition to being rejected from the Stalinist and Maoist canons from the 1930s, this idea had fallen under special opprobrium in official Communist circles in the 1950s because of Wittfogel's use of it as a weapon for discrediting Soviet-style governments during the McCarthy period. Needham nevertheless defended both the Marxian notion and Wittfogel's 1930s formulation of it, treating both as equivalent to his own notion of "bureaucratic feudalism" 27 . His understanding of it is conveyed in the following passage: "Broadly speaking it [the Asiatic mode] was the growth of a State apparatus fundamentally bureaucratic in character and operated by a non-hereditary elite upon the basis of a large number of relatively selfgoverning peasant communities, still retaining much tribal character and with little or no division of labour as between agriculture and industry. The form of exploitation here consisted essentially in the collection of taxes for the centralised State... " $" 28$.

Distinguishing later in the same essay between Wittfogel's earlier and later works, Needham wrote : "Wittfogel now seeks to attribute all abuses of power, whether in totalitarian or other societies, to the principle of bureaucratism ; but the fact that he has become a great opponent of the ideas which I and many others favour does not alter the fact that he once set them forth quite brilliantly himself, and thus I admire his first book while deprecating his last one $"{ }^{29}$.

26. J. Needham, "Science and Society in East and West", Science and Society, 4 (1964), 385-408. References above are to the reprint in Needham 1969a, 191-192.

27. J. Needham, Moulds of Understanding. A Pattern of Natural Philosophy, G. Werskey (ed.), London, 1976, 1969b, 32.

28. J. Needham, The Grand Titration. Science and Society in East and West, London, 1969a, 194-195.

29. Ibid., 204. 
Now, it can be argued that Wittfogel followed in a long line of thinkers, including not only Marx but also Montesquieu, Herder, Comte and Weber, who posited essential differences between the West and Asian civilisations. That broad analytical tradition meant that anyone in the mid-twentieth century who sought theoretical justifications for such a distinction would have been in a position to choose among several. This raises the question of what it was that attracted Needham specifically to the notion of the Asiatic mode. The answer to that seems to be that it accorded with his desire to specify naturalistic, indeed geographical, parameters for the distinction in social evolutionary capacities he was trying to establish. This was a preference apparently not served sufficiently for his taste by Marxism in its orthodox form, which concentrated on social relations of production. One suspects that his choice of "feudalism" as an analytic category was determined by a source independent of historical materialism, though compatible with it, viz. his preference for a historiography of science that is comparative.

It has sometimes been thought curious that, while the main thrust of his work was to demonstrate the capacity of a non-Western people for technical and scientific achievement, Needham continued to see the task of explaining why China did not develop capitalism and modern science as central to his endeavour. His desire to identify features of Chinese society that blocked the types of historical change found in the West has sometimes been seen as deriving from the orthodox Marxist assumption that all societies progress at a greater or slower pace along the same route of historical development. However, it seems myopic to locate the roots of Needham's notion of progress solely in Marxism, for in elaborating that notion he drew on a variety of sources, e.g. including Weber and the positivist tradition, particularly the contributions of Comte, Spencer and Sarton.

Another important issue is whether his Marxism lay at the origin of his "great problem" of why China, despite its many achievements, did not develop capitalism and modern science. Attempts to derive this question from Marxism are rather speculative. A more obvious precedent would be Max Weber's introduction to The Protestant Ethic and the Spirt of Capitalism, where he asked, "Why did not the scientific, the artistic, the political, or the economic development there [in India or China] enter upon that path of rationalisation which is peculiar to the Occident?"

Needham's interest in factors that inhibited historical development was shaped by his identification of "traditional " China as an example of social

30. M. Weber, The Protestant Ethic and the Spirit of Capitalism (Translated by Talcott Parsons, introduction by Anthony Giddens), London, 1976, 25. 
homeostasis. This may be seen as shaped partly by his biochemist's outlook, but if there was a Marxist influence in his conception of social homeostasis, it was one that, like Marx's Eighteenth Brumaire of Louis Bonaparte, was focused on explaining why the oppressed had failed to fight against the oppressors. From this particular angle, Needham's interest in the historical inhibition of capitalism and modern science in China was quite consistent with " classical" Marxist concern for explaining absence of epochal change in particular historical circumstances, though it deviated from the orthodox Marxist tendency to try to identify sprouts of revolutionary resistance everywhere.

In conclusion, Marxism was an essential part of Needham's intellectual equipment, and his historical scholarship cannot be understood without his Marxism. I would argue however that Needham cannot be understood as having been simply a Marxist thinker at any stage in his career. Instead, he was primarily a synthetic thinker who drew selectively on various theoretical traditions in pursuit of the topics that interested him. Gerald Holton has suggested that in understanding how scientists historically develop their ideas one needs to examine not only their theoretical models or the empirical data available to them, but also the broad thematic concerns which underlie their research ${ }^{31}$. For Needham, Marxism was one of several theoretical models which he found useful and compatible; emergent evolution was another; the Whiteheadian notion of process was a third. Underlying these, one can discern a number of essential thematic commitments that pervade his work : his affirmation of progress, his opposition to reductionism, his search for a unified, comprehensive account of the world, and his conviction of the continuity of human experience.

31. G. Holton, Einstein, History and Other Passions, Wondbury NY, 1995, 32-35, $177-$ 184. 


\section{JosePh NEEDHAM's GRaND QUESTION, AND How to MAKE IT PRODUCTIVE FOR OUR UNDERSTANDING OF THE SCIENTIFIC REVOLUTION}

\section{H. Floris COHEN}

"For us the Chinese experience through the ages is a control experiment for Europe ", Joseph Needham stated in 1961.

"If sometimes we overemphasize the Chinese contributions, it has been consciously to redress a balance which in the past tilted over much too far on the other side. We were out to redress a secular injustice and misunderstanding ", he wrote at another occasion.

In the paper that follows I wish to show that Needham's contribution to our understanding of how modern science arose in $17^{\text {th }}$ century Europe may usefully be thought of as situated in the highly charged field of tension between these two, widely dissimilar yet equally steadfastly held viewpoints of his.

Needham's celebrated " Grand Question ", as is well known, goes back to 1937, when three Chinese students in Cambridge addressed their Reader in biochemistry, asking him how it was that " modern science originated only in Europe". This innocent query came to mark the decisive break in Needham's life. You and I and everybody else would surely have shrugged off so vast and apparently speculative a question, yet Needham went ahead, quickly to turn himself into what he remained till his death - the far and away foremost expert in the history of global science. Whatever one may think of Science and Civilisation in China (and my own as most everybody's sentiments about this work and its numerous companion volumes are decidedly mixed), 
it is certain that it was set up by Needham as his chosen way toward finding the answer to that vaguely intriguing yet highly questionable question put before him now sixty years ago.

Why did Needham attach so much significance to the question?

One reason surely resided in the sheer attraction exerted by China's otherness. "Chinese culture", so he wrote, " is really the only other great body of thought of equal complexity and depth to our own... Chinese civilization has the overpowering beauty of the wholly other, and only the wholly other can inspire the deepest love and the profoundest desire to learn ".

Two further reasons stand expressed in those distinct sentiments I quoted right at the start - the idea that Chinese history provides an occasion to test our ideas on why modern science arose in Europe by counterfactual means, and the urge to set right the, at least in those times, widely spread notion that China never had any science worth mentioning let alone examining.

One more reason for Needham resided in the following consideration. Modern civilization is so profoundly shaped by universally valid, modern science, and the West, by virtue of the fact that that is where modern science arose, has since gained such a world-historical ascendancy, as to turn the question of why Europe, not China, spontaneously produced modern science into no less than " one of the greatest problems in the history of civilization".

These sentiments of his taken together go far to explain the dual set-up of the great work, which was meant both to survey China's forgotten riches and to use that survey for arriving at a definitive answer to the original Grand Question. Joseph Needham never did arrive at that definitive answer - he died with the final, seventh volume of the great work in incomplete state. Still, the Grand Question was so uppermost in his mind that numerous fragments of an answer are to be found strewn over both a variety of passages in Science and Civilisation in China and many an accompanying essay of his, with The Grand Titration serving as the principal yet hardly the sole focal point for all this (as he once called it) "thinking aloud" on the "Grand Question ". Some years ago, in chapter 6, "The Non-emergence of Early Modern Science Outside Western Europe", of my book The Scientific Revolution. A Historiographical Inquiry', I made a sustained effort to collect those fragments and put them together in as much of a consistent pattern as I think actually corresponds to what Needham must have had in mind. By way

1. The Scientific Revolution. A Historiographical Inquiry, 1994. 
of a summing-up of results attained in that lengthy chapter ${ }^{2}$, I here present a brief outline of how Needham variously put his Grand Question, of his range of answers to it, and of how these hang together. I then conclude with a view of my own on what we can learn from all this if we share Needham's aim to arrive at a deepened understanding of the Scientific Revolution by comparative means.

To begin with, two major stages can be distinguished in how Needham posed his Grand Question. Asking originally why traditional China did not produce modern science, a deeper acquaintance with China's scientific riches convinced him of China's superiority over the West up to the late $16^{\text {th }}$ century, so that his more pointed question became something like this: How is it that the science of traditional China, on a par, to say the least, in brilliance and depth with the West prior to the Scientific Revolution, nevertheless did not spontaneously produce modern science?

Now it is hardly the case that Needham came to his question with a blank mind over what caused modern science spontaneously to be produced in Europe. His favorite explanation soon became and always remained the one embodied in the Zilsel thesis. This thesis says that modern science came into being owing to the breakdown, around 1600 , of an originally very wide social gap between university men skilled in formal argument (Galileo, Bacon, Gilbert) and those superior artisans (Leonardo, Stevin, Agricola) whose work in practical arithmetic, practical mining, practical navigation, and so on, actually embodied, though it did not formally express, such basic scientific laws as formed the heart of the Scientific Revolution. This is a rich yet (as I have argued in ch. 5 of my just mentioned book) highly overstated thesis. Needham always picked up for special emphasis the alleged tendency of merchants and the higher artisanate in late Renaissance Europe to foster physical science, in the sense of a supposed affinity between the merchant mentality and mechanical science, especially. At first upheld by Needham with primitive, orthodox-Marxist assurance, in later years the precise nature of this particular historical link became more doubtful to him. As he wrote in passing in 1964, "What the exact connection was between modern science and the merchants is of course a point not yet fully elucidated".

Let us now see to what extent Needham did indeed use the Chinese experience as a " control experiment" for the European Scientific Revolution.

2. For the provenance of all previous and following quotations, and also more generally of all Needham's pertinent views discussed in the present paper. I refer the reader to the notes appended to that chapter. I further wish to thank Dr Peter Engelfriet for his comments. 
If I have counted well, there are six answers to his "Grand Question" Needham more or less consistently adopted, four more he quite firmly rejected, and two he somewhat deliberately avoided.

The rejected ones first. Needham had very little time for explaining the absence of a Chinese Scientific Revolution out of some alleged inability of the Chinese to think scientifically, or out of differences in climate, or out of features of language and script (a thesis, by the way, recently defended by Derk Bodde), or out of an allegedly predominant conception of time, not as unilinear but as recurrent (the latter thesis being the sole one he found worthy of a sustained rebuttal) .

Now for Needham's six explanations of why China had no Scientific Revolution. Quite early on, while roaming through Yunan province in the midst of the Second World War, Needham's pertinent thoughts began to center on " democracy". Modern science could only emerge in a democratic environment as provided by then progressive, early merchants capitalism, so he argued in a very general sort of way; hence, China's feudal bureaucratism, despite some democratic access to officialdom through the examination system, precluded the rise of modern science. A second, somewhat more thoroughly argued answer centers on the alleged "opposition" between establishment "Confucianism" with its concern for social rather than for natural order, further text-oriented, rationalist, conservative, rigid, and masculine, and mostly suppressed "Taoism" with its favorable impulses for science and technology, its receptivity and lack of prejudice, its antifeudal collectivism, its worship of the feminine and more generally its democratic progressivism. In that sense Galileo was a Taoist and those adversaries of his who refused to look through his telescope Confucians, Needham remarkably remarked in passing, going on at a later stage to amend his own argument by pointing at the fact that, in the end, the Tao in the sense of the cosmic order was held to be inscrutable, thus setting serious limits to what Chinese science, for all the stimulus received from Taoist impulses in alchemy and elsewhere, could accomplish even in the best of cases.

A third explanation puts those " merchants" of Zilsel at the center. Never in Chinese history did the reigning bureaucracy allow the merchant class to attain a position of some social autonomy. Hence, the very merchant mentality could not arise without which modern, mechanical science is impossible, as stands confirmed by the relative poverty of Chinese physical thought as compared to the extensively documented richness of virtually all other scientific work in ancient China. 
In answer $n^{\circ} 4$, on China's " bureaucracy", Needham began to acknowledge that, for instance, seismology was greatly fostered by the bureaucracy for obvious, utilitarian reasons. He went on to focus on the many ways in which China's feudal bureaucracy nonetheless hampered scientific pursuits. It did so primarily in that, as noted, it prevented a merchant class from coming into its own, but also in that its general posture of political nonintervention stood athwart the kind of interventionism embodied in modern scientific experiment.

Incidentally, the aura of facile, somewhat far-fetched and certainly empirically underargued speculation likely to be exerted by my very brief summaries is not, in my own view, too far removed from those arguments as they appear in full in Needham's original essays. Such is emphatically not the case, however, with his fifth answer, the " laws of nature", which is set forth in a very exciting, intellectually daring, and richly detailed argument. Once again starting from an idea of Zilsel's, Needham here concluded that no Chinese philosophy offered a counterpart to the late Renaissance European notion of things natural being ruled by law. Order is certainly recognized, yet, quite unlike the inexorable regularities imposed by the Divine Lawgiver of the West, natural order in Chinese thought is held to be one of interdependence and spontaneous co-operation. In the end, Needham reveals himself to be sympathetic to that point of view: "One feels that the Taoists would have scorned such an idea [of natural law] as being too naïve to be adequate to the subtlety and complexity of the universe as they intuited it ".

A sixth answer may be called that of "Chinese homoeostasis". It was no more than sketched by Needham in one extraordinarily inspiring passage in The Grand Titration. Here the self-regulating equilibrium characteristic of Chinese society, which adopted many a home-grown technological feat and many a scientific finding without significantly altering thereby, is set off against the restless roving of dynamic Europe ; against the pluralist divisions of a subcontinent ready to allow itself thoroughly to be transformed by many a scientific insight or labor-saving tool.

Now how do these six answers hang together? We address that question, first, from Needham's own inferred point of view, and then from structural likenesses and differences we may perceive to reside at the respective cores of those answers.

Needham's own mode of thought (very much directed toward higher syntheses and the overcoming of apparent contradictions) was such as to allow one to infer that, in his own view, his six explanations complement one another nicely - no most-favored-explanation status for any one among those six answers to the Grand Question, nor even a definite hierarchy be- 
tween them. Still, one can see that the early, extremely schematic " democracy" answer soon receded very much to the background in his work, as (to a lesser degree) did the "Confucianism vs. Taoism" answer. Further, regrettably, and for reasons I come back to, the " homoeostasis" answer never made it beyond that one inspired passage. Next, we may note that the "merchant" answer and the "bureaucracy" answer are very much two sides to one and the same coin. Jointly they read something like: " no modern science without an autonomous merchant class which China's feudal bureaucracy forever prevented from coming up ". Thus we are in essence left with two full Needham answers. Of these, one (" the merchants") is on the societal and the other (" the laws of nature") on the intellectual level, and Needham, for all his broadly conciliatory view of things, never wavered in his Marxist conviction that, ultimately, societal circumstances are decisive. Altogether, then, it seems safe to say that in Needham's view, in the end, its lack of an autonomous class of merchants is what mostly prevented ancient China from giving rise to modern science.

Now one big problem with that answer is the scarcity of empirical evidence advanced by Needham over the decades to underpin it with - nor is it easy to think how such evidence could possibly come forward from the Chinese case. Rather than providing an independent control experiment, we actually have here little more than projection - little but the mirror image of a particular conception (Zilsel's) thought up for Europe and provable only for the European experience, not the Chinese. More than that, Needham's answer in consequence suffers fatally from the weakest point in Zilsel's thesis, which is precisely its widely overstated claim that merchants had some uniquely privileged connection to the very kind of science that came to the fore in the early stages of the Scientific Revolution. Hence, to the extent that a control experiment has been carried out here, it has failed.

But let us now dig a little more deeply below the surface of Needham's six answers. For starters, we consider those two possible further answers he can be seen consistently to have avoided. One concerns the possibility that the edge China had in Needham's view gained over Europe in matters scientific got lost, not only due to the magnificent passing maneuver of the European Scientific Revolution, but also to an overall movement of retrenchment under the Ming. If one screens the fine print, so to say, of Needham's detailed treatment of mathematics, or astronomy, or navigation, in distinct tomes of Science and Civilisation in China, enough indications can be assembled for such a broad picture of overall scientific and other decay in late Ming society to arise. But Needham steadfastly avoided drawing his lines together that way, rather going on to insist forever that ancient China, instead of obeying 
the Western cliché of its scientific stagnation, displayed throughout its history ongoing, rectilinear progress in scientific thought. Here as at many other places in his work we can see that there were really two Joseph Needhams one, the cautiously balancing, surely one-sided yet eminently reasonable scholar, the other the somewhat outrageous proselytizer and historiographical extremist. And my main message on this score is that, notwithstanding the reasonableness and the many qualifying statements of long stretches of Science and Civilisation in China, the simplified, radicalized picture that arises from most of the essays never ceased to govern Needham's mind whenever he directed it toward his Grand Question. Overall, his better insights on this score are strewn over the large work, and very unfortunately, under the probably semi-conscious influence of a range of respectable and less respectable, yet from a scholarly point of view jointly pernicious sentiments, he never bothered to make these better insights of his cohere.

What if he had done so ? That is, what are the best insights on the origins of modern science to be distilled from Needham's life's work, and how can we make them serve in the most fruitful way the goal of a deepened understanding of how modern science came into the world?

Among the most exciting passages in Science and Civilisation in China are those which Needham devoted to expressions of what he called the perennial Chinese philosophy of " organic materialism ". He saw organic materialism exemplified in neo-Confucian thought during the Sung period; he used it to speculate on the possibility of an alternative, organic Scientific Revolution in China in the sense of a short-circuit to Einstein bypassing Newton; its distinctive features can even be seen to underlie much of his argument on " the laws of nature ". "Going with the grain of nature"; the spontaneous flow of things; their organic wholeness as opposed to their mechanical divisibility; "correlative thinking "; causation taken as interdependence rather than as successive " if/then " relations : all such and many similar notions were presented by Needham as a route out of primitive thought alternative to the one taken in the Graeco/Western approach to nature. And at that very point of his thought a conclusion seems to impose itself which Needham ever refused to draw. But if we discard the hopes he set upon such an organic philosophy as the required complement to modern "billiard ball physics", and if we also discard his insistence that such a principal difference in respective approaches to nature has no independent interpretative validity but must in the end be reduced to allegedly overriding differences in Chinese and European society ; if we discard all these a priori convictions Needham held over a lifetime, there is every reason to arrive at a conclusion like the following. There appear indeed to be at least two distinct 
roads leading out of primitive thought. Both of these were fully worth pursuing; neither possessed an apparent, built-in superiority. Just as Su Sung's water clock rediscovered by Needham was probably a more accurate timekeeper than its mechanical counterpart in medieval Europe, just so one may well, if one likes, call conceptions of nature in traditional China more advanced in several respects than natural philosophy in Europe prior to the Scientific Revolution. Only, as David Landes has shown for the case of those two distinct principles of time measurement, the one approach happened to contain a larger potential for further development than the other. Organic materialism, like Su Sung's clock, ultimately ran into what Landes strikingly calls a "magnificent dead end", whereas somehow out of some scattered, meanwhile enriched remnants of the Greek legacy a kind of science could be forged that went on to conquer the world.

Perhaps an outsider on matters Chinese like me is ill-advised to put forward such a view with any assurance, mostly dependent as it is upon data and interpretations advanced by Needham himself which $I$ am in no position to check by direct means. If it does make some sense, though, it puts into a quite different perspective the historiographical status of Needham's Grand Question. The short answer to it becomes something like this : China had no Scientific Revolution because such an outcome was not contained in the developmental possibilities of an organic approach to nature in the " correlative" mode of the Chinese.

Now does this short answer thus ultimately derived from Needham throw us back upon the original problem put before him by those inquisitive Chinese students at Cambridge - the question of how it is that modern science arose in Europe only? In other words, has Needham's very long detour over China, quite apart from what it has taught us about ancient China itself, been in vain?

I do not think so, for two reasons mainly, which I shall now sketch out by way of a conclusion to this paper.

For one, I believe that, in a wider sense, Needham did indeed use the Chinese experience as a control experiment for Europe. Few scholars ever acquired so perceptive and so thorough a sensitivity for structural differences between China and Europe - more specifically, for whatever it may have been that, in the "Old World" of traditional civilizations, caused Europe to turn into the one exceptional civilization that in the end broke through its limits. As Needham clearly saw, this broad historical movement, while containing the rise of modern science as its most significant landmark, was even richer than that particular event signifies. We face here that major historical riddle of "the West and the Rest" on which so much, and so little truly 
conclusive, has been written by so many a truly great historian, and to which this other, truly great historian, Joseph Needham, has contributed some precious insights, particularly so in that single, profoundly perceptive passage of his on Chinese homoeostasis and European dynamism.

Why did he forever leave it at that? From the viewpoint of what we know more about China's science, technology, and medicine than we knew before Needham decided to step in, his almost boundless sinophilia as expressed in the second quotation I used to open this paper was of course an unmitigated boon. But in the end - as implied in the first passage I quoted - Needham was out to catch even bigger fish. Ultimately, he wished to understand something about his own civilization - he wished to understand nothing less than what is that made Europe break out of the ways of traditional society. How did the Old World give way to the New World we live in ? Needham felt sure - and this made him rather the exception among those historians concerned ever since Max Weber and before with finding answers to that question - that the Scientific Revolution forms the most outstanding (not the only, but surely the most outstanding) landmark in that world-historical process of incipient, global modernization. This is what lends an added urgency to his Grand Question; this is what stands behind this feeling of his that that Question forms " one of the greatest problems in the history of civilization". And here, in this sense of what Needham perhaps less than fully consciously strove to accomplish, his sinophilia was a very mixed blessing, and his Marxism (however much toned down in the end) even less so. Needham had this (by itself, quite understandable) perennial urge to lean over backward ; to forgo serious comparison in favor of his beloved method of historical " titration" - that is, to weigh priority and then, often with apparent justice but no less often implausibly and almost always irrelevantly, to grant it to China.

It always seems to testify to a profound lack of gratitude to a great man if, in response, we wish him to have been greater still. It does make sense to do so in Needham's case because it helps clarify what his unique achievement consisted of. If Needham had felt capable of reining in this sentimental side to his thought, he might well have become, not only the superbly pioneering historian of China's ancient riches in science and technology, but also the one comparative historian of Europe's setting the world on the path toward modernity fully to include into that event the seminal contribution made by modern science and its (at least on the face of it) miraculous rise in Europe in the first place. True, in order fully to make himself that as yet non-existent but - in my opinion - very much needed historian, Needham should in addition have given up those cheap formulae of Marxist provenance - rei- 
fied Feudalism, Capitalism, Bureaucratism, and so on - he was in the habit of falling back on when addressing societal issues. His dauntless courage to go beyond the historical details that also held him captivated and to address major world-historical issues is very much worth sticking to when we seek to make up the balance of Joseph Needham's intellectual legacy; the way he actually used to address them, less so.

Finally, I wish to invoke the profound inspiration exerted by Needham's explorations in cross-culturally comparative history of science. As already suggested between the lines, I think there are few methodological traps in this particular field of study Needham did not fall into, loudly, clearly, and, with his characteristically generous disregard of covert ways, in a manner open for all to see. But his experience should serve only as a warning to us whose path, cleared of at least some pitfalls, may be easier because he pioneered it for us. It should by no means serve to give up the search itself. With unprecedented clarity of vision Needham saw that there is no better way to throw that uniquely European event of the rise of modern science into relief for the historian of science than to consider it, not only, obviously, from the inside, but also at one remove ; to take a step backward and compare.

True, I do not think that, in the case of the Scientific Revolution, China offers the most fruitful source of comparison. Too much is truly incommensurable there ; as Needham himself, in one of his less propagandist, more balanced moods wrote, "The sciences of the mediaeval world were in fact tied closely to their ethnic environment, and it was difficult if not impossible for people of those different environments to find any common basis of discourse ". A far better "common basis of discourse" and, hence, of comparison is provided by the several civilizations that successively made an effort to receive, and went on to appropriate in their partly similar partly different ways, the Greek legacy in science and natural philosophy. Sustained comparisons between what the Islamic world, medieval Europe, and Renaissance Europe successively and distinctly made of that Greek legacy before the latter went on to transform it so drastically as to usher in the Scientific Revolution, is what fills pertinent chapters in a book-in-progress of mine which at present goes under the title "How Modern Science Came Into the World. Its Conditioned Emergence ; Its Threefold Dynamics". Still, in at least three major respects I have also found a comparison between China and, not so much Europe but rather Greece, helpful in seeking to answer the question of how modern science could arise where and when it did.

My first, partial answer is the one already mentioned, which would certainly not have been endorsed by Needham but still, I think, forms the gist of his own best answers. This is the seemingly trivial idea that modern science 
could (not "was bound to", just " could") grow out of the Greek corpus, not out of China's organic materialism, because it rested as an unrealized possibility in the former, not the latter.

A second partial answer posits the immense fertility of processes of " cultural transplantation ", i.e., chances for novel things to happen to habits and ideas and modes of doing things grown stale, or otherwise worn out, in their original setting. Chocolate and the potato began to unfold their full potential upon transplantation from America to Europe ; science in the Alexandrian mode, never followed up in the Hellenist world, similarly got new chances upon its entering novel environments. It is striking that for a potentially no less fruitful approach, the one embodied in the Mohist "Canons and Expositions", which were just as marginal in China as Alexandrian science was in the Hellenist world, the one setback it received from the bookburnings under the $\mathrm{Ch}$ 'in sufficed to make it wither away for good. Primarily responsible here seem to be the vicissitudes of China's political fate which, in forever keeping its cultural integrity intact, as one unintended by-effect made China by and large insensitive to the kind of drastic reinvigoration Archimedes in late Renaissance Europe was to benefit from in Galileo's hands.

A third partial answer (here to be rendered in even more schematic a way than all the others) rests in such distinct attitudes taken toward nature as Needham sometimes enjoyed pointing at rather in passing. No mere passivity lay in the aim of the Chinese to live in harmony with nature; yet Chinese activism in this respect was constrained by a consistent reluctance to "go against the grain of nature " (to use Needham's favorite rendition of wu-wei). There is good reason to suppose, with hindsight, that such an overall posture of world-acceptance, however admirable and (quite possibly) superior to that of the West in many respects, was not conducive to the emergence of modern science.

These three comparisons, to repeat, were not those of Needham, and he would not have liked them much. Still, whatever they may be worth they could not possibly have been thought up but for the inspiration received from the happy months I once spent with Needham's Grand Question and his tentative answers to it. Those months more than anything else have persuaded me that the business of clearing up further that decisive event in the history of humankind, the rise of modern science, can benefit from nothing quite so much as from broadly following in Joseph Needham's footsteps. 



\title{
NeEdHAM's Vision of THE ENCOUNTER OF ChINA AND EUROPE THE CASE OF THE History OF Botany ${ }^{\prime}$
}

\author{
Georges MÉTAILIÉ
}

First of all, I should like to acknowledge the very important contribution of Joseph Needham to the history of the traditional botanical knowledge in China. His volume entitled Botany ${ }^{2}$ is the second significant work on the subject. The first step had been taken a century earlier by Emil Bretschneider with several still valuable publications, among them the well-known Botanicon Sinicum".

In his " Address to the opening session of the $15^{\text {th }}$ International Congress of the History of Science, Edinburgh, 1977 " 4 , Joseph Needham wrote: "I suppose we all generally agree that there is only one unitary science of nature, approached more or less closely and built up more or less successfully and continuously, even if very slowly, by the several groups of mankind from age to age. This means that we could expect to trace an absolute continuity between the first beginnings of astronomy and medicine in ancient Babylonia or ancient Egypt, through the advancing natural knowledge of mediaeval China, India, Islam and the classical Western world, to the break-

I. I would like to thank Francesca Bray for her kind reading and suggestions.

2. J. Needham, Science and Civilisation in China, vol. 6, 1, Botany, Cambridge, 1986.

3. E. Bretschneider, "Botanicon Sinicum ", Journal of the North-China Branch of the Royal Asiatic Society, New Series 16 (2) (1881), 1-467. (Facsimule edition : Nendeln, Liechenstein, Kraus Reprint, 1967, vol. 1-2).

4. J. Needham, "Address to the opening session of the $15^{\text {th }}$ International Congress of the History of Science, Edinburgh, 11 august 1977 ", The British Journal for the History of Science, 11 (38) (1978), 103-113. 
through of late Renaissance Europe when, as has been said, the most effective method of discovery was itself discovered" ".

"Of course we must not see in the traditional sciences of China or India simply failed prototypes of modern science; we must get inside the minds of those who cultivated them and understand how it was that they came to their conclusions. But we must never deny the fundamental continuity and universality of all science $" 6$.

In another paper, first published in 1967 , Joseph Needham ${ }^{7}$ considered that in order to analyse the respective roles of Europe and China in the evolution of this ecumenical science two questions had to be asked: "First, when in history did a particular science in its Western form fuse with its Chinese form so that all ethnic characteristics melted into the universality of modern science; and secondly, at what point in history did the Western form decisively overtake the Chinese form? We may thus try to define the date of what may be called the fusion point on the one hand, and that of the transcurrent point on the other " 8 .

Here is the figure ${ }^{9}$ which illustrates this proposal for several sciences. We see that for botany the transcurrent point goes from 1700 to 1780 . Actually, Joseph Needham considers that it should occur some time between 1695, when Camerarius first demonstrated the nature of the flower and 1780 , soon after the publication of Michel Adanson's Famille des plantes in 1763 ; he qualifies this by adding that " it would perhaps be fairer to take Adanson as the turning-point about 1780 and to say that it was then that botany in the West began to be decisively ahead of Chinese botany" ". And in $S C C$ ", he wrote: "We find that indigenous Chinese botany reaches a Magnolian or Tournefortian level, rather than a Linnean one ; just as we found in earlier volumes that the physical sciences there reached a Vincean rather than a Galilean stage".

Let us begin with the problem of the fusion point. Needham considers that it did not occur until after 1880 . Actually nobody in China could be acquainted

5. J. Needham, "Address to the opening session of the $15^{\text {th }}$ International Congress of the History of Science, Edinburgh, 11 august 1977 ", The British Journal for the History of Science, 11 (38) (1978), 110.

6. Ibid., 111.

7. J. Needham, "The roles of Europe and China in the evolution of Ecumencal Science", in J. Needham, Clerks and Craftsmen in China and the West, Cambridge, 1970, 396-418.

8. Ibid., 397.

9. Ibid. . 414, fig. 99.

10. Ibid., 406 .

11. J. Needham, Science and Civilisation in China, vol. 6 (1), Botany, Cambridge, 1986, xxvi. 
with modern botany prior to the publication in 1858 of the first Chineselanguage book in this discipline, entitled Zhiwuxue 植物學“ Botany”. This book was a synthesis of various manuals by John Lindley made by two Christian missionaries, Alexander Williamson and John Edkins, and adapted and transcribed into Chinese by the well-known mathematician $\mathrm{Li}$ Shanlan 李善蘭 ${ }^{2}$. It seems that this text had more influence in Japan than in China proper, and from then till the end of the century we find only two more modern botanical treatises, both translated by John Fryer : the Zhiwu tushuo 植物圖說 (Illustrated explanations of plants) 1895 and Zhiwu xuzhi 植物須知 (What one must know about plants) 1898. The illustrations of Zhiwu tushuo were edited with a short text in rhymes by Ye Lan 葉瀾, who in this book can perhaps be said to have produced the first Chinese text by a Chinese author on modern botany ${ }^{13}$. In fact real fusion did not occur till the first two decades of this century, once Western botanists, mainly taxonomists ${ }^{14}$, had started teaching in China proper, and once Japanese modern botanical works were available to provide an indispensable aid, namely easily readable technical texts written in classical Chinese ${ }^{15}$.

When we consider the first three botanical texts in Chinese, it is worth remarking that they were all produced by foreigners, botanical books by Chinese modern botanists having been written only after 1910. This situation is just the opposite of what happened in Japan where all the books on modern botany had been written by Japanese authors since the Botanika kyô 菩多尼訶經, by Udagawa Yoan 宇田川榕庵, written in 1822 and based on Western sources.

One preliminary conclusion we can draw is that when comparing the roles of China and Europe in the history of botany, we must also take into account other countries of East Asia, namely Japan, and probably Korea and Vietnam.

In the previous discussion of books on "botany", whether in Chinese, Japanese, English, German or French, note that they all belong to the same field with the same basic references. But this is not true of botany in China before 1858. This brings us back to the problem of the transcurrent point. Within the logic of his ecumenical conception of science, in comparing China and Europe

12. Pan Jixin, “Tan 'zhiwuxue' yi ci zai Zhongguo he Riben de youlai ”, Daziran tansuo, 3 (1984), 167-172 (About the Origin of the word zhiwuxue in China and Japan).

13. G. Métailié, "Plantes et noms, plantes sans noms dans le Zhiwu mingshi tukao ", Extrême-Orient Extrême-Occident, 15 (1993), 140-148.

14. W.J. Haas. "Botany in Republican China: The Leading Role of Taxonomy", in J.Z. Bowers, J.W. Hess. N. Sivin (eds), Science and Medicine in Tiventıeth-Century China Research and Education, 1988. 31-64.

15. G. Métailié, "Sources for Modern Botany in Chına during Qing Dynasty ", Japan Review, 4 (1993), 241-249. 
Joseph Needham considers that Chinese botany reached a Magnolian or Tournefortian level. When we turn to these two botanists we learn that Magnol was the first French botanist interested in natural classification " who, inspired by Ray's most natural and philosophical method had proposed the family as natural taxonomic grouping and had discussed the criteria for defining them with extreme acumen " 16 in his Prodromus Historiae Plantarum in quo Familiae Plantarum per Tabulas Disponuntur (1689). Tournefort on the other hand proposed an artificial system of an "attractive simplicity" 17 " principally on the basis of characters of the corolla and the fructification" 18 in his Institutiones Res Herbariae (1700) in which he defined and illustrated 698 genera.

The question we must now ask is whether among the abundant Chinese literature on plants we find any theoretical texts of that kind - and the answer is definitely not. In a comparative study of the taxonomic side of the botanical works of Li Shizhen 李時珍(1518-1593) in China and Jacques Dalechamp (1513-1588) in France, both physicians and naturalists, I came to the conclu$\operatorname{sion}^{19}$ that their main differences were attributable to their respective cultural and historical environments. First, in European universities at the time, botany was emerging as a subject distinct from medicine. Secondly Dalechamp was working within a European network of intense scientific exchanges on botanical subjects (plants, letters, texts). His botanical work went beyond pharmacopoeia - it belonged to what was emerging as modern botany. And Dalechamp made botanical excursions and described new plants. Li Shizhen declared that as well as its medicinal purpose his Bencao gangmu also belonged to gewu zhi $x u e$, "the study of investigation of things" and in fact he did provide much botanical information - as well as information on minerals and animals. However he remained primarily a pharmacologist. He did not give any descriptions of new plants, for instance, even though he introduced in his book medicinal plants not mentioned in earlier works of materia medica. In such cases he presented not the result of his botanical investigations but quotations from his readings or inquiries. Parts of his botanical work may have been borrowed, but I think we may say that he had no botanical heirs. Dalechamp's work, quite to the contrary, represents a landmark in what was becoming modern botany. If we look for a transcurrent point, it should be when European scientists began to

16. A.G. Morton, History of Botanical Science, London, New York, Toronto, Sydney, San Francisco, 1981, 294.

17. Ibid., 295.

18. Ibid., 228.

19. G Métailié, "Histoire naturelle et humanisme en Chine et en Europe au XVI ${ }^{\boldsymbol{c}}$ siècle : Li Shizhen et Jacques Dalechamp ", Revue d'Histoire des Sciences, 42 (4) (1980), 353-374. 
think of botany as a system, abandoning the more or less personal and subjective classing of plants to adopt systematic classifications. The first to do so was probably Andrea Cesalpino (1519-1603) in his De Plantis (1583) and another century would pass before the decisive works of John Ray and Tournefort. In the European case we would thus transform the concept of transcurrent point to ask: " at what point in history did the modern form decisively overtake the traditional form?". From this perspective, Dalechamp and Li Shizhen would both be on the same left side of the point.

We are now faced with another question : "What does botany mean?". My first answer would be that it is a polysemic term. Within the contemporary context it is "the scientific study of plants" ${ }^{20}$. This allows us to class the work of Magnol and Tournefort, and the various texts published in China after 1858, as " botany ". But other definitions of botany may be given. In his Landmarks of botanical history, chapter titled "The philosophy of Botanical History" Greene ${ }^{21}$ declares : "Botany did not begin with the first books on botany, nor with the men who indited them, though every historian of the science whom I have read has assumed that it did. The most remote and primitive of botanical writers, of whatever country or language, found a more or less extensive vocabulary of elementary botany in the colloquial speech of all. The chief organs of plants - stem, trunk, branch, leaf, flower, fruit, pod, seed, root, tendril, thorn, and a multitude of others - had been discriminated and named; the organs even known by all who had acquaintance with plants and trees, and the names were everywhere in use. Even the functions of several of the organs had been correctly ascertained before ever a line of botany had been written, most probably even before letters had been invented. The improvement of wild things by cultivation, the propagating of the newly acquired sorts of cuttings, by division of perennial roots, and, in the case of trees, by grafting, are likewise arts that seem to antedate history ; as do also the designating of different varieties or species that are evidently nearly akin, by two-fold names, one generic, the other specific or varietal".

With this text, first published in 1909, Edward Lee Greene (1843-1915) gives an example of what Joseph Needham ${ }^{22}$ calls " those individual anticipations of modern scientific knowledge", for he introduced the topics which would be investigated in contemporary human communities in various parts of

20. The Oxford Paperback Dictionary, 1979.

21. E.L. Greene, Landmarks of botanical history, 2 vols. (edited by F.N. Egerton), Stanford, $1983,118$.

22. J. Needham, "Address to the opening session of the $15^{\text {th }}$ International Congress of the History of Science, Edinburgh, 11 august 1977 ", The British Journal for the History of Science, 11 (38) (1978), 111. 
the world, mainly after the fifties, by anthropologists in the field of ethnobotany. Doing this in the context of history of botany he was really a precursor. I agree with André Georges Haudricourt and Scott Atran ${ }^{23}$ that botany, at least where its history is concerned, has to be considered and analysed from an ethnobiological point of view. I mean, for instance, that an ancient text must be studied within its historical and cultural context, that one must take it as a whole and not begin to separate the " scientific" from the "superstitious" content, in reference to the modern state of the field.

Once we realise that some kinds of basic botanical texts (like floras and botanical manuals) never existed in China, and that, even though China boasts a vast literature which reveals a great interest and broad knowledge about plants, the concept of botany as a distinct and rational knowledge of plants never appeared nor was named in China until the nineteenth century, then we may feel impelled - as Joseph Needham said again about traditional sciences - to " get inside the minds of those who cultivated them and understand how it was that they came to their conclusions" ; however, I differ from Joseph Needham's view that : "All the ancient and mediaeval systems before the coming of modern science need to be studied and defined in contrast with our present-day pattern of ideas, which itself is of course not final (...) Modern ecumenical science was indeed their common end, but their appearance can only be explained in the context of the various possibilities open or closed within the totality of ideas, values and social attitudes of their times and places " 24 .

In my view, if we first study the history of botanical knowledge in China in its own terms, without any reference to Europe, and only as a second step proceed to the comparative analysis of the two cases, we may possibly be better able to appreciate the differences between the two, as well as their respective specificities ${ }^{25}$. An example of the two approaches may help. In a lecture given at the $12^{\text {th }}$ International Congress of Sciences in Paris, in 1968, on " The Development of Botanical Taxonomy in Chinese Culture", Joseph Needham began, quite logically from his perspective, with this question: "At what period did Chinese scholars interested in plants and animals begin to classify them in a dendritic or hierarchical manner? (...) More especially when did three levels of groups or classes and sub-classes appear?". He continues: "Perhaps the best way to open this subject is to have a look at the terms used by modern

23. S. Atran, Cognitive foundations of natural history. Towards an anthropology of science, Cambridge. 1990.

24. J. Needham, "Address to the opening session of the $15^{\text {th }}$ International Congress of the History of Science, Edinburgh, 11 august 1977 ", op. cit., 103-113.

25. G. Métailié, "Des mots, des animaux, des plantes", Extrême-Orient ExtrêmeOccident, 14 (1992) : "Regards obliques sur l'argumentation en Chine ", 169-183. 
Chinese botany and zoology for the various levels of classification ". Noting " that nearly every one of these terms, defined in strict hierarchical order today, occurs in ancient texts going back to the middle of the $1^{\text {st }}$ millenium ", even if "they were not ranked always in the same order or with the exact meanings which they have now", he assumes that "there are certain examples in the Erya where we can find a classification in three levels - very roughly corresponding to family, genus and species" 26 .

All this is true ; however in my opinion the perspective should be inverted. Up to the sixth century we can find different ways of classing plants depending on context. Toxicity, taste and therapeutic nature are basic for plants considered as materia medica ; secondary criteria for these classing of plants are their form (lignous or herbaceous), the method of appropriation (gathered or cultivated) and their common uses (as fruit, pot-herbs or staple food). But what are secondary criteria for plants considered as materia medica become primary in agricultural books. On the other hand, in the tree chapter of the Erya, the type of fruit appears as the only criterion in the one classification clearly introduced with examples. Through an ethnobotanical analysis of the various texts I have found several ways of classing plants with covert categories which Joseph Nedham called " submerged families", and considered proof of an anticipation of the modern natural families. Apart from that, beginning with the Erya, I have found a basic folk classification in five levels underlying all the others and intermingling with them. It may be summarized as follows [Using Berlin ${ }^{27}$ and Atran $^{28}$ terminologies :

\begin{tabular}{|lc|}
\hline unique beginner : & plants : zhiwu-caomu \\
life-forms : & herbs cao / trees $m u ;$ \\
intermediate categories (generally covert but in some case expressed) : & taoli, songbai, xingmei.. \\
& tao, $l i, z h u, g u a, z a o ;$ \\
generic-specimene : & yingtao. \\
\hline
\end{tabular}

Of course these various levels do not correspond to the levels of a modern taxonomy, even if (as Atran ${ }^{29}$ shows) there are analogies, due to the fact that

26. J. Needham, "The development of botanical taxonomy in Chinese culture ", XII" Congrès International des Sciences. Paris 1968. Actes, Tome VIII: Histoire des Sciences Naturelles et de la Biologie, Paris, 1971, 127-133.

27. B. Berlin, Ethnobiological Classification : Principle of Categorization of Plants and Animals in Traditional Societies, Princeton, New Jersey, 1992.

28. S. Atran, Cognitive foundations of natural history. Towards an anthropology of science, Cambridge, 1990, 25-29.

29. S. Atran, Cognitive foundations of natural history, op. cit. 
modern taxonomic nomenclature (Linnean) is rooted in the traditional folk classifications of Europe.

In sum, I am not sure that the model of physical sciences chosen by Joseph Needham provides a fit for the history of biological sciences. The main reason is that by focusing on pre- or proto- scientific facts, it implicitly eliminates or sets apart the systematic aspect of traditional scientific knowledge at one period. So doing, on the one hand it prevents us considering all the cultural aspects - frequently qualified " superstitious " or "limitative" in the papers of our Chinese colleagues - and introduces distortions mainly through translations of ancient Chinese terms by modern but inaccurate technical terms (e.g. rendering fenlei in a Zhou context as "taxonomy", or rui in a thirteenthcentury text as " pistil ") $)^{30}$. On the other hand, it encourages the sad habit of the " race to anteriority" which inexorably invades recent papers, claiming for $\mathrm{Li}$ Shizhen's classification of plants in his Bencao gangmu, for instance, that it was a more elaborate and scientific system than the Linnean one which only appeared 157 years later, or that Xunzi was the first person to write on genetics! We do not mean here that Joseph Needham went so far. However he surely set the pace when, in order to rehabilitate the scientific aspects of Chinese culture, he emphasises Chinese achievements in comparison to Western ones - for instance when he accords the same importance to Theophrastus' texts on plants as to the two botanical chapters of the Erya, then minimises the whole Greek literature on plants from Antiquity to the Byzantine empire ${ }^{31}$; or when he portrays the whole European Middle Ages as a "dark age" in comparison with the steady development of science in China at the same period. A final example is the case of the youming wuyong category in the bencao literature. Translating the Chinese title by " things that have a name (and description), but are not used (in medicine) "Joseph Needham considered the plants in this category as proof of a pure botanical interest in bencao literature. Actually, under this title such texts group plants already known and previously named, which the author did not choose to insert in the main body of his work but for which he indicates medical properties only and do not give any morphological or other information. This title should be understood as " things that have a name (and whose medicinal uses are known) but which are no longer used" $" 32$.

30. G. Métailıé, "A propos du sexe des fleurs : le cas des rui" Cahiers de Linguistique Asie Orientale, 23 (1994), 223-230.

31. M.H. Thomson, Textes grecs inédits relatifs aux plantes, Parıs, 1955, 7-8.

32. J. Needham, "Science, Technology, Progress and the Break-Through: China as a Case Study in Human History ", in T. Ganelius (ed.), Progress in Science and its Social Conditions, Oxford, New York, Toronto, Sydney, Frankfurt, 1983, 1-22. 


\section{CONCLUDING REMARKS}

If we adopt Joseph Needham's perspective, we simply point to a difference of level of evolution between Western and Chinese botany. Yet we may be puzzled by an apparent paradox. China has one of the richest flora of the world (more than 30.000 species of plants), yet there is not a single attempt at systematic inventory, and the various Chinese books on plants up to the $19^{\text {th }}$ century (whether bencao materia medica or encyclopaedias) seldom count more than one thousand entries - a figure that corresponds to that typical of Western herbals up to the end of the fifteenth century ${ }^{33}$. But in 1613 Jean Bauhin describes 4.000 plants in his Historia Universalis Plantarum; Gaspard Bauhin, his brother, lists more than 6.000 in his Pinax of $1623^{34}$, and John Ray includes more than 10.000 at the end of the century. Maybe, as André Georges Haudricourt suggests, the making of inventories in the merchant tradition of the West was a factor affecting the European botanists. When we look at the last book of traditional Chinese botany (and the first to include only plants, the Zhiwu mingshi tukao (1843) by Wu Qixun, we get a hint of what this traditional botany was. The purpose of the author was properly to identify 1.723 plants, considering both their names ming and their reality shi. To do so he relied not only on texts but also on direct inquiries. The work contains a great number of good descriptions of plants, with a lot of quasi botanical pictures - the book was sent by Bretschneider to several libraries in the world as a testimony of the level of Chinese botany. Some new plants are even described, but there are also ancient and very crude pictures, as well as rough descriptions of as yet unidentified plants mentioned in ancient texts. The author explains that this is to help his readers to make further investigations ; on the other hand, he does not give any name but wuming " unnamed" to the plants previously not known, probably following the kaozheng school's habits or some taboos concerning the fundamental role of the emperor as far as naming was concerned. In a second volume, without illustrations, he only quotes ancient texts on plants - sometimes in full. So clearly this work is not within the scope of modern botany, for the author shows a quite different approach to the living world, one that is

33. A.G. Morton, op. cit., 145.

34. Idem. 
more cultural, in that it emphasises the relationships that humans have and have had with their plant environment. 


\title{
TECHNOLOGICAL ILLUSTRATION IN CHINA A Post-NeEdham Perspective
}

\author{
Peter J. Golas
}

One of the great virtues of Joseph Needham's Science and Civilisation in China, and one unlikely to be seen in any similar work published these days, is its prolific use of illustrations. Many of these consist of reproductions of drawings from traditional Chinese woodblock printed books. Throughout the five-and-a-half decades he was engaged in this project', Needham tenaciously mined these illustrations for every bit of information they could yield to help us understand the development of science and technology in China and, as an integral part of that story, what they could tell us about the place of science and technology in Chinese culture ${ }^{2}$. Some of the major points to emerge from these discussions were :

(1) Illustrations of technology in China, from earliest times, dealt mainly with agriculture and sericulture (the production of silk). It was the machines and implements used in these activities that remained the subject of most Chinese technical illustration down to the twentieth century. This remained true despite exposure of at least a core of educated Chinese to the broad range of Renaissance and post-Renaissance engineering literature brought to China by the Jesuits in the $17^{\text {th }}$ century.

(2) Despite the overall emphasis on rural productive activities, it was in the area of architectural drawings that technological illustration in China

1. J. Needham et al., Science and Civilisation in China. 7 vols. Cambridge. 1954, (hereafter, $S C C)$. Needham concisely describes how he came to begin this project in vol. 1. 10-11.

2. See especially SCC, 4 (2), 166-174 and 4 (3), 104-119. 
reached its zenith, in the late $11^{\text {th }}$ century Yingzao fashi 營造法式 or "Treatise on Architectural Methods" 3 . Not only did this work give unprecedented prominence to its illustrations, but the drawings also represented a standard of accuracy and precision never reached in the portrayal of machines or, for that matter, never replicated again in architectural illustration ${ }^{4}$. By contrast, military engineering drawing, which played so prominent a role in $15^{\text {th }}$ and $16^{\text {th }}$ century European advances in scientific and technological illustration, was never particularly well-represented in China 5 . Nor did the technology of shipbuilding attract much attention from Chinese artists and illustrators, unlike the case in Europe where shipwrights pioneered the use of scale drawings ${ }^{\circ}$. As Needham notes, the Chinese in traditional times simply wrote no systematic nautical treatises and the scattered illustrations we have of ships in other works generally show very little interest on the part of the artist in details of nautical construction. For example, an illustration from the 1510 edition of the mid-1 $11^{\text {th }}$ century Wujing zongyao 武經總要 (Collection of the Most Important Military Techniques) portrays a "tower ship" or battleship (Fig. 1) not only with a poorly drawn rudder but with the masts and sails omitted altogether ! ${ }^{7}$

$3 S C C, 4(3), 110$, fin $\mathrm{C}$

4 Indeed, the shapes of component parts are so clearly delineated that Needham suggests they can almost be seen as working drawings in the modern sense : $S C C^{\circ} .4$ (3). 107. Its author, Li Jie 李誠 knew thoroughly whereof he wrote, emphasizing in his preface that he put a great deal of study into learning (1) the practices, and (2) the orally transmitted rules of the mastercarpenters and the actual artisans; SCC, 4 (3), 84 Unfortunately. he was not motivated to include illustrations of actual building processes with their tools and machines. We have almost no information on the handling machinery used to construct large buildings in early times, and very little more for later periods

5. SCC. $4(2), 165,4(3), 107-110$

$6 S C C, 4$ (3), 379 ff. esp. 404. fn. I and 428-429, A. Pacey, The Maze of Ingenuty, Ideas and Idealism in the Development of Technology, Cambridge. 1992. 79.

7. SCC. 4 (3), 380, 404 and esp. 426, fig. 949. When surveying the written sources available to me for my own work on the history of mining in China (SCC. 5 (13), in press), I found only one illustrated account of Chinese mining before the $20^{\text {th }}$ century. and that did not appear until

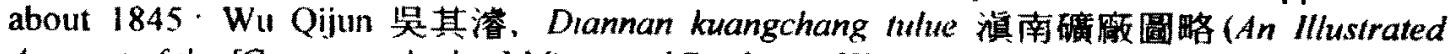
Account of the [Copper and other] Mines and Smelters of Yunnan). woodblock cd.. c. 1845. 
Figure 1
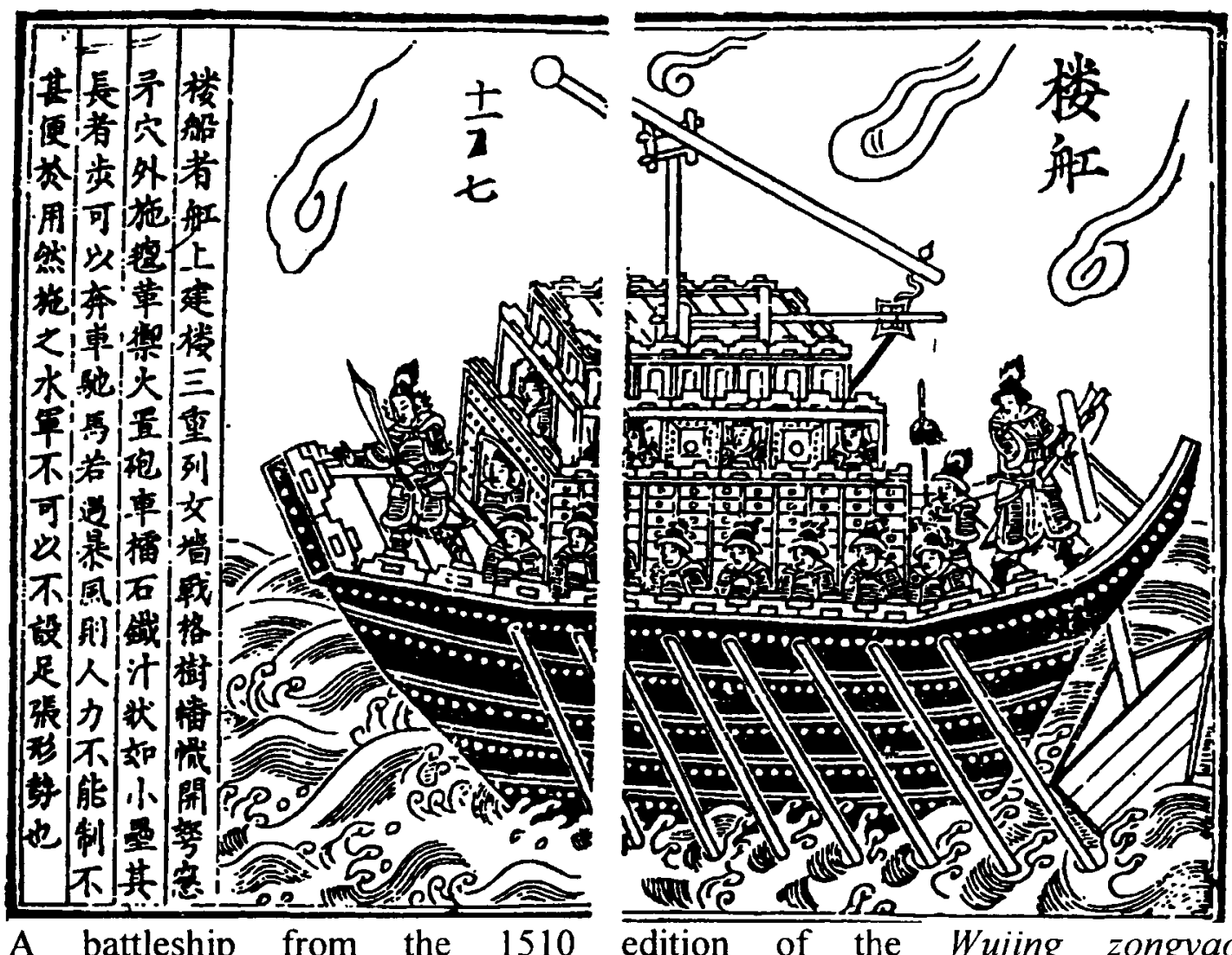

A battleship from the 1510 edition of the Wujing zongyao 武經總要 (Collection of the Most Important Military Techniques). Reproduced in $S C C, 4(3), 426$.

(3) Just as with technology itself, Chinese technological illustration in general reached its maturity around the time of the Song and Yuan dynasties from the $10^{\text {th }}$ to the $14^{\text {th }}$ centuries. The aforementioned Yingzao fash itself was first published in 1097. Two other major illustrated works, the Gengzhi $t u$ 耕織圖 or Pictures of Tilling and Weaving (presented to the emperor in 1145) and the Nongshu 農書 or Agricultural Treatise of Wang Zhen 王禎 (1313) set a new standard for illustrations of the processes and machines of farming and silk production ${ }^{8}$.

8. Two old but classic studies of the Gengzhi tu exıst in western languages: (1) P Pelliot, "A Propos du Keng Tche T'ou"., Mémotres concernant l'Asie Orientale. 95 (1913), 65-122 and (2) O. Franke. Kêng $T_{s c h l} T^{\prime} u \cdot A c k e r b a u$ and Seidengewinning in ('hnna. Hamburg. 1913 For the Nong shu, see F. Bray's discussion in SCC 6:2, 59-64. and Liu Keming 劉克明 and Hu Xianzhang 胡顯章. “Zhong-Xi jixie zhitu zhi bijiao”中西機械制圖之比較 (“A Comparison of Mechanical Drawing in China and in the West "). Gongcheng tuxue "I Isuanj tuxue (The Journal of Engineering and Computer Graphics), 9 (1) (Dec 1995). 92-94 
After this time, however, technical illustration in China assumed a strongly conservative character. The result was that much of the work in later centuries, perhaps especially in the case of agriculture", consisted mainly of copies or reworkings of earlier illustrations, all too often perpetuating their errors and omissions. Thus many illustrations of even the $18^{\text {th }}$ and $19^{\text {th }}$ centuries fall short, technically if not aesthetically, of the best drawings done as early as the Song, and none of them display any marked superiority. "Stylistic" differences there surely were over time ${ }^{10}$, but little cumulative improvement in the ability of artists of later centuries to portray machines accurately.

(4) Finally, in his very insightful discussion of architectural drawing, Needham focuses mainly on the Chinese use of parallel perspective and the absence of convergent (linear, optical) perspective in China until it was introduced to the court by the Jesuits in the $17^{\text {th }}$ century (Fig. 2).

Figure 2
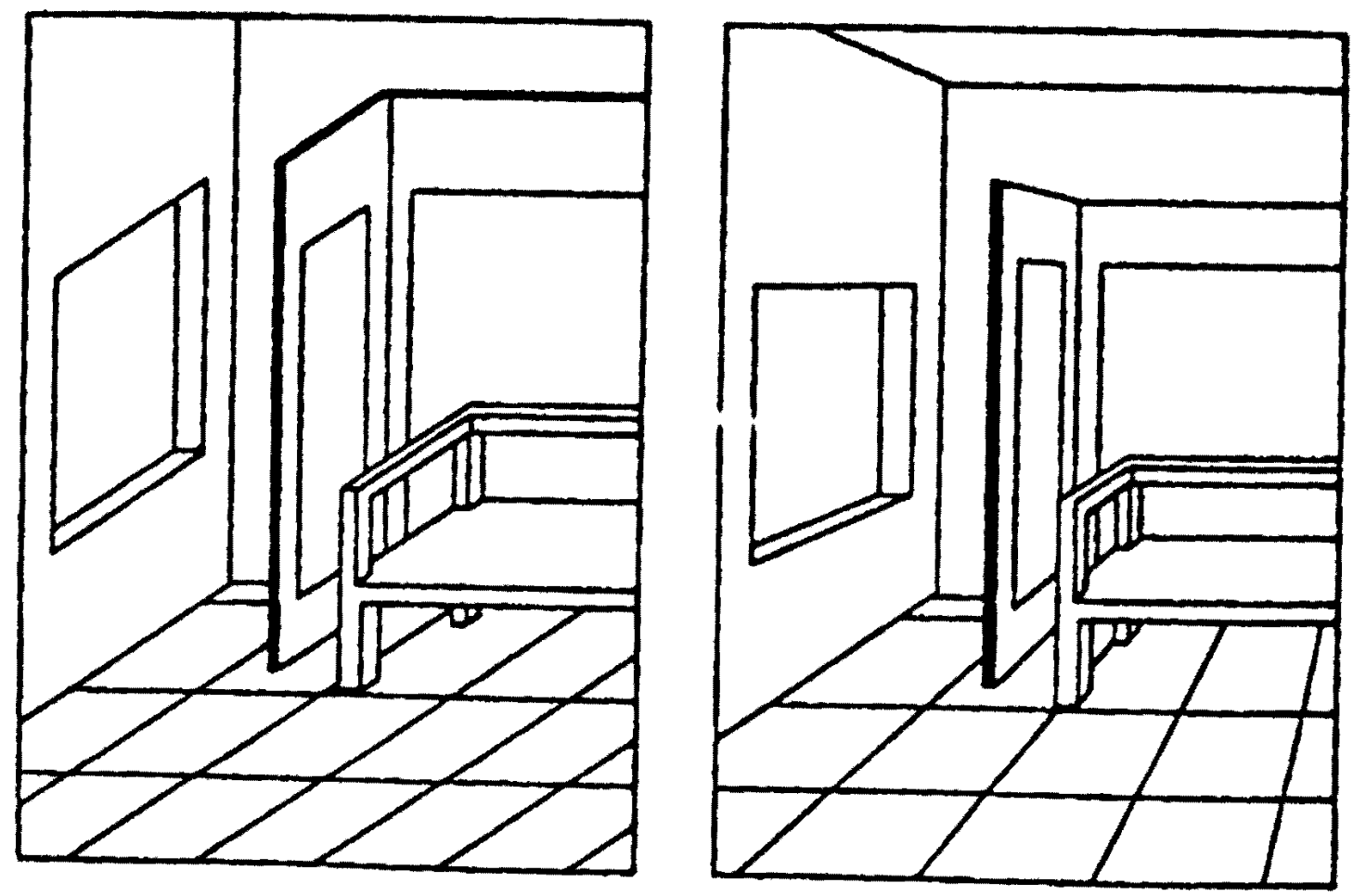

The contrast between Chinese "parallel perspective" (left) and linear or convergent perspective (right). SCC, 4 (3), 114.

9 SCC. $6(2), 49$.

10. SCC. $4(2), 167$, fi. e 
He concludes, however, that the absence of convergent perspective is unlikely to have significantly inhibited mechanical invention in traditional China".

However that may be, there is a related question on which Needham himself seems never to have reached a conclusion. He mentions at one point " the inability or unwillingness of Chinese book-illustrators in olden days to depict machinery accurately" 12 . It is the question suggested in that phrase that I would like to consider in the remainder of this paper. What is it that accounts for the limitations, to our eyes at least, of most Chinese depictions of machines in traditional times ? $^{13}$ I shall not have much to say about "scientific" illustrations. I am convinced that there are significant differences that separate technological illustration in China (machines, architectural drawings, ships, weapons) from " scientific" illustration (that having to do for instance with astronomy and cosmology [though astronomical instruments of course fall under technological illustration], alchemy, anatomy, botany, mineralogy, mathematics). I found those differences to be too great to be bridged in this paper and have thus decided to focus only on technological or pseudo-technological illustrations, above all the portrayal of machines $^{14}$.

11. SCC. $4(3), 114$.

12. SCC. 4 (3), 427. For a related comment, cf. SCC. 4 (2). 1.

13. Not all scholars would agree with this stress on the limitations of traditional Chinese depictions of machines. Liu Keming and his collaborators. who have researched this topic at length, are decidedly more enthusiastic about Chinese accomplishments in this area. See, for example. in addition to the article cited above (fn. 8), Liu Keming. Yang Shuzi 杨叔子 and Cai Kai 蔡凯, "A Study of Geometric Constructions in Ancient China ". Paper presented at the 8' International Conference on the History of Science in East Asia. Seoul. Korea. August. 1996 ; Liu Keming. Hu Xianzhang and Fan Weiwei 焚蔵藏." A Brief Survey of Engineering Drawing in the Song Dynasty". Paper presented at the Second International Conference on Graphic Education Research in China and Japan, Chengdu. 1995 ; and Liu Keming. "Songdai gongcheng tuxue de chengjiu” 宋代工程图学的成就 (“Achievements of Engineering Drawing in the Song "). Wenxian. 4 (1991), 238-246.

14. After deciding to proceed in this way, I came upon B.S Hall's comments on M. Mahoney's criticism of S.Y. Edgerton's contention that the new pictorial techniques of the Renaissance period in Europe (especially linear perspective and chiaroscuro) were essential prerequisites to the Scientific Revolution of the $17^{\text {th }}$ century. Drawing on Mahoney's critique, Hall concludes that "Edgerton's error lay in assimilating under the banner of " science " all forms of what we would plainly now call technology (machine design. for example) along with biological or "life" sciences and such studies as astronomy. mathematics, and physics... it is usually not useful to the historian to regard science and technology as a single. unitary enterprise..." (B.S. Hall. " The Didactic and the Elegant ; Some Thoughts on Scientific and Technological Illustrations in the Middle Ages and Renaissance". in B.S Baigrie. Picturing Knowledge: Historical and Philosophical Problems Concerning the Use of Art in Science. Toronto. 1996, 27. I agree. 
In trying to account for the character and limitations of traditional Chinese technical illustration, we might begin by suggesting that sheer artistic ability (whether native ability or ability developed through training and practice) must have played a key role. One of China's greatest painters, Dong Qichang, writing in the early 1600 s when he was already over 50 , complained: "I still cannot do human figures, boats, carriages, or architecture... $\mathrm{Ni}$ Zan [perhaps the greatest painter in $14^{\text {th }}$ century China] suffered from the same defect" 14 . Now this obviously suggests a further question: how did one get to be a great painter in China without being able satisfactorily to portray human figures, boats, carriages, etc.? The answer, on which we cannot elaborate here, is that the aesthetic values surrounding the most highly regarded painting in China from the $10^{\text {th }}$ century on (i.e., that done by the educated elite of scholar-officials) assigned relatively low priority to realistic painting, emphasizing instead expressiveness and spontaneity.

An even more telling remark comes from Wang Zheng (1571-1644), a close associate of the Jesuits at the Ming court in the early $17^{\text {th }}$ century. He was thoroughly familiar with Western portrayals of machinery that by this time had reached a level of realism, detail and accuracy that would never be achieved in Chinese drawings. Wang was fascinated by Western machines and himself published in 1627 the Qiqi tushuo 奇器圖說 (Illustrations and Explanations of Wonderful Machines) in collaboration with Father Johann Schreck 鄧玉函 (1576-1630) which, in Needham's words, presented “ for the first time in Chinese dress the principles of Renaissance mechanics and an account of their applications by the engineers of Europe " 16 . Nevertheless, after writing the earliest Chinese description of the verge-and-foliot escapement for mechanical clocks, Wang concluded: "This is a most delicate piece of machinery, and the very essence of the "wheel clepsydra". But though everything depends on it, it is extremely difficult to describe in writing, and can hardly be represented in a diagram " 17 . One can see the prob-

15. A. Waley. An Introduction to the Study of Chinese Paintıng. New York, 1923, 250.

16. SCC, 4 (2), 171, fn. i, Zhang Baichun 张柏春." Wang Zheng yu Deng Yuhan Yuanxı qrqı tushuo luzu xin tan”王微与双玉函《远西奇器图说录最》新探 (“A New Investigation of the Collected Diagrams and Explanations of Wonderful Machines from the Far West by Wang Zheng and Deng Yuhan [Johann Schreck] "). Ziran bianzhengfa tongxun, 18 (1) (1996), 45-51. English abstract, 80 In the same year. Wang also produced a short work, the Zhuqi tushuo 諸器圖說 (Illustratıons and Explanations of Various Machınes). which included chiefly agricultural machines invented or adapted by Wang himself, partly inspired by what he had learned of European mechanical devices. Ibid., fn. a, A.W. Hummel, Eminent Chinese of the Ch'ing Perrod, vol. 2, Washington. D.C., 1943, 808.

17. SCC, $4(2), 513$. This is a problem that becomes greater as machines become more complex. As George Basalla notes: " all of the relevant information needed to build an intricate machine could not and, indeed, still cannot be conveyed in pictorial form. This holds true for 
lems Wang faced by comparing a modern drawing of the verge and foliot (Fig. 3) with Wang's effort (Fig. 4).

Figure 3

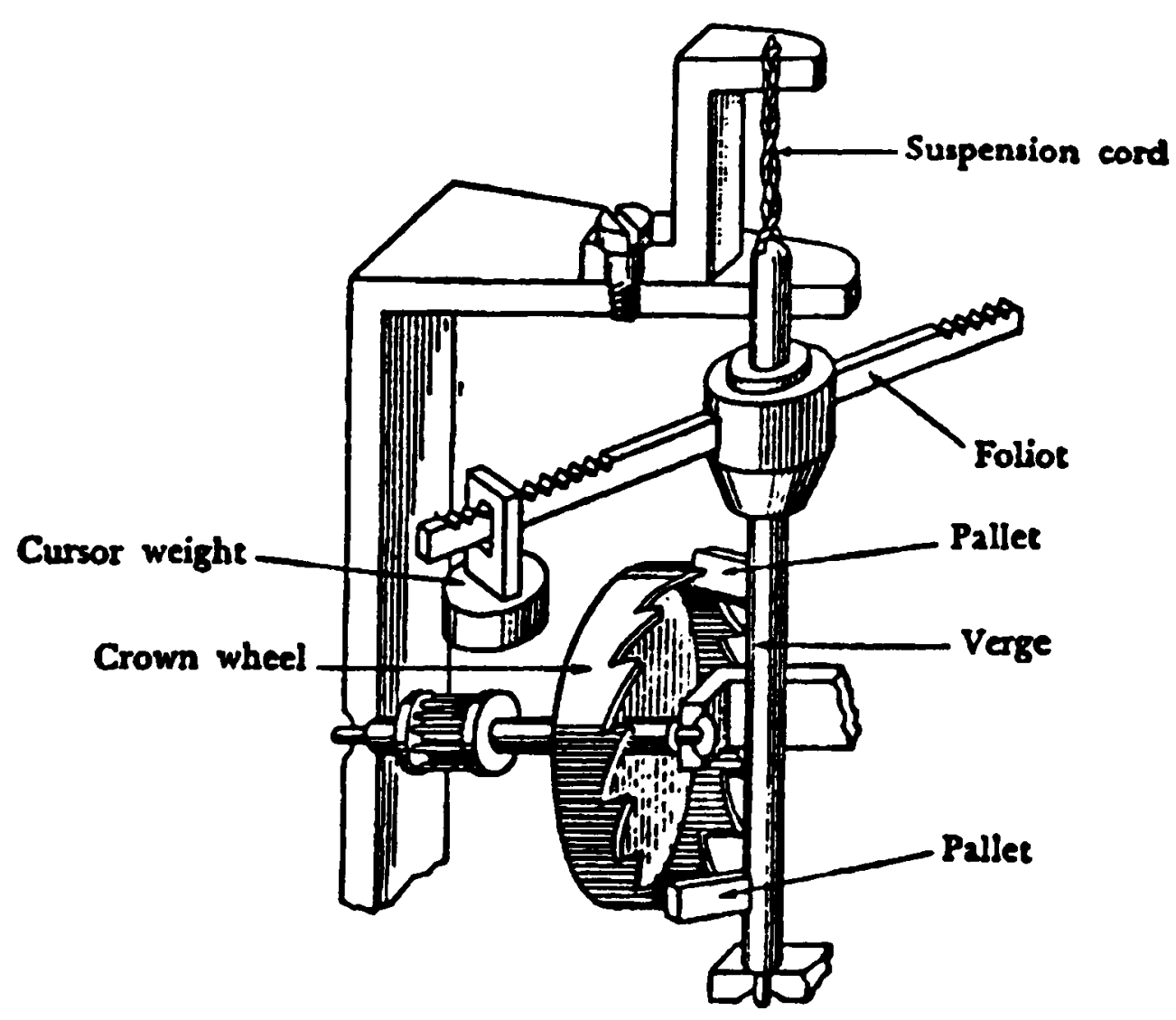

A modern drawing of the verge and foliot escapement. Maurice Daumas (ed.), A History of Technology and Invention; Progress Through the Ages, vol. 2, Trans. Eileen B. Hennessy, New York, Crown Publishers, 1969, 296 ( 2 vols).

seventeenth-century engravings as well as for the best modern engineering drawings. The complete interpretation of a depicted machine can only be made by persons who possess an intimate, practical knowledge of the construction and operation of the actual machine". G. Basalla, The Evolution of Technology, Cambridge, 1988, 84. Dieter Kuhn, whose knowledge of Chinese spinning and weaving technology is unrivalled in the West, agrees; D Kuhn, "Where did the Roads Meet?", Review of Claudio Zanier, Where the Roads Met. East and West in the Silk Production Processes (1 $7^{\text {th }}$ to 19th Century), Kyoto, 1994. T'oung Pao, 83 (13) (1997), 189. 
Figure 4

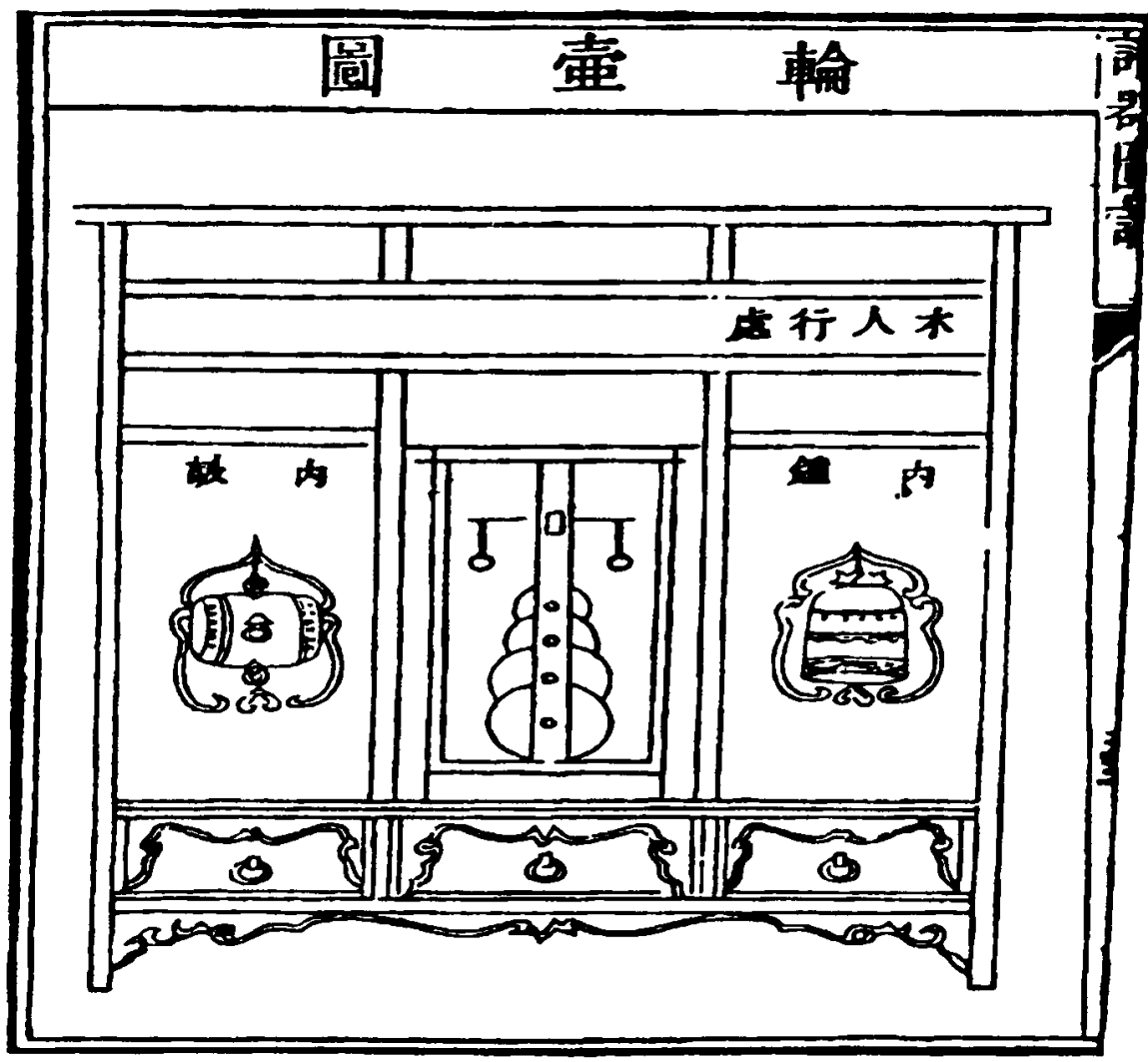

Wang Zheng's illustration of the verge and foliot escapement (in the center compartment). Joseph Needham, Wang Ling and Derek J. de Solla Price, Heavenly Clockwork The Great Astronomical Clocks of Medieval China, $2^{\text {nd }}$ edition with supplement by John H. Combridge, Cambridge, Cambridge University Press, 1986, Fig. 53, PI. 14.

What is especially striking about Wang's statement, and this stemmed undoubtedly from his unique familiarity with the products of Renaissance engineering, is that he recognized that his drawing was not satisfying. For most Chinese artists who did illustrations of machines, however, it probably never occurred to them that their drawings could or should be any more precise and accurate than they were. This introduces the crucial question of motivations. Any machine illustrations, from China or elsewhere, cannot but reflect what was wanted in the illustrations by those who made or commissioned them. Insofar as those Chinese who described and pictured machines did so mainly for purposes quite different from those that motivated authors and illustrators of technical texts in Europe from the $15^{\text {th }}$ century 
on, one would expect the resulting illustrations also to be quite different. As indeed they were ${ }^{18}$.

Once one begins reflecting about motivation, it rapidly becomes clear that not every drawing of a machine or an implement deserves to be labelled a technical drawing. Machines and implements often appear in contexts devoid of technological import where they serve decorative or other purposes. These I have referred to above as pseudo-technological illustrations. The loom in Fig. 5, for example, is there simply to contribute to the illustration of a famous story in which the mother of the philospher-to-be, Mencius, admonishes her son to persist in his studies because stopping would be like cutting threads from a weaving. In other cases, including many scenes specifically portraying farming or other productive activities where the machines are more integral to the illustration, portrayal of the tasks they perform may still not be the prime motive or even a major motive of the artist. I would argue that, only when the focus is on how the machine looked and worked are we unequivocally dealing with something that deserves to be considered a technical illustration.

Figure 5

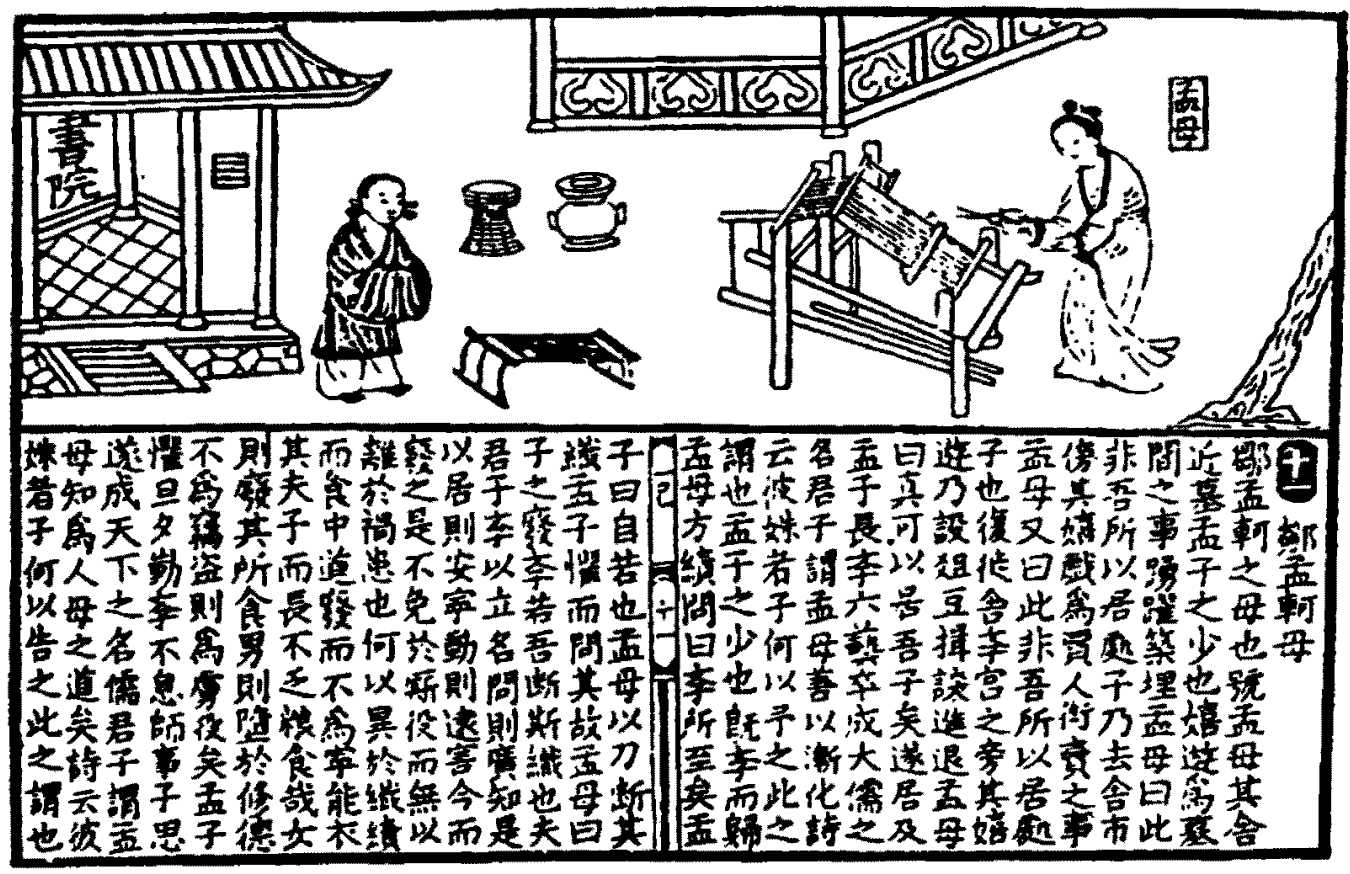

An illustration of Mencius and his mother, from the Lienü zhuan 列女傳 (Biographies of Famous Women). Reproduced in SCC, 5 (1), 258.

18. To familiarize myself with developments in early modern Europe. I have relied on the subtle and incisive studies of a number of historians especially Samuel Edgerton. Eugene Ferguson, Bert Hall and Pamela Long. 
In the Chinese literature, technical illustrations turn out to be exceptional even where we might most expect to find them. Song Yingxing's 宋應星 Tiangong kaiwu 天工開物 (The Exploitation of the Works of Nature) ${ }^{19}$, for example, is the most important traditional account of Chinese technology. Song is quite explicit in his preface, completed in 1637, about the motivation that led him to write this work. He is concerned that knowledge about the "tens of thousands of things" that surround us in our daily life is sadly lacking among those who occupy the highest positions in $17^{\text {th }}$ century China. Thus there are those who, " not knowing the measurements and care of cooking pots, would prefer to discourse emptily on ancient sacrificial vessels of [the state of] Lu", a clear jibe at one of the most bookish elites in the history of the world. Then there are the imperial princes and scions of good families "born and raised in vast palaces, cut off from the outside world" who, just possibly, as they enjoy their fine meals, might want to know " what farming implements look like". Little chance, however, or at least so he says, that the book will appeal to government careerists since it " is in no way concerned with the art of advancement in officialdom "20.

Now some of this smacks of disingenuousness, with Song subtly trying to shame his potential audience into reading his book. But its importance for us is that it suggests that his illustrations of machines have a purpose that actually has little in common with what we take to be the aims of " technical drawing ". Given the make-up of his target audience, it seems highly likely that Song's major hopes (conscious or unconscious) for its illustrations were that they entice readers, make them a little more comfortable when exposed to topics about which they knew little, and generally add to the interest of the work. Machines and implements appear in abundance in the Tiangong kaiwu, of course, but aesthetic appeal almost certainly made a higher claim than technical accuracy ${ }^{21}$. Like so many Chinese illustrations which include machines of one kind or another, Song's illustrations normally seem to be focused mainly on people doing something rather than on the machines or implements they used to do it. Indeed, many of the illustrations contain only the most simple, commonplace implements or even none at all (Fig. 6).

19. Taipei: Shijie shuju, 1962. For a translation of this work, see Etu Zen Sun \& Sun Shiouchuan (translators). rien-kung $k^{\prime} a 1-w u$; Chinese Technology in the Seventeenth Century, Pennsylvania, 1966.

20 lbid. xiv See also 3.35.

21. It is interesting that Song's book was written and illustrated in precisely the period generally recognized to be the aesthetic peak of Chinese woodblock printing : SCC. 5 (1). 262. 269. 
Figure 6

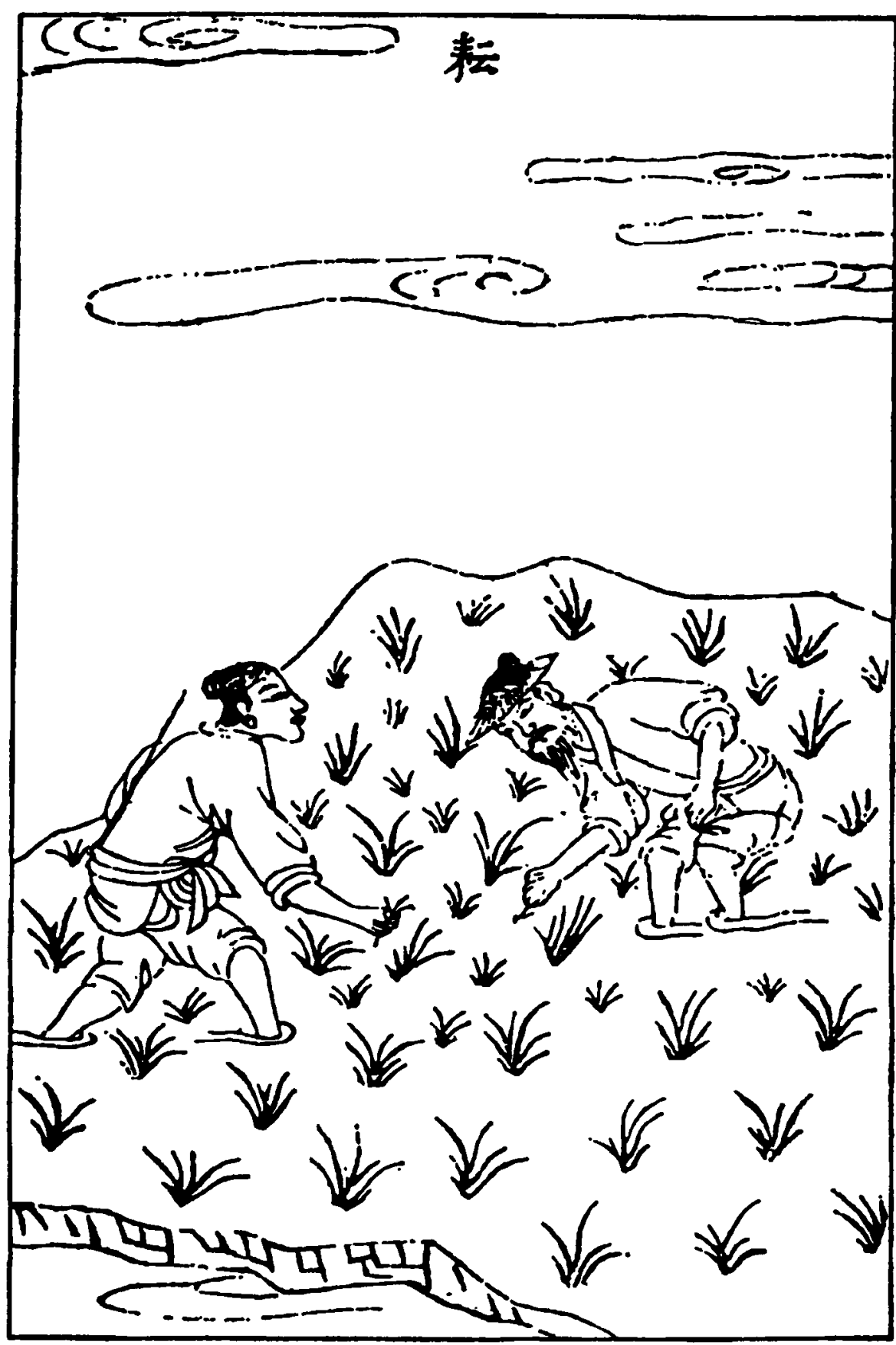

Hand weeding illustrated in the Tiangong kaiwu, Sun and Sun, T'ien-kung $k^{\prime} a i-w u, 10$.

Moreover, the strong tendency toward simplification of the more complicated machines, as in the case of the seed drill (Fig. 7), may be the result of not wanting to tax the imaginations of a readership who would have little 
familiarity with or interest in the working of intricate machines. It is also significant that every illustration ${ }^{22}$ that portrays implements or machines where the farmers or their animals provide the motive power includes human figures. Borrowing the terminology of Bert $S$. Hall, the emphasis is not mainly on the didactic conveying of technical information in convenient form to the viewer, but rather on elegance to make the illustration more attractive and appealing ${ }^{23}$.

Figure 7

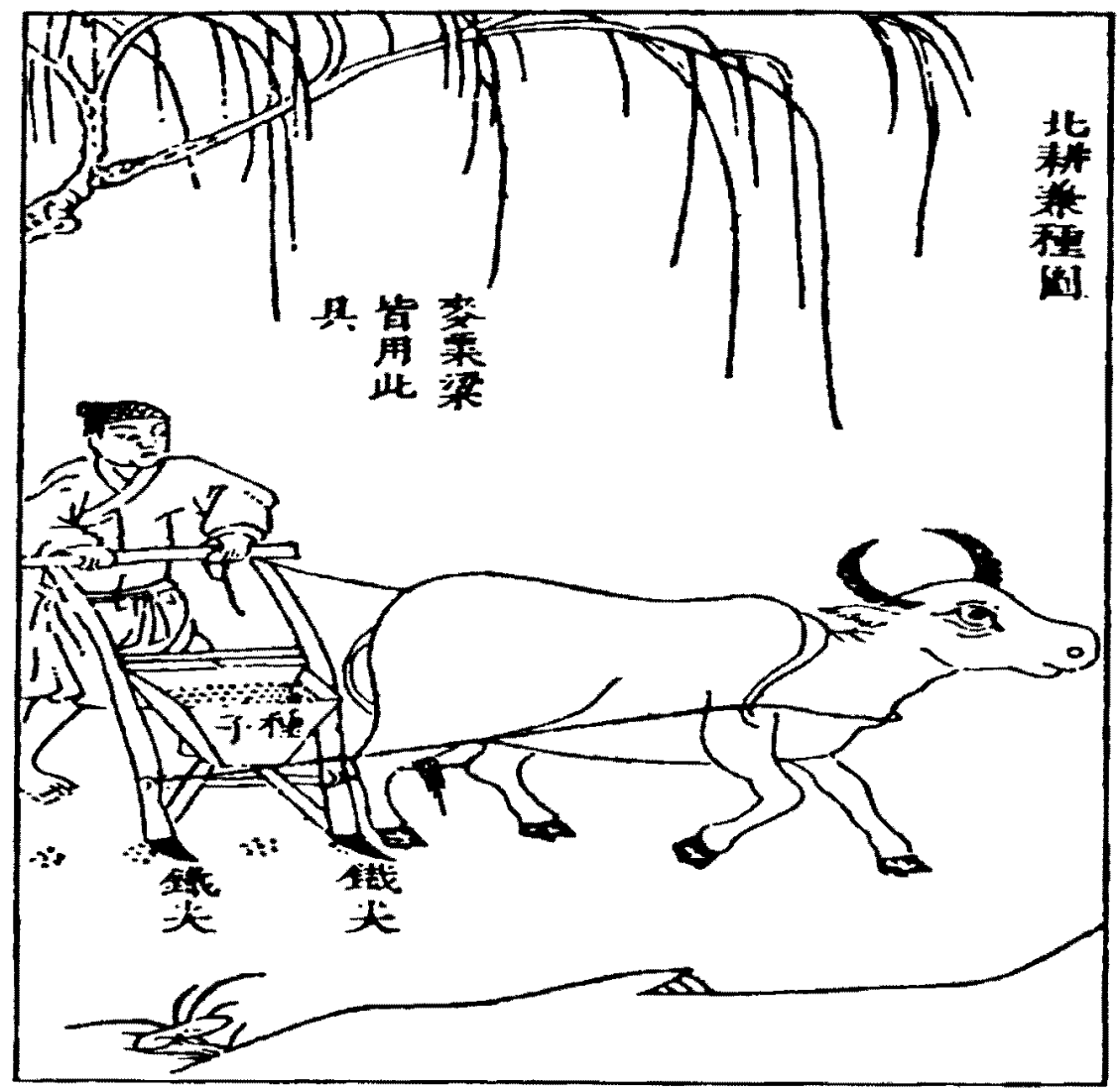

Combination plow and seed drill illustrated in the Tiangong kaiwu, Sun and Sun, T'ien-kung k'ai-wu, 26.

On the other hand, it is striking how much of the motivation behind these illustrations is didactic, if not in Hall's sense of the term. We have noted above the degree to which Chinese illustrations of technology focused on the rural activities of agriculture and sericulture. The earliest records we have of illustrations of farming, dating back perhaps to the fourth century of

22. Except for one later addition.

23. B.S. Hall, " The Didactic and the Elegant ", 28. 
our era, refer to pictures on the walls of imperial palaces intended to remind the rulers of their obligation to be benevolent toward especially the poor people in the countryside. This custom was preserved down to the end of the imperial period ${ }^{24}$. The effect that such portrayals were supposed to have on the court and also on local officials was very effectively expressed in the preface to the Aobo tu 謷波圖(Illustrated Boiling of Sea Water) of $c$. 1335 , a work describing the production of sea salt in a series of illustrations with accompanying explanations: "Those who have a mind to love the people will be moved by these illustrations and will certainly be able to devise excellent policies to improve the livelihood of the people. In this way, it will doubtless be of some use in the governance of the state "25.

In pictures made for such purposes as well as in the many paintings depicting rural scenes that were simply meant to be enjoyed as works of art or decoration, there was little incentive to emphasize the technology that appeared in them. Sometimes, however, we do find a more direct concern with technology along with non-technological motives. Again, the Aobo tu preface provides a nice example, telling us that Qu Shouyi 翟守義, who initiated the work, " had a thoroughgoing knowledge of the origins of the methods of boiling sea water, of the differences in soil and wind conditions, and of the timing of the methods and the regulations of salt boiling. He therefore ordered a painter to make a long scroll which he called the Aobo tu so that those who came later would know the methods of boiling salt and the toil of labor service, and the knowledge would be preserved forever $" 20$.

One of the rare examples of a writer in traditional China who clearly put technological considerations first in his exposition and in his illustrations was Wang Zhen 王禎 (not to be confused with Wang Zheng) whose Nongshu 農 書 (Agricultural Treatise) of 1313 set a new standard for illustrating farming and silk production. It did so with no less than 265 illustrations and diagrams $^{27}$. Wang's main purpose was to instruct local officials on the best existing agricultural methods so that they could help the peasants in north China recover from the devastation that area had experienced as a result of the Mongol invasions. Although Francesca Bray sees Wang as something of a " gentleman farmer" who probably had little if any hands-on experience ${ }^{28}$, Wang is a rarity among Chinese writers on technological matters in his intent

24. P. Pelliot. "Keng Tche T"ou". 95, 109 and passim.

25. Yoshida Tora, Salt Production Techniques in Ancient ('hina, the Aobo Tu, Tr. and rev. by H.U. Vogel, Leiden. 1993. 157.

26. Ibid. 156, translation modified and emphasis added.

27. SCC. $6(2), 169$.

28. Ibid. 63-64. 
that his drawings not only be accurate but that they serve, together with his descriptions, as guides for the actual making machines and utensils. For example, after describing the hand-harrow in detail (including dimensions), he adds : "It seems to me a great shame that this tool is not more widely known and used, so I have drawn and described it on purpose that philanthropists may disseminate the practice " 2 ?

We noted above how Song Yingxing in his Tiangong kaiwu always shows his man - or animal - powered machines and implements in use, thus drawing at least equal or even greater attention to the people and animals using or powering them (Fig. 8).

Figure 8

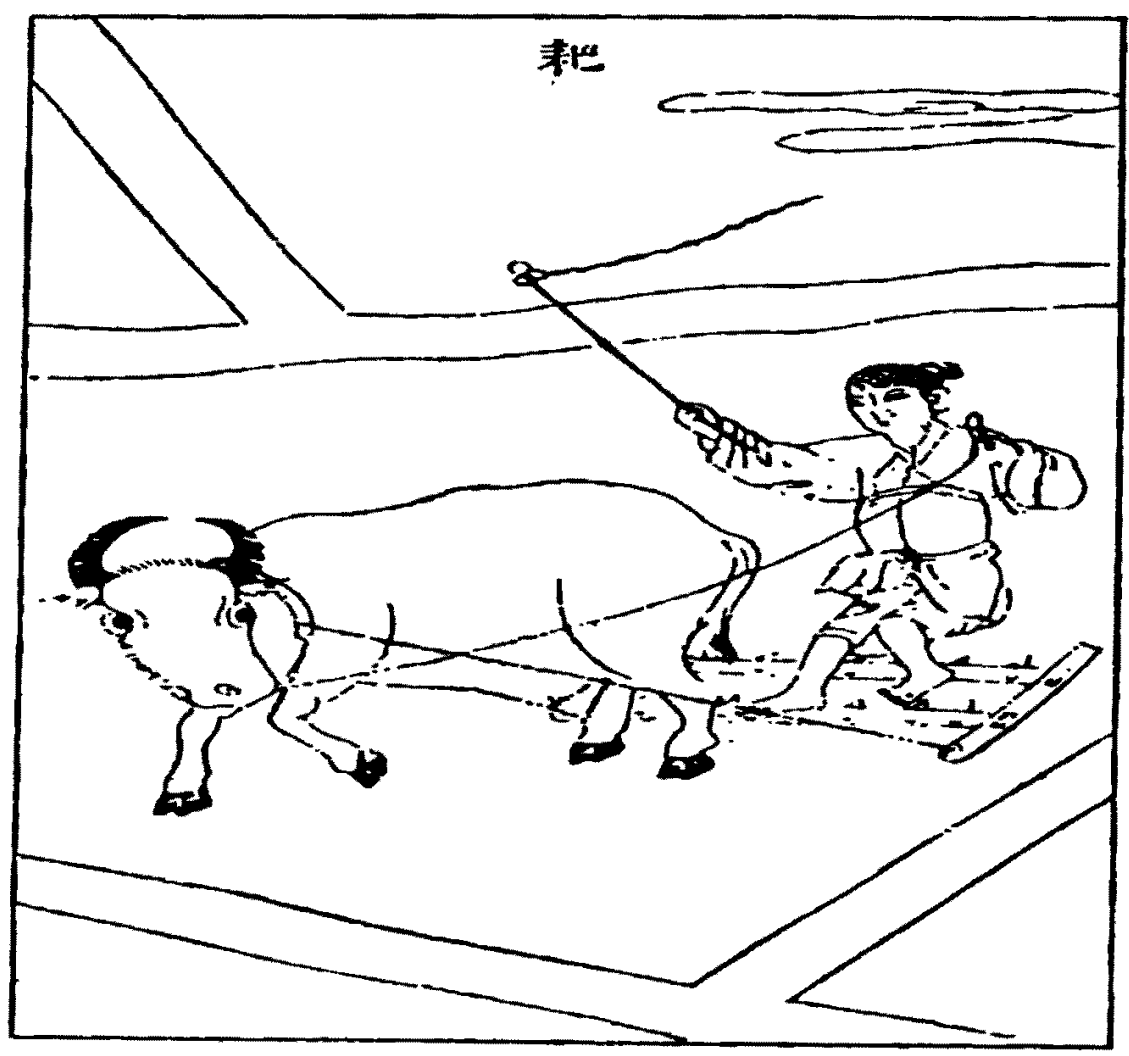

A harrow being pulled by a water buffalo, Sun and Sun, $T^{\prime} i e n-k u n g ~ k^{\prime} a i-$ $w u, 7$.

$29 \mathrm{Ibid.}$ 62. Wang also includes a vivid portrayal of the hardshıps of farmers who do not use the hand-harrow in order to persuade the officials to make efforts to extend its usage: "I have seen farmers weeding their fields by hand, crawling between the crops on their hands and knees with the sun roasting their backs and the mud soaking their limbs - a truly pitiable fate.." Ibid Wang may not have gotten down into the mud himself, but he was certainly capable of empathizing with those who did. 
In Wang's Nongshu, however, we normally have the machines illustrated by themselves, in other words true technical drawings (Fig. 9).

Figure 9

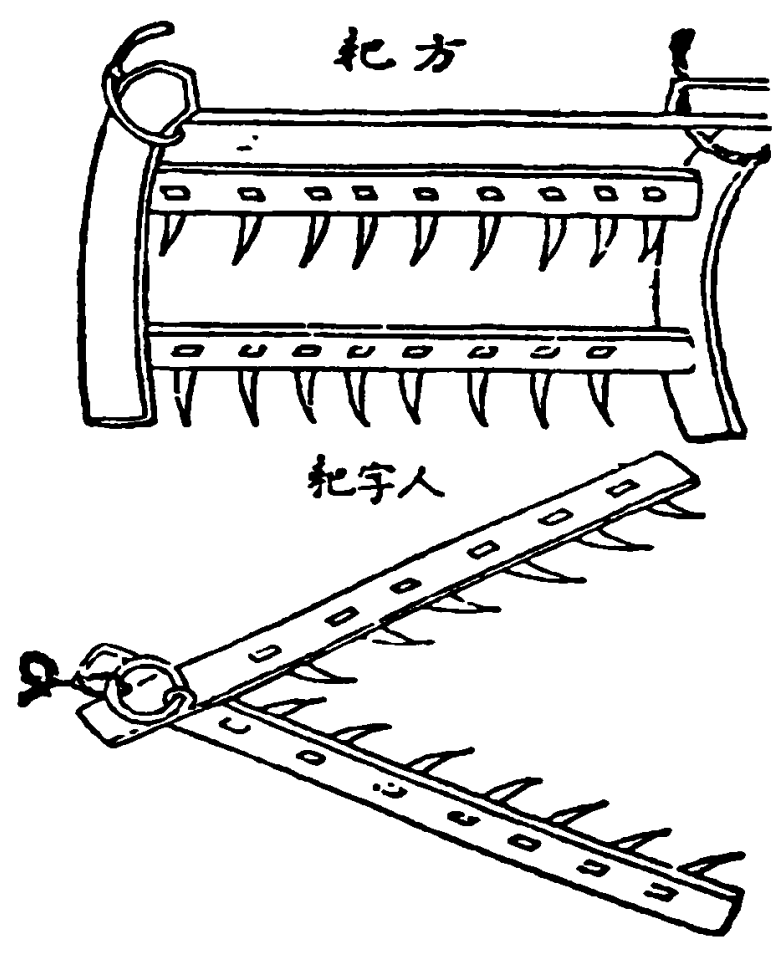

Animal-drawn harrows from Wang Zhen's Nongshu, Wang Yühu 王毓瑚 (ed.), Wang Zhen Nongshu 王祯农书 (Wang Zhen's Agricultural Treatise), Beijing, Nongye chubanshe, 1981.

Wang's illustrations and explanations do not always provide, by themselves, sufficient information to construct the indicated machine ; his treatment of the seed drill falls into this category ${ }^{30}$. Nevertheless, he probably came closer to this particular goal than any of his successors ${ }^{31}$.

30. Bray suggests two explanations to account for this - (1) Wang's artist may not have been fully familiar with or may even, as in the case of the coulter, have been largely unfamiliar with the device he was portraying. and Wang may not have exercised close enough supervision over the drawings ; or (2) Wang may have been less than diligent in checking his tinal text, leading to inconsistencies between text and illustration. Ibid., 63 and 194-196

31. Wang may have been motivated by the fact that many new implements and machines had appeared in Chinese agriculture during the Song. That was much less the case for later centuries, however, thus encouraging writers who followed him to rely over and over on the illustrations of the Nongshu. 
Finally, there is one potential motivation to better technical illustration that seems to have been entirely lacking in China. I am aware of no references to any Chinese in traditional times using drawings to think through an engineering idea, along the lines of a Mariano Taccola or a Leonardo da Vinci. There is, however, one striking negative case, that of Huang Lüzhuang 黃履莊, about whom an account was written by his close friend Dai Rong 戴榕 in 1683, when Huang was 27 years old. It recounts more than 25 kinds of machines that Huang made or described, and speaks with awe about the intensity with which he worked out engineering problems in his mind. It may be significant that Dai makes no mention of Huang using drawing to help him solve engineering problems ${ }^{32}$. And this despite the fact that Dai and Huang had studied together western geometry, trigonometry and mechanics. To be sure, this negative evidence is far from conclusive, but it does square with the absence of any other evidence suggesting this particular use of drawings in traditional China ${ }^{33}$.

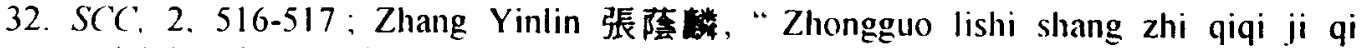
zuozhe“"中國歷史上之奇器及其作者, in Zhang Yinlin. Zhang Yinlin wenji. Taipei and Hong Kong. 1956, 81-82.

33. One wonders if this function of drawing may not lave been inhibited by the ubiquitous use in China of the writing brush. not a very handy implement for rapid and/or detailed sketching. 


\title{
INFLUENCE OF ISLAMIC ASTRONOMY IN SONG AND YUAN CHINA SOME FACTS AND DISCUSSIONS
}

\author{
SUN Xiaochun*, Jacob KISTEMAKER
}

The Song-Yuan period (960-1368) of China witnessed a peak of scientific development, especially in astronomy and mathematics. It is marked by Guo Shoujing's (1231-1316) great achievement in astronomical instrumentmaking and calendrical science.

The Song-Yuan period was also a period of wide-range contacts between China and the Islamic Arabic world, where science also flourished. During the Song dynasty, along the south-east coast area, China had a longestablished and relatively large scale trade with the Arabic world via the South China Sea and the Indian Ocean. In the north and the west, the Song had continuous conflicts with kingdoms of northern and western tribes. Conflict meant contact, and perhaps the most effective contact. These tribes had more direct connections with the Arabic world due to their geographical proximity. In the end, the Mongols conquered the total area from China to central Europe. This Mongolian empire brought Yuan China into direct contact with the Islamic Arabic world.

These two historic phenomena were not isolated from each other. History of science seems to show that the development of science in one culture is often stimulated by the inflow of fresh elements and ideas from other cultures. From this point of view, it would be of great interest to investigate the

* I would like to thank the Society of Eurasiatıc Celestial Science and the Spinoza Funds of Prof. Ed van den Heuvel for their financial support, and the FOM Institute of Amolf in Amsterdam for their hospitality. 
exchange of scientific knowledge between China and the Islamic world during the Song-Yuan period. In Needham's Science and Civilisation in China, the problem of the exchange of scientific knowledge between Chinese and other civilisations was one of the main themes. In his work Needham already made investigations on the exchange of scientific ideas between China and the Arabic world, but it seems that he over-emphasized Chinese contribution'. In fact, the influence was mutual ; the Arabic influence was quite appreciable during the later Song and the early Yuan period. This paper concerns astronomy. From Chinese sources we investigate the Arabic (Islamic) astronomical knowledge recordedly transmitted into China. Then we try to connect it with the new developments in astronomy of that period. The idea in making this connection is that new concepts and methods, if not obviously stemming from Chinese tradition, might show Arabic influences. In this paper we discuss the following problems.

\section{ARABIC ASTRONOMICAL INSTRUMENTS AND THEIR INFLUENCE ON CHINESE INSTRUMENT-MAKING}

\section{Zhamaluding's Arabic instruments}

In the $48^{\text {th }}$ chapter of the Yuan shi (History of the Yuan Dynasty), under the heading Xiyu yixiang 西域儀象, “Instruments from the western region ", it is recorded that, " in the fourth year of the Zhiyuan reign (1267), Zhamaluding 札馬魯丁 constructed astronomical instruments of western origin. "There were seven of them, the phrase "western origin " suggesting that they were of Arabic-Persian origin. About the Arabic origin of the instruments many studies have been made before. Hartner and Ma Jian have made efforts to identify these instruments, for which the Yuan shi 元史 (Yuan History) not only lists the foreign names in Chinese transliteration, but also gives the Chinese equivalents, and short descriptions of their use.

The first instrument is called zatu halaji 咱秃哈刺吉; the Chinese equivalent is the armillary sphere huntian $y i$ 混(渾)天儀 The Chinese reading corresponds to the Arabic term dhatu al-halaqi, in Persian pronounced as zatu al-halaqi $i^{2}$. Ever since the time of al-Battani (d. 928), the

1. J. Needham, Sctence and Civilisation in China, vol. III, section 20. Mathematics and the Sciences of the Heavens and the Earth. Cambridge, 1959, 367-382.

2. In this paper all Arabic or Persian terms are adopted from the work of W Hartner." The astronomical instruments of Chamaluting, their identification. and their relations to the instruments of the Observatory of Maragha ". Isis, 41 (1950), 184-194 and from that of Ma Jian 
armillary sphere used to be called dhat al-halaq, " the owner of the rings". The armillary sphere was not new to the Chinese. It had already been devised by Luo Xiahong 落下䦎 in the Western Han. During the Tang very sophisticated armillary spheres were constructed by Li Chunfeng 李淳風 (late $7^{\text {th }}$ century AD.) and by Yixing 一 行 ( $8^{\text {th }}$ century AD.)

The second instrument has the transliterated name zatu shuobatai 咱秃朔 八台; apparently there is no Chinese equivalent to this instrument, so the text explains that " it is an instrument to observe and measure stars and planets in the sky". Hartner gave the Arabic term dhatu 'sh-shu 'batai, the " instrument with two legs", which is the Arabic name for Ptolemy's parallactic ruler, or the triquetrum. Ma Jian gave the Arabic term dhatu sumut, designating "instrument for determining azimuth". These two Arabic names could mean the same instrument. According to the description in the Yuan shi, the instrument is most probably the parallactic ruler (Dhat al-shu 'batayn).

The third and the fourth instruments have similar nature; both are related to the measuring of shadows. Thus they should be analyzed jointly. The third is called luhamayimiaowazhi 魯哈麻亦渺凹只; the Chinese explanation says that it is a hall in which to measure the shadow of the gnomon (sundial) at the vernal and autumnal equinoxes. The fourth is called luhamayimuyitayu 魯哈麻亦木思塔余; the Chinese explanation indicates a hall for measuring the shadow of a gnomon at the summer and winter solstices. Hartner suggested these two instruments to be two types of sundials, and he gave the following equations : luhamayimiaowazhi = rukhama-i-mu awwaj, " sundial for unequal hours", luhamayimusitayu = rukhama-i-mustawl, " sundial for equal hours".

In comparing these interpretations with the corresponding Chinese explanations, Hartner pointed out that the two terms must be interchanged in order to make sense. That is to say, luhamayimusitayu (rukhama-i-mustawi) should stand for the third instrument, while luhamayimiaowazhi (rukhama-i-mu awwaj) should stand for the fourth instrument. This correction may be justified by the fact that, at the vernal or autumnal equinoxes, the day and night are equally divided, while at the summer and winter solstices, they are unequally divided. Although the word gui 㫫 in Chinese equivalents of the two instruments suggests sundials, the description in the Yuan shi does not mean that

馬堅, “Huihui tianwenxue dui zhongguo tianwenxue de yingxiang”回回天文學對于中國 天文學的影管 (The Muslim influence on Chinese astronomy). Huizu shi lunı (Papers on the History of Muslims in China), 1983. 179-192. We do not know Arabian or Persian language. 
they have been used to measure time during the day, as a sundial is used to, but that they have been used only to determine the equinoxes and solstices.

The fifth instrument is called kulaiyisama 苦來亦撒麻; the Chinese equivalent is a celestial globe. The Arabic term is kura-i-sama', a celestial globe. There is doubt about this.

The sixth instrument is kulaiyiaerzi 苦來亦阿儿子. The original Arabic term is kura-i-ard (Persian pronunciation kura-i-arz), a terrestrial globe. Terrestrial globes were unknown in China before the period in question. The Chinese translation is dili zhi, " a geographical map". The description says that it is " a globe made from wood, upon which seven parts of water are represented in green, three parts of land in white, with rivers, lakes, etc. Small squares are marked out so as to make it possible to reckon the sizes of regions and the distances along roads". It is clear enough that this is a terrestrial globe.

The seventh instrument is wusuduerlabu 兀速都儿刺不; the Chinese explanation says it is an instrument to determine time at day and at night. The description in the Yuan shi obviously indicates it is an astrolabe. The Arabic term is asturlab, which in Persian is always pronounced as usturlab, the phonetic congruence with the Chinese translation is as perfect as it can be.

The identity of the person Zhamaluding is somewhat obscure. Needham suggested that he might have been Jamal al-Din ibn Muhammad al-Najjari who had declined to take on the full responsiblity of the Maraghah observatory, near Tabriz, in 1258. Then, as an alternative, he might have been dispatched by Hulagu Khan to Kublai Khan's court to present the Arabic instruments. This suggestion can be justified because, in the Baiguan zhi of the Yuanshi, it is recorded that " just before Shi $\mathrm{Zu}$ (Kublai) assumed the throne (in the year 1260), a decree was issued to call up Muslim astronomers. Zhamalading and others recommended themselves with their skills, but did not get any official posts". But this Zamalading (another transliteration of Jamal al-Din) soon brought his talent in astronomy into full play. He constructed the seven Arabic astronomical instruments and compiled a Muslim calendar ${ }^{3}$ called Wannian li 萬年曆; all were presented to the court of Kublai. In the eighth year of the Zhiyuan reign (1271), Kublai established the Islamic Astronomical Observatory (huihui sitian jian 回回司天監), and Zhamaluding became the director. In the tenth year of Zhiyuan (1273) he also took up the position of Imperial Librarian ${ }^{4}$.

3. Only to be used by Muslim people in China.

4. A. Sayili, The Observatory in Islam, New York, 1981. 
According to the Yuan bishu jian zhi 元秘書監志 (Collection of Official Records of the Yuan dynasty) by Wang Shidian and Shang Qiweng', at the home of the director, there were another four astronomical instruments ${ }^{\circ}$. These were:

1) Wusulabage kule 匹速刺八個窟勒; it is a mis-transcript of wusutulaba kule 兀速上剌八窟勒. The Arabic term is Usturlab Kura, which suggests a spherical astrolabe. The astrolabe mentioned above is planispherical, but this one has the shape of a sphere $(k u l a)$. This may be an intermediate form of astrolabe in which flat rings were made so as to slide over a solid celestial globe. The text gives the Chinese equivalent xiao huntian tu 小渾天圖, a small celestial globe.

2) Aladishamila 阿剌的殺密刺, it is the transliteration of the Arabic term 'alat al-Shamlah, which means "a revolving parallectic ruler or a hemisphere with a revolving disk" ". The Chinese equivalent is an instrument for " measuring the shadow of the gnomon".

3) Yatulu 牙秃魯, the Arabic term is Yaduru, which means " revolving instrument". The Chinese equivalent is xiao hunyi 小渾儀, a small armillary sphere.

4) Pai'erke'er 拍爾可爾, the Arabic term is Pargar. In Chinese it is called ding fangyuan chi 定方圖尺, a ruler to compose squares and circles. Apparently it is a compass.

\section{The instruments of Guo Shoujing}

The above seven plus four instruments were Arabic astronomical instruments known to be transmitted to China through the hands of Zhamaluding just before the beginning of the Yuan dynasty. How much influence did have these instruments upon the Chinese astronomer Guo Shoujing, who devised seventeen instruments (or associaries of instrument) between 1267 and 1279 ?

The two most important inventions by Guo Shoujing are jianyi 簡儀, the “Simplified Instrument", and yangyi 仰儀, the "Upward-looking Instrument". The word " simplified" suggests that the instrument was a simplification of a more complicated instrument. Needham suggested it to be an

5. Wang Shidian 王士點, Shang Qiweng 商企翁 (Yuan, 1350), Yuan bishu jian zhi 元秘書監志 (Collection of Official Records of the Yuan Dynasty), Siku Quanshu, vol. 596.

6. See section Islamic Mathematical ... of this paper.

7 Here we follow the suggestion by Prof. V.N. Sharma through correspondence. See also V.N. Sharma. Sawal Jai Singh and his Astronomy, Delhi. 1995. 24. 
Arabic torquetum, for a torquetum consisted of a series of discs and circles which were not placed concentrically, unlike those of the armillary sphere. The ecliptic components were removed to fit into the Chinese equatorial system. The horizontal components were set aside to form another instrument called liyun $y i$ 立運儀 in this way the original instrument was simplified. Because a torquetum is not among the above listed eleven instruments of Zhamaluding, we have no direct evidence that the invention of jianyi has been inspired by the Arabic torquetum. Nevertheless, we have some circumstantial evidences that it might have been the result of some Arabic influences.

Firstly, in the jianyi, the traditional Chinese sighting tube was replaced by the diametral alidade, which was commonly used on Western instruments.

Secondly, the diurnal circle on the plane of the equator was graduated in 12 hours and 100 quarters, each of the latter having 36 sub-divisions, thus the circle had 3600 subdivisions. This division system might have been inspired by the 360 degree division system used on circles of Arabic instruments.

Thirdly, the design of jianyi might have already existed before Guo Shoujing constructed it. In the Jin shi 金史 (Jin History) it is recorded that in the fourth year of the Cheng'an reign of Emperor Zhangzong 章宗(1199), a " shabby monk" presented to the throne designs of many instruments, one of which was called jianyi $t^{8}$. It is well possible that Guo Shoujing, who lived in Northern China, had got information about the design of jianyi from the Jin court. In Chinese a "shabby monk" could mean an exotic person or a foreigner. So the design might originally come from a foreigner, most probably an Arab or a Persian. In the Islamic world the invention of the torquetum has often been ascribed to Guo Shoujing's elder contemporary, Nasir al-Din al-Tusi of Maraghah, but more probably goes back to the Spanish Muslim Jabir ibn Aflah (born c. +1130$)^{9}$.

The yangyi was also new to the Chinese. It is an inverted hemispherical sundial. It has a concave hemispherical surface marked with circles and coordinate systems, with a cross bearing a plate with an aperture at the center of the rim-circle of the hemisphere. This structure of yangyi is very similar to the Jaya Prakasa, one type of Sawai Jai Singh's (1688-1743) instruments at the ancient observatory of Jaipur. Because the Jaya Prakasa has a eclipticpole circle on which the pole of the ecliptic revolves, it can be identical to the

8. The Jin shi (ch. 11) recorded: "In the sixth month of the fourth year (of the Cheng'an reign of Zhangzong), the service man Chou Heshang (shabby monk) presented (to the throne) the designs of a steelyard water-clock, a yingyi, and a jıanyı. Orders were given to have them made according to the designs".

9. J. Needham. Science and Civilisatıon in China, vol III, section 20, 372. 
Arabic instrument 'alat al-Shamlah: a hemisphere with a revolving circle ${ }^{10}$. That means that Guo Shoujing's yangyi could be the same type of instrument as the second instrument at Zhamaluding's home, the aladi shamila 阿刺的 殺密剌 ('alat al-Shamlah). The Indians kept the Arabic astronomical tradition very well. Jai Singh's instruments are primarily of Arabic tradition. Jai Singh has had several Muslim astronomers at his service when he started to build his observatories. The Muslim astronomers constructed the early instruments of the Raja, which were based on Islamic books". If the Guo Shoujing's yangyi can be identified with the aladi shamila at Zhamaluding's home, then it is obvious that it had its origin from the Arabic world.

It is must be pointed out that among the instrument designs presented by the " shabby monk", there was one instrument called yingyi 影儀, the "Shadow Instrument" 12. By the name it means a type of sundial, but not an ordinary one with flat plane, for the Chinese had the specific term gui 㫡 for a flat sundial. Being called yingyi but not gui suggests a special type of sundial, probably a hemispherical sundial or yangyı. So it is possible that Guo Shoujing's yangyi was made after the design of the yingyi from the Jinastronomers. The yingyi (i.e. instrument for measuring shadows) by its name means the same thing as the aladi shamila (alat shamira). This is again a circumstantial evidence that Guo Shoujing's yangyı could be the result of the Arabic influence on Chinese instrument-making.

\section{THE INTRODUCTION OF THE CONCEPT LICHA 里差 INTO THE CALENDAR}

Licha was a new concept in calendrical calculations. It marks the time difference of the same celestial event when observed at any two places sepa-

10. William Hunter published a report on the instruments of Jai Singh in Asratic Researches, $n^{\circ} 5$ (1799), in which he identified Jaya Prakasa with alat al-shamlah Cited from V.N. Sharma, Sawat Jat Singh and his Astronomy, 89.

11. V.N. Sharma, "Muslim astronomers at Jai Singh's court ". Journal for the History of Arabic Science, 9 (1991), 23-30.

12. The Jin shi (ch. 11) recorded: "In the sixth month of the fourth year (of the Cheng'an reign of Zhangzong), the service man Chou Heshang (shabby monk) presented (to the throne) the designs of a steelyard water-clock. a yingyi, and a llanyı. Orders were given to have them made according to the designs". 
rated by a certain distance from each other. It is due to the difference between the geographical longitudes of the two places. This new concept was first introduced by Yelü Chucai 耶律楚材(1190-1244) in his calendar Xizheng gengwu yuan li 西征庚午曆(1220).

Yelü Chucai was a very talented astronomer. His father, Yelü Lü, had served as an astronomer at the Jin court and had once devised a calendar. After the conquest of the Jin by the Mongols, Yelü Chucai began to serve at the court of the conqueror Gengis Khan. In 1220, while Yelü Chucai served at Gengis Khan's headquarter in Samarkand during the expedition to central Asia, he presented to the Great Khan his newly compiled calendar Xizheng gengwu yuan li. His calendar was based on the Daming $/ i$ 大明暦 calendar of the Jin dynasty, but considerably improved. The most important invention was the introduction of the licha.

In the Xizheng gengwu yuan li, licha was involved in the determination of the time of occurrence of celestial events such as the phases of the moon. It had formerly been thought that the time of occurrence was independent of the place where the celestial phenomenon was observed. Yelii Chucai recognized that this is not true; the observed time of occurrence of a celestial event depends on where the observer is on the earth. In his memorial to the throne he used an observed lunar eclipse to demonstrate the difference. He said: " In the year of gengchen 庚辰(1220), Your Excellent Majesty (Gengis Khan) was in Samarkand on a westward expedition. In the fifth month of the year, on the fifteenth day, (a lunar eclipse happened). According to the Daming / $i$ calendar, the moon would be obscured to twenty percent, the greatest immersion of the eclipse should happen at midnight. Our on-spot observation, however, show that this happened actually even before the first geng 更 (the Chinese divided the night into five equal time sections called geng) ran out. The reason is that the (calculated) midnight (according to the Daming $(i)$ is the (local time) midnight of central China, and that the first geng in the Western region is (only the local time) first geng in the western region. Why can it not be so that the late first geng in the western region corresponds to the moment of midnight in central China? (The two places) are tens of thousands $l i$ apart, a difference of more than one (Chinese) hour ${ }^{13}$ is not a thing to be wondered!" 14 .

The eclipse happened one and a half geng (approximately 2.6 hours) earlier than the computed time in the Daming li calendar. To solve the problem,

13. The ancient Chinese one hour equals two modern hours.

14. Su Tianjue 蘇天䨖, Yuan chao mingchen shilue 元朝名臣事略. “Jin Xizheng gengwu yuanli biao" 進西征庚午元曆表, ch. 5, 58 . 
Yelü Chucai introduced a correction term to obtain the right time. The time correction is directly proportional to the east-west distance between the two places, as follows :

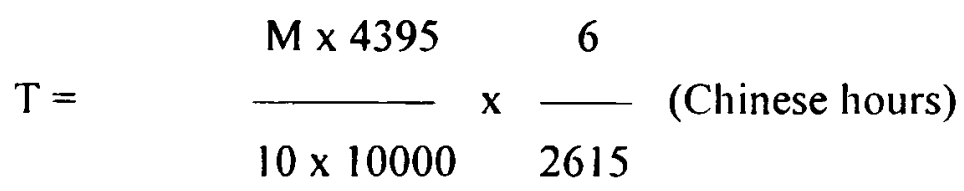

where $T$ is the time difference in Chinese hours; $M$ is the east-west distance between two places. The first factor on the right of the equation is called licha. The second factor on the right is a constant coefficient reducing the licha into a difference in time. 0.04395 is the licha coefficient reducing the distance measured in li into the value of the licha.

From the above we see that the concept of licha is equivalent to that of geographic longitude. In the Xizheng gengwu yuan li, the " prime meridian" is chosen at Samarkand. For a place to the east the correction term licha is positive ; for a place to the west the licha is negative. This concept can only be understood in the context of a spherical earth. The traditional Chinese astronomy did not have the concept of a spherical earth before the period in question. As we have seen above, a terrestrial globe was first introduced into China by Zhamaluding. So it is well possible that the concept of licha was derived from the concept of geographic longitude in the western (Islamic) world. This inference is strongly supported by the following facts :

1) Yelü Chucai was a learned man and skilled in Islamic calendrical science.

In Tao Zongyi's 陶宗儀 Chuogeng lu 輟耕錄 (1366) Yelü Chucai is described as " an erudite in all branches of knowledge : astronomy, divination, arithmetics, music, Confucianism, Buddhism, and books from foreign countries. He once admitted that calendars from the Western region are more accurate than Chinese calendars to describe the movement of the five planets. Therefore, he devised a calendar called Mataba li 麻塔巴曆 a kind of Muslim calendar".

2) The magnitude of the licha determined by Yelu Chucai was in good accordance with Ptolemy's geographical measurements.

The Greeks already knew the method of determining geographical longitude by means of observing a lunar eclipse at different places. But it was impossible to carry out this kind of observation at places too far away. Ptolemy actually derived the geographical longitudes from the land distances 
between places. He estimated the distance from Alexandria to the most easterly habitable place (i.e. China) as being 72000 stadia $^{15}$. Ptolemy's prime meridian was at the Fortunate Islands (present-day Canary Islands); according to him, China reached to about 180 degrees of the longitude to the east ${ }^{16}$. But actually China is about 130 degrees of longitude from the Canary Islands ${ }^{17}$. So Ptolemy exaggerated the longitude by a factor of 1.38 simply because the land distance was exaggerated, which was likely to happen due to the difficulties in travelling by land.

Now Yelü Chucai, by observing the lunar eclipse, determined the time difference between Samarkand and central China to be approximately 2.6 hours. According to his licha equation, the distance between Samarkand and central China (Kaifeng) can be easily calculated, it should be $12892 \mathrm{li}$. But the actual distance, which can also be easily calculated by means of modern method, is 9157 li. The distance was exaggerated by a factor of 1.40 , very close to that of Ptolemy. This can not be a coincidence ; it may indicate that Yelü Chucai has got Ptolemy's data through the Arabs. It is also possible that he has used a Ptolemaic terrestrial globe which was available to him through Arabic hands.

\section{THE ISLAMIC ASTRONOMICAL OBSERVATORY AND THE HUIHUI CALENDAR}

At the early stage of the Mongols' empire, in 1260, Kublai decided to choose the newly built city of Kaipingfu 開平府as his capital (Shangdu 上都). In the capital, an observatory was established by taking over equipment from the former royal observatory of the Jin dynasty. In the meantime, a bureau of Western (Arabic) Stars and Calendar was set up, with Aixue 愛薛 from the Eastern Roman Empire as the head officer. In 1264, Kublai moved the capital to Yanjing (the present Beijing), called Dadu' ${ }^{18}$. In 1271, the Bureau was enlarged as to house two Islamic observatories. One was the new and central Islamic Observatory (Huihui sitian tai 回回司天台) in the capital Dadu ; the other was the original Bureau of Western Stars and Calen-

15. One Greek mile (mille passus) equals 8 stadia or $1.48 \mathrm{~km}$.

16 This can be seen on the world map according to Ptolemy"s geographical knowledge. See E.H. Bunbury, A History of Ancient Geography, London. 1879.578. We also used the Ptolemaeus Cosmographia 1482 made by Johannes of Armsheim. Germany See P. Allen, The Atlas of Atlases, London, 1992. 14.

17 Kaifeng, the capital of the Northern Song Dynasty, is at 114 degrees to the east. Most capitals of the other kingdoms in China at this period were around this longitudinal line.

18. The Mongols called it Khanbalik. 
dar in Shangdu, which was now upgraded, and was called Xing jian 行監, the (Islamic) Observatory Station, to distinguish it from the central Islamic observatory. The latter was often referred to as Bei sitian tai 北司天

台, the Northern Observatory. Zhamaluding was appointed as director of the observatory at Shangdu (probably also of the observatory at Dadu), Aixu was the head astronomer. In both observatories, astronomical work was carried out in the tradition of Arabic astronomy ${ }^{19}$.

After 1271, two astronomical observatories, one Islamic and the other of the Han people, co-existed in Dadu. They were all under the administration of the Imperial Secretariat (Bishu jian 秘書監). From 1274 to 1278, these two institutes were put together to co-operate in astronomical work. It was during this period that Guo Shoujing constructed many astronomical instruments, including jianyi and yangyi, and made astronomical measurements for the purpose of making his new calendar Shoushi li 授時曆 ${ }^{20}$.

One of the missions of the Islamic Astronomical Observatory (Huihui sitian jian) was to issue a civil calendar for the Muslims in China. This calendar (Huihui li 回回曆) was based on Islamic methods and traditions. In the fourth year of Zhiyuan (1267), Zhamaluding compiled and presented to Kublai a calendar called Wannian li 萬年曆. This calendar was used by the Muslims in China during the Yuan. About this calendar, Song Lian (13101381) said in his Song Lian ji 宋濂集 (quoted in the Yuan Ming shi leichao 元明事類鈔)：“ In (Zhamaluding's) calendar, the twelve zodiac signs were used, the circle was divided into 360 degrees, there was no use of the twentyeight lunar mansions ". Obviously it was not a traditional Chinese calendar, but a calendar based on Islamic methods and traditions.

\section{ISLAMIC MATHEMATICAL AND ASTRONOMICAL BOOKS TRANSMITTED TO CHINA}

In the Yuan bishu jian zhi 元秘書監志 (1350) by Wang Shidian 王士點 and Shang Qiweng 商企翁, under the heading “ Islamic (huihui) books", there is a list of books used at the Northern (Islamic) Observatory. In this Zhi it is recorded that " in the tenth month of the tenth year of Zhiyuan (1273), the Northern Observatory reported: there are 242 volumes of classical

19. Chen Jiujin 陳久金. Huihu tuanwenxue sh yanyu 回回天文學史研究(A Study on the History of the Muslim astronomy in China), Guangxi, 1996. 187.

20. Qian Baocong 錢寶琮, “Shoushi lifa lüelun”授時曆法略論 (On the Shoushi calendar), Tianwen xuebao (Acta Astronomica Sinica), $4\left(\mathrm{n}^{\circ} 2\right)$ (1956). 
books, 195 volumes of which are available at our observatory". Then follows the list of 195 volumes of books.

These books were all original foreign books, presumably in Arabian or Persian $^{21}$. In the list, the book titles were given in Chinese transliteration based on pronunciation, then followed by Chinese translations of the titles. In many cases, the translations are not clear enough to tell the exact contents of the books. Ma Jian ${ }^{22}$ attempted to trace the original Arabic or Persian titles from the Chinese transliterations, and gave his own translations or descriptions of the book titles. All are summarised in the following table; YBZ means the book Yuan bishu jian zhi.

21. These books have long been lost. But they were available during the Ming. According to the Ming shi 明史 (Ming History), the Ming general Xu Da 徐達, after taking over the Yuan capital Dadu, took hundreds of volumes of Arabic astronomical books as trophy to Nanjing (the Ming capital). In 1382, the Ming emperor Zhu Yuanzhang ordered the astronomical bureau to translate these Arabic books into Chinese.

22. Ma Jian, “Yuan bishu jian zhi huihui shuji shiyi” 元秘書監志回回書籍釋義 (Interpretation of the Muslim books listed in the Yuan bishujian zhi), Huizu shi lunji (Papers on the History of Muslims in China), 1983, 193-198. 
Table : The Arabic books listed in the Yuan bishu jian zhi (1350)

\begin{tabular}{|c|c|c|c|c|}
\hline $\begin{array}{l}\text { Chinese transliteration } \\
\text { of the book titles } \\
\text { given in the YBZ }\end{array}$ & $\begin{array}{l}\text { Original } \\
\text { Arabian titles } \\
\text { suggested by } \\
\text { Ma Jian } \\
{[1983]}\end{array}$ & $\begin{array}{l}\text { Chinese } \\
\text { translation of } \\
\text { the book titles } \\
\text { given in the } \\
\text { YBZ }\end{array}$ & $\begin{array}{l}\text { Translation or description } \\
\text { of the Arabian titles (based } \\
\text { on Ma Jian [1983]) }\end{array}$ & $\begin{array}{c}\text { Number of } \\
\text { volumes of the } \\
\text { books }\end{array}$ \\
\hline 兀忽烈的 & Euclid & 四䢃算法段 & Euclid's Elements & 15 \\
\hline 帘里速窟 & & 掕解算法段 & & 3 \\
\hline 踭唯那帘答昔牙 & $\begin{array}{l}\text { Sarina handsi- } \\
\text { ya }\end{array}$ & 篰般算法段 & geometry & 17 \\
\hline 麥者思的 & Almagest & 浩司天儀式 & Almagest & 15 \\
\hline 阿堪 & $\begin{array}{l}\text { Alikam } \\
\text { (Kwakib) }\end{array}$ & 㚘福 & astrology ; star divination & $?$ \\
\hline 藍木立 & Raml & 占下法度 & sand divination & $?$ \\
\hline 席塔合正 & Mwhtaj & 災福正義 & essentials (of astrology) & $?$ \\
\hline 海牙剔 & Hayat & 原法段數 & & 7 \\
\hline 呵些必牙 & Hisabija & 諸般算法 & arithmetics & 8 \\
\hline 積尺 & Zij & 諸家算 & astronomical tables & 48 \\
\hline 速瓦里可瓦它必 & $\begin{array}{l}\text { Suwali Ka- } \\
\text { waki-bi }\end{array}$ & 星筮 & explanation of stars & 4 \\
\hline 㯙那的阿剌式 & San'at'Alat & 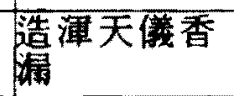 & construction of instruments & 8 \\
\hline 潵非那 & Safina & $\begin{array}{l}\text { 諸般法度复 } \\
\text { 要 }\end{array}$ & astronomy or medicine & 12 \\
\hline \multicolumn{5}{|c|}{ The following are the 47 volumes of books in the house of the director } \\
\hline 亦乞昔儿 & Iksir & 焼舟溃火 & alchemy & 8 \\
\hline 武里 & Tibb & 經 & medicine & 13 \\
\hline 艾竭馬答 & Hikmat & 碖說有無源 & philosophy & 12 \\
\hline 帖里黑 & Tarik & 總年踫國名 & world history & 3 \\
\hline 密阿 & $\begin{array}{l}\text { Mir at (al- } \\
\text { ghaib) }\end{array}$ & 辢認風水 & geomancy & 2 \\
\hline 福剌敖 & Firasah & 相書 & physiognomony & 1 \\
\hline 者瓦希剌 & Jawahir & 䛨害貝 & cameology : jewellery & 5 \\
\hline 黑牙里 & Hiyai & $\begin{array}{l}\text { 捁香漏并諸 } \\
\text { 般機吅 }\end{array}$ & mechanics & 2 \\
\hline (蟲也) 获立 & Shi'r & 颜 & poems & $T$ \\
\hline 兀速剌八個窟勒 & Usturlab Kura & 小渾天國 & spherical astrolabe & one \\
\hline 阿剌的殺密剌 & alat Shamira & 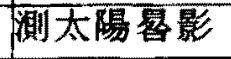 & instrument of all purpose & one \\
\hline 牙香灰 & Yaduru & 小渾儀 & a revolving instrument & one \\
\hline 拍爾可雨潭 & Pargar & 定方圆尺 & compass & one \\
\hline
\end{tabular}


The last four items in the table are not titles of books, but names of astronomical instruments, on which much has been said above. The books in the official library of the observatory are all on mathematics, astronomy or astrology. The books for personal use of the director include some books on history, philosophy, etc., showing the director's personal interest.

The mathematical and astronomical books include Euclid's Elements, Ptolemy's Almagest, descriptions of instrument making, astronomical tables, and astrological manuals. Although they were not translated into Chinese, they might have had their influence on Chinese astronomy since astronomers of the Han people and astronomers at the Islamic Observatory once worked together at the beginning of the Yuan. Guo Shoujing's great achievements in instrument making and in calendar making were made during this period. In the Shoushi li, Guo Shoujing introduced a mathematical method equivalent to spherical trigonometry. Although technically it was presented in the form of traditional Chinese algebra, the idea might be Arabic.

\section{DISCUSSION}

\section{TO WHAT EXTENT DID ISLAMIC ASTRONOMY INFLUENCE CHINESE AS- TRONOMY?}

From the above we see that there was considerable inflow of astronomical and mathematical knowledge from the Arabic world into China during the later Song and the early Yuan. Arabic astronomical instruments, astronomical books and tables were brought into China by Muslim astronomers. Muslim observatories were set up at the early Yuan, and Muslim calendars were made. No doubt Islamic astronomy became a new branch of astronomy in China. Then the question is: How has this new branch of astronomy influenced traditional Chinese astronomy?

Guo Shoujing's astronomical enterprise was basically a Chinese achievement. But several of his innovations seem to have been stimulated by the Arabic influence. In a very short period, and that was the period of the collaboration between the Han observatory and the Muslim observatory, he constructed seventeen astronomical instruments. Some of them were completely new to the Chinese tradition ; for example, the xinggui dingshi yi 星

㫫定時儀 (Stardial for Time Determination) and the riyue shi yi 日月食儀 (Instrument for Demonstration of Solar and Lunar Eclipses). The former one was apparently a modification of the astrolabe, which was one of the seven Arabic astronomical instruments of Zhamaluding. It is almost certain that 
Guo Shoujing's high gnomon ( 40 feet high) was stimulated by the trend towards large instruments which had already started among the Arabic scholars.

About the Simplified Armillary Sphere fianyi, the most significant innovation is that the equatorial ring is not placed concentrically with the meridian circles. The similar structure is visible in the above mentioned Indian instruments of Arabic design, i.e. the two chakra yantra at the observatory of Jai Singh at Jaipur. Needham strongly emphasized the polar-equatorial characteristics of Chinese astronomy and tended to see these chakras as the result of the influence of Guo Shoujing's equatorial mounting. But this can equally be viewed as the other way round: the non-concentrical placement of the circles of the instrument was most probably of Arabic origin.

It is also interesting to see that the scope of astronomical observations was enlarged by Guo Shoujing. Among his lost works there are two significant titles : the Xingce ershiba xiu zazuo zhuxing ruxiu quji 新测二十八宿雜坐 諸星入宿去極 (New catalogue of Star positions of Xiu and other Constellations in Right Ascension and Declination), and the Xince wuming zhuxing 新測無名諸星 (New list of Positions of hitherto unnamed stars). Although the original star catalogue was lost, there still exists an early Ming revision of it. The catalogue gave positions of 740 stars, quite unusual for traditional Chinese practice. Before the Yuan, Chinese star catalogues only gave the positions of 283 leading stars of the Chinese constellations ${ }^{23}$. Guo Shoujing measured other stars, and even those stars not included in the Chinese constellations. There must have been a stimulus behind it; and the stimulus might have been a certain Arabic star catalogue ${ }^{24}$, just like what happened when a European star catalogue was introduced into China at the end of the Ming dynasty.

23. The Ming version of the catalogue was found in a Ming book. Iianwen huchao 天文龨鈔 (A Collection of Astronomical Texts) see Sun Xiaochun. Bo Shuren. J Kistemaker. "The Tianwen huichao star catalogue and the early Ming astronomy '. Ortental Astronomy from Guo Shoujing to King Sejeong (Proceedings of the Second International Conterence on Oriental Astronomy. Seoul. October. 1993) See also Sun Xiaochun \& J Kistemaker. The Chinese Sky during the Han Constellating Stars \& Socrety. Leiden. 1997. 33

24. There were several Western star-catalogues which might have stimulated Guo Shoujing's new observations : Ptolemy's Megale Syntaxis from about $100 \mathrm{AD}$. It was translated into Arabic in 825 with the title Almagest and contained the positions of 1022 stars, Al Battani's improved star catalogue of 920 . observed in the Syrian Racca. Al Biruni's work at the court of Mahmud the Great in Merw (West Turkestan), about 1000 to 1048 (translation of the Almagest in Sanskrit).

Actually the Almagest was among the books at the Northern Islamic Observatory in Shangdu. See section Islamic Mathenatical and Astronomical Books transmutted to ( hina 
Guo Shoujing's other important achievement was the introduction of a new mathematical method called hushi geyuan 弧矢割圓 in his most advanced Shoushi li calendar ${ }^{25}$, which is equivalent to the method of spherical trigonometry. It has long been a controversial topic among scholars whether Guo Shoujing developed this method independently or whether he got it from the Arabs. Indeed, mathematically the method can be developed purely based on previous Chinese knowledge of mathematics, but it might have been stimulated by some knowledge of spherical trigonometry, which Guo Shoujing got from the Muslim astronomers.

Yelü Chucai's licha is a completely new concept introduced to solve a new problem : the time of occurrence of identical celestial phenomena observed at different places. The concept was derived from Arabic astronomy, but it was modified and well incorporated into the traditional Chinese calendrical system.

Although Islamic influence was considerable in the development of Chinese astronomy during the Song-Yuan period, it did not go so far as to revolutionize or replace the traditional astronomy. Islamic astronomy was treated as a separate branch of astronomy by Chinese astronomers. Some merits could be used, but not the complete system. During the Yuan, there was no particular effort to translate the astronomical and mathematical books at the Muslim Observatory into Chinese, therefore the influence was limited. At the beginning of the Ming (1368-1644), the Imperial Astronomical Bureau in Nanjing organized the translation of Arabic astronomical works, apparently in recognition of the merits of the Islamic astronomy. The achievement of this effort was represented by the work Qizheng tuibu 七政推步 (On the Motions of the Seven Luminaries [planetary ephemerides prepared according to the methods of the Muslim astronomers]) (1482). But soon after that the Chinese came in contact with European missionaries who brought European astronomical knowledge into China. Towards the later Ming dynasty, the superiority of Western astronomy compared to Arabic astronomy was recognized, and all the effort which could have been put on Muslim astronomy was now put on Western astronomy. It is in strong contrast with the situation in India : as late as the eighteenth century, the Indian prince Jai Singh was modernizing Indian astronomy by constructing huge Arabic astronomical instruments.

25. Yamada Keiji 山田㢇兒, Jûji reki he no michi 授時暦への道, Kyoto, 1980. 


\title{
SOME REFLECTIONS ON THE WESTERN SCIENTIFIC TRADITIONS FROM THE EAST ASIAN PERSPECTIVE
}

\author{
Yung Sik KIM*
}

There is a general - and to a large degree healthy - scepticism, among historians of science of traditional cultures, about the possibility of making meaningful and productive comparisons between sciences of different cultures. The sceptics insist that the intercultural comparisons should be postponed until the sciences of the different cultures are themselves more thoroughly understood. They also argue that one has to be very careful in choosing what one compares. If one compares wrong things, they say, one tends to distort one's understanding, not only of the things compared but also of the two cultures in general. Even when one comes up with a right thing to compare, many other things of the two cultures - the so-called cultural " contexts" - can be so different that the comparison of the particular thing may not add to one's understanding of the two cultures'.

Of course I agree with these unexceptionable positions. But I still feel that one can, and should, make comparisons. I endorse A.I. Sabra's following statement, for example, which expresses exactly what 1 feel concerning intercultural comparisons, though he made it in a broader perspective, in

* I was supported, in the writing stage of this paper, by a research fund for faculty research abroad from Korea Research Foundation.

1 For a recent example of such scepticism, see N. Sivm. " Comparing Gireek and Chinese Science " . in Hashimoto Keizo, C. Jami, and L. Skar (eds), East Astan Science Tradition and Beyond (Papers from the $7^{\text {th }}$ International Conference on the History of Science in East Asia, Kyoto. 2-7 August 1993). Osaka. 1995, 23-31. 
acknowledging the inevitability of asking big questions in historical scholarship.

"As for the argument that "we do not yet know enough to ask the big questions ", my answer is this : it is only by attempting to formulate appropriate questions that can be fruitfully examined in light of what we now know that we make it possible for others to come up with deeper and more probing questions in the future. We do not know much (that is for certain), but the day when we know " enough" will never come. On the other hand, by altogether abandoning all programs of full-fledged historical research, we only tempt others to fill the vacuum with easy and useless essentialist generalizations ${ }^{2}$. Actually, in spending the past 20 years or so in studying the ideas of the twelfth-century Chinese thinker, Chu Hsi 朱熹(1130-1200), I could not quite make myself give up comparing him with those in other traditional cultures, in particular the Western scientific traditions which culminated in modern science "?

I have compared Chu Hsi's ideas mostly with those of the medieval European scholastics. They are natural candidates of comparison because Chu Hsi and the scholastics belong to roughly the same period, the period in which the main characteristics of the thought of learned men that were to continue for centuries in the two cultures took forms. At times, however, I have made comparisons between Chu Hsi's ideas and those of modern science, which might appear rather ahistorical. I have done this because, of course, such comparisons are not entirely avoidable for anyone who tries to discuss traditional ideas in the modern world using modern words. But part of my purpose has been to redress the balance by showing how different certain traditional ideas were - in contents as well as in contexts - from those notions of modern science to which they have frequently been compared on the basis of some rather superficial similarities.

I cannot claim that I have come up with a correct " methodology" - or " secret" - of comparison free from the dangers and problems I mentioned earlier. I simply believe that such comparisons will enhance our understanding of how Chu Hsi's thought differed from those in the other cultures, including the modern science. And if these comparisons can be achieved with minimum distortion, they will keep us from imposing upon him standards

2. A I. Sabra," Situating Arabic Science : Locality versus Essence ". Isis. 87 (1996), 654670 , on 664

3 Yung Sik Kim. The Natural Phlosophy of Chu Hst, Philadelphia. (forthcoming), especially chap 13 . 
alien to him, and will help us to understand his thought better in its own context.

To be sure, there are problems in the many comparisons that have been, and are being, made between sciences and natural philosophies of traditional East Asia and those of the West. The most serious problem lies in the hidden assumption frequently underlying those comparisons, namely the assumption that the factors which were significant in the Western scientific development are the factors which must have affected the development of the sciences of East Asia also ${ }^{4}$. This has often led students of traditional East Asian science to look at such concepts as time, causality, and laws of nature, and such socio-economic factors as capitalism, urbanization, merchant class, and religious beliefs, as if these factors would have played the same roles in the development of science in East Asia. This is clearly a vastly mistaken position. But I cannot agree that one should therefore stop making intercultural comparisons of these sorts of things. For the problem does not lie in the fact that one makes comparisons but rather in the assumptions underlying them. I believe that it is possible to make comparisons over these things without making such assumptions. And obviously, if the things to be compared had been chosen for their importance in the East Asian context rather than for their significance in Western development, they would have led to more fruitful comparisons.

Another problem accompanying the intercultural comparisons is that one often compares concepts and factors in isolation, without paying much attention to their contexts. Such comparisons tend to stress superficial similarities between what were in fact quite different ; when their contexts are examined, one will find that in different cultures they were quite differently perceived or used. Let me mention the differences in the general intellectual backgrounds of the two traditional cultures between which my comparisons have frequently taken place.

One notable difference is that in the medieval West natural philosophy was accepted by the universities and formed an essential part of their curriculum. Natural phenomena were thus frequently discussed and often became subjects of heated debates'. The situation was very different in traditional China. It is not to say that subjects dealing with the natural world were not accepted by the intellectual mainstream in China. They were accepted ; at

4. For a more detailed discussion of this point, see Yung Sik K'im. " Natural Knowledge in a Traditional Culture : Problems in the Study of the History of Chinese Science ". Mınerva, 20 (1982), 83-104.

5. See. e.g., E. Grant. "Cosmology", in D.C. Lindberg (ed.). Sctence in the Middle Ages, Chicago, 1978, 265-302. 
least, they were not excluded. Nor is it my point that objects and phenomena in the natural world were unimportant to traditional Chinese thinkers. They were important also : they even provided a kind of " cosmic basis" for morality, i.e. the notion of a moral order underlying the natural world providing a basis for morality. The point is, rather, that they were unproblematic. They were not excluded, but were taken for granted and hence simply accepted. It is for this reason that natural phenomena were not discussed very often by traditional Chinese thinkers and that natural philosophy did not belong to the list of subjects in which they showed much interest.

This is evident in the manner in which Chu Hsi discussed natural phenomena. Frequently, he spoke of them not for their own interest but for some external purposes. He alluded to them mainly in the course of resolving some moral and social problems, by adducing analogies between those familiar and obvious natural phenomena and the latter problems that are usually more complicated and difficult. Only rarely did he mention such common natural phenomena for themselves ${ }^{6}$.

In this respect the occasional tensions in the medieval West between natural philosophy and the main moral - that is to say " theological " - force of the period, the Church, seem to have been significant. For those tensions made certain topics of natural philosophy controversial - or interesting, or even "important" - to the medieval scholastics, and thus facilitated discussions of them". In traditional China there was not much possibility of such tensions between morality and natural knowledge which was taken for granted and simply accepted. It is clear that one should take these different contexts into consideration in making comparisons between ideas and events that existed or happened in those contexts.

I have spoken so far about what are, I think, the two main problems that frequently plague intercultural comparisons in history of science. Yet, when we have put these problems under control, first by bringing in the East Asian perspective in our comparisons, and then by looking at the contexts surrounding the ideas, artefacts, institutions, and events we are comparing, we will not only make more useful and meaningful comparisons that will help us better understand the East Asian science, but will also be able to see what happened in the West in a new light. As a result, some events in the West can appear more significant and interesting. And this is another fruit of making

6. Yung Sik Kim. The Natural Philosophy of Chu Hsi, chap. I

7 I.E Murdoch. "From Social into Intellectual Factors : An Aspect of the Unitary Character of Late Medieval Learning" . in J.E. Murdoch and E.D. Sylla (eds). The Cultural Context of Medieval Learning. Boston, 1975, 271-339, esp. 274. 
intercultural comparisons - that is, if they are done prudently. Realization of this advantage must be what lies beneath Shigeru Nakayama's proud remark :

"I claim that scholars like myself usually have a wider perspective than those in Berkeley or Paris. Since scholars at the "periphery" know what is going on at the "center", and few of the latter are interested in what is going on at the periphery, it is more correct to see those at the center generally as narrow specialists in the history of Western science " 8 .

In the remainder of my presentation, I shall speak about some of the events in the history of Western science which we can see in such a new light by bringing in the East Asian perspective. Because of the limit of time, I will be able to discuss them only very briefly.

Of such events, the "Scientific Revolution" would, of course, be the most natural and important subject. One aspect of the Scientific Revolution is particularly interesting to me, namely that the developments that began in the $16^{\text {th }}$ century in Western Europe did not reach peaks which are then followed by fortifications and stagnations or even declines. This was what happened in nearly all other cases of scientific flourishing in the history of the world - in the Sung China, ancient Greece, and medieval Islam, for example. Unlike these other cases where the flourishing scientific development reached a peak after a while and then slowed down in a few hundred years, the developments initiated by the European Scientific Revolution went on and even accelerated. I am not going to dwell on the topic of Scientific Revolution, however, which has already been studied and compared abundantly". I will move on to other cases, and sample some of them.

\section{ABSTRACT, THEORETICAL DISCUSSIONS AND DEBATES}

My first example is the tradition of the abstract, theoretical discussions and debates among the medieval scholastic circles. Such discussions and debates established a foundation for critical scientific discussion, and these seem to have been the most important medieval contribution to the Scientific Revolution - more important than any of their achievements in individual

8. Shigeru Nakayama. " History of East Asian Science : Needs and Opportunities ". Ostris, 10 (1995), 80-94, on 82 .

9. For a recent example, see H.F. Cohen, The Scientific Revolution A Historiographical Inquiry. Chicago. 1994. 
sciences, or any other factor or achievement that those " medievalists" advocating the so-called "Continuity thesis" stress as significant contributions of the medieval science ${ }^{10}$.

This is brought into a sharp relief when we consider the situation in China where the perennial Confucian emphasis on the reality of the external world discouraged such debates. The Confucians considered the acceptance of the reality of the world to be what distinguished them from Taoists and Buddhists whose other-worldly philosophies denied the reality of the phenomenal world and tended to lead men to concentrate on introspection without paying attention to the actual world. Thus, the Confucians rejected concepts like emptiness and " nothingness", or "infinity", "space" and matter, and avoided discussions of them, because to them they were only imaginary concepts that were of no help in reckoning with the reality of the actual world. Nor were these concepts useful in dealing with the moral and social problems of that world which were what really counted for them.

Yet, abstract, theoretical speculations about such basic concepts could have contributed to a fundamental understanding of phenomena in the actual world. In the West at least, it was the continuing discussions and debates over the interpretation of precisely those concepts that helped bring modern science into being during the Scientific Revolution, and ultimately, the " useful" science that we have today. And here we see an irony: emphasis on the reality of the actual world, and on the necessity of the usefulness of discussions, made it difficult for the Confucians to consider in detail those very concepts that could have proved useful in understanding, and living in, that actual world".

\section{THE ISSUE OF SCIENCE AND RELIGION}

The issue of science and religion comes in a new light also, when we bring in the East Asian perspective. The conflicts which occur frequently in history and are referred to by the expression, " science vs. religion ", turn out really to be the conflicts between "philosophy and religion", when examined more carefully. A good case in point is the Greek (or Arabic) science which came to Christian Europe in the Middle Ages not alone but accompanied by the Aristotelian philosophy. The problem for medieval Europeans was not

10 For a brief discussion of the "Continuity thesis", see DC Lindberg. "Conceptions of the Scientitic Revolution from Bacon to Butterfield : A Preliminary Sketch ", in D.C. Lindberg and R.S Westman (eds). Reappratsals of the Sctentufic Revolution. Cambridge. 1990, 1-26.

11 For fuller discussions of this point. see Yung Sik Kim. " Natural Knowledge in a Traditional Culture ". The Natural Philosophy of Chu Hsi, chap 13 
the science itself, much of which was readily accepted. It was how to reconcile what accompanied that science, i.e. the Aristotelian philosophy, with the Christianity, the dominant force of the medieval Europe ${ }^{12}$.

One can realize this more clearly when one looks at a similar situation in East Asia. When Western science came to East Asia accompanied by Christianity, the problem was how to reconcile Christianity with the Confucian philosophy, the dominant intellectual force of the East Asian world. In this East Asian situation, we see that the positions of the philosophy and the religion are reversed: it is now religion that had to be reconciled with the dominant philosophy. And the efforts at such reconciliation were far less successful. But all the same, science was not the problem, it was readily accepted here (or is it " there" ?) also. I tell my colleagues working on this East Asian case of scientific transmission to look at what the historians of Western science do for a similar case. Now I like to suggest that the Western historians have a lot to learn from the East Asian case.

\section{SPECIALIZATION AND THE SPECIALISTS}

My next example is concerned with three events or phenomena that occurred in the West, which are more or less related to one another :

i) the convergence of the traditions of philosophers and technical specialists ;

ii) the separation of the topics on the natural world from the general concern of the intellectuals, but still as important topics ;

iii) the emergence of " scientists" as a self-respecting group as the result of specialization and professionalization.

Of course, these important phenomena in the history of western science have been extensively studied on their own light. But it will be helpful to realize that these were not the phenomena that had to happen at some stage in the historical development of all cultures. They were uniquely Western phenomena : nothing like these happened in East Asia for example. Therefore, instead of asking why something like these did not occur in East Asia, it would be useful to look at the unique situation of Europe in which these developments took place in those several centuries ending only in our own. What is especially notable is that the specialization took place in the West with an increase of prestige of both the knowledge and its practitioners. This

12. E. Grant. "Science and Theology in the Middle Ages". in D.C. Lindberg and R.L. Numbers (eds), God and Nature: Historical Essays on the Encounter Between Christianity and Science, Berkeley. 1986, 49-75. 
did not happen in East Asia ; if any degree of specialization took place there, it did so with a decrease rather than increase of the prestige.

\section{TRANSMISSION OF SCIENCE}

Now let me take up a subject, which has been touched upon already, but now in a more general way. The subject of transmission of science, either between different cultures, or within a single culture or cultural sphere also comes up in a new light, after we have considered the East Asian case. It has to be noted that many changes in history of science, some of them so great that they could even be called " scientific revolutions" came up as the result of such transmissions.

We see many instances of scientific and technical transmissions in the history of science in East Asia. For example, in China, important changes occurred as the result of transmissions of the Indian, Islam, and Western sciences. In Korea, transmissions of the Chinese science, and the Indian, Islam, and Western sciences (usually through China) caused such changes. In Japan, transmissions of the Chinese science (frequently through Korea), and the Indian, Islam, and Western sciences (often by direct contacts) produced the changes.

Many of these changes, though they appear to be of singular importance for the culture that underwent them, were to a large degree events of local significance, when we look at the developments from a global perspective. We should realize, then, that similar types of changes occurred frequently in the West also. Even the great "Scientific Revolution" of the sixteenth- and the seventeenth-century Europe could be seen as an event of this nature.

Related to this is another topic that becomes interesting when comparison with the East Asian case is made : i.e. the shift of the scientific superiority within one culture from one place to another. This happened continuously in Europe, and it is interesting because this is in a sharp contrast with the situation in the Chinese cultural world, in which China always had the scientific superiority ; China was the "center" where significant developments almost always took place first, and then they spread to the "peripheries", to use Shigeru Nakayama's favorite terminology ${ }^{13}$. It would be interesting to consider, for example, what kind of influence this fluidity, reflected in such continuous shift of the place of scientific superiority, exerted on the development of science in the Western culture. How did the development of West- 
ern science, characterized by this "fluidity", differ from that of the East Asian science, for example?

\section{“REFLeCTIVE" UNDERSTANDING}

The kind of fresh understanding of the Western situation that one can acquire as the result of bringing in the East Asian perspective can, in turn, throw new light back upon what happened in East Asia. Here I will discuss just one example of what might be called a " reflective" understanding: namely Japan's success in the latter half of the nineteenth century in the adoption of Western science and in the industrialization ${ }^{14}$.

We are used to seeing this phenomenon as part of the East Asian history in which an East Asian country adopted science and technology from the West after the Western countries had developed them. But if we look at the Westem history of the period more closely, what happened in Japan could, and I think should, be seen as part of the Western history (or should we say the world history ?). Japan was taking part in the competitive industrialization of the leading Western countries that was going on in the latter half of the nineteenth century. To look back now at the situation of the scientific and technological developments of various countries at the time, we cannot but notice that in many respects Japan was either on a par with, or ahead of, major Western countries, and did similar things in similar ways. Whether the Japanese at the time realized it or not, much of what Japan did was not so different from what other European countries or the United States did in the late decades of the nineteenth century when they considered themselves to be trailing behind in some aspects of modern science and technology and exerted efforts to catch up. This was quite different from what the other East Asian countries were doing : countries like China and Korea were not participating in the competitive process, but were merely trying to import and adopt what had already been accomplished in the West.

I think that the mentality of many Japanese even today who seem to refuse to consider themselves as part of East Asia has something to do with this. Also, one is tempted to find some significance of the earlier history of Japan which went through paths considerably different from those of the other East Asian countries and in many ways similar to the West. I am struck, for example, by the similarity between the situation surrounding the so-called

14. For science in Japan of this period. see J.R. Bartholomew. The Formation of Science in Japan. New Haven. 1989. 49-237. 
"decline" of ancient Japanese science and that of the ancient Greek science $^{15}$.

\section{THE NOTION OF THE “ WORLD SCIENCE"}

Finally, the kind of new understanding that I have been discussing will help better formulate a key notion of Joseph Needham whom this symposium memorializes, i.e. the notion of the "single", "universal " science of the world. I have been basically opposed to this notion of Needham that there is only one "unitary science of Nature" and that all the sciences of the past have progressed towards a common end - namely modern science - in " a single history and a single ever-growing structure" of this "unitary science "16. But I feel that this notion did some good for Needham by making him not avoid the intercultural comparisons. When we have learned to make comparisons properly, and to benefit from the resulting " reflective" understanding of sciences in different cultures, we will have a better, more fruitful formulation of the notion of the "world science", one that will do a full justice to the "multi-branched" and " multi-faceted" nature of this notion. That, after all, may have been what this giant pioneer of our field was really aiming at in the course of the gigantic project to which he had devoted the second half of his life.

15. Masayoshi Sugimoto and D.L. Swain (eds), Sctence and Culture in Tradttonal Japan. $A D$ 600-1854. Cambridge, 1978.

16 Needham's view is expressed in a numerous places of his corpus; see. e.g. Sctence and Civilisation in China, vol. 5. part II. Cambridge, 1974, xxi. 


\title{
NEEDHAM'S IMPACT ON JAPANESE HISTORY OF SCIENCE
}

\author{
Togo TsUKahARA, Keizo HaSHIMOTO, Noriaki MATSUMURA
}

In this paper, we would like to examine the impact of the late Doctor Joseph Needham's works on Japanese history of science, and to discuss how his works have been received, or criticised in Japan.

It is perhaps unnecessary to mention that Needham had an impact on Japanese historians of science. A large part of his works were translated into Japanese and they were enthusiastically read by a wider audience, not only those professionals and academics such as historians of science, technology and medicine and/or historians of China and Japan, but also by those who were interested in the subject whether they were professional or amateur historians. His voluminous works on the history of Chinese science, technology and medicine have become the standard work in the subject for Japanese scholars and the general public.

Now let us consider our topic from a historical perspective. In other words, we think the reception of and reactions to Needham's work in Japan deserve further analysis. It is true that Needham's influence on Japan was wide and significant, but the questions we are asking now are how and why. In addition to this, a series of questions are to follow : namely, who read and welcomed his works, and when, where and how were his works, especially the series of Science and Civilisation in China (SCC), translated into Japanese ; and last but not the least, in what context were Needham's works discussed and which contents of his works appealed to the Japanese audiences most. 
In order to answer these questions, we need to distinguish some different levels of reactions and examine them one by one. Needham's impact was not only large, it was also multi-layered as his voluminous works were. Even limited to the topic within the history of science community, we are able to discern four different aspects for our presentation. They are specified as follows :

1. The influence of Needham's study on Chinese history of science on the scholarship achieved by the Japanese researchers.

2. The contribution of Needham's works to Japanese history of science, technology and medicine.

3. The interaction and exchange between Needham and Japanese scholarship.

4. The impact and the inspiration given by Needham's presence to Japanese historians of science.

With regard to the first point, it is most appropriate to examine the reactions at the Kyoto school of Chinese history of sciences, which was then led by Professor Yabuuti Kiyosi of Kyoto University. Yabuuti was a contemporary to Needham, born in 1907. Institutionally speaking, this Kyoto school mainly consisted of historians educated at, and then gathering around and organized by the Jinbun Kagaku Kenkyujo (which is literally means the Research Institute of Humanities) affiliated to Kyoto University. Yabuuti's professorship was officially attached to the Institute, and he organized his research group there. His group was known to be one of the most active research centers on the history of Chinese science, and most of its achievements were published by the Institute. Through a series of publications, we are now able to access the presentations and discussions of his seminar, and these are still relevant to the examination of present day scholarship. During the cold war period, when access to mainland China was limited, Kyoto attracted scholars of sinology from all over the world, since the library in Kyoto was famous as one of the most precious and largest collections outside China. Needless to say, research carried out by the Yabuuti's school explored and made full use of the collection and as a result, the contributions of the Yabuuti school were highly original. It is not an overestimation to say that the existence of the Yabuuti school maintained the highest standard of Chinese studies, leading the field internationally.

The scholarly origin of the Kyoto school of Chinese history of science can be traced back to the time of Nagaoka Hantaro's (1865-1950) who was interested in Chinese ancient sciences and technology. He was the first of the modern scientists after the Meiji restoration to show scholarly interest in 
ancient sciences of their own culture. Nagaoka's interests were followed by some of his successors, especially Shinjo Shinzo (1873-1938), who established the Kyoto tradition of studies on oriental astronomy.

As a leading physicist, Nagaoka's hypothesis of the orbit model atomic structure was associated with the name of Rutherford, and the model is known now as "Rutherford-Nagaoka model". Among his followers and students, we can find such Nobel laureate physicists as Yukawa Hideki (1907-1981) and Tomonaga Shin'ichiro (1906-1979). As has been mentioned, it is, however, very important that Nagaoka was not simply a singleminded physicist, his interest were broad enough to cover ancient sciences, too. This part of scholarly pursuit was continued by Shinjo, originally Professor of astronomy at the Kyoto University. In this regard, the Kyoto astronomy school became a unique place where the combination of interests in modern astronomy and ancient sciences were studied together.

For this school, Japanese colonial expansion provided a fortunate opportunity to explore their interests, particularly in China. Shinjo was appointed as director of the Shanghai Institute of Science, which was the center of the Japanese colonial sciences in China. Needless to say, he made full use of the position to exploit Chinese historical resources.

Quite coincidentally, Joseph Needham was dispatched to the other side of the war front in China. We know how Needham worked and carried out his research on the Chinese history of science from his book Science Outpost, which vividly recorded his excitement in his historical researches amidst the war, even when, at one point, he and his friends were surrounded by the Japanese army.

Shinjo's work was continued by his successors, and the scholarly tradition of the Kyoto school of Chinese or oriental history of sciences has emerged in the aftermath. Yabuuti was central in the formation of this school. It is wellknown that Yabuuti and his group made important contributions to Chinese astronomy. As these have been closely examined by Kawahara Hideki and Yano Michio in a recent issue of Historia Scientiarum', we need not further discuss the contents of his and his school's contribution. Instead, let us focus on some aspects of the school's formation.

Yabuuti was not only an excellent scholar, he was also an excellent organizer and teacher. He produced students of international standard, such as Yoshida Mitsukuni and Yamada Keiji, and later Yano Michio, then Tanaka Tan and Kawahara Hideki. Also among those who participated in his seminar, we see several major contributors to the history of Chinese science from 
foreign countries as Nathan Sivin, Donald B. Wagner and Joen Sang-Woon. There is no doubt that the Kyoto school, or Yabuuti school, formed a leading scientific community in the subject of history of Chinese science.

After Needham returned to Cambridge, he launched his $S C C$ project in early fifties, and the first volume of the series was published in 1954. Yabuuti's school can be compared to his project in some respects : both were based on a colonial tradition of studying China and collection during the war. But in the Cold War period, a difference is again marked, that Yabuuti's school enjoyed relative favour during the close of continental China, and except Nakaoka Tetsuro and Yamada Keiji, most of its members of the school tactfully evaded political conflict by adopting an apolitical attitude, while Needham was in trouble as an alleged " red" sympathizer. While Yabuuti organized his group and produced his students within the favourable institutional framework of Research Institute of the Humanities within Kyoto University, Needham's project was carried out by his personal efforts without institutional support.

For the Yabuuti school, it was indeed a surprise to come across Needham's achievement, and his works were warmly welcomed. For the Japanese historians, this encounter is rightly described with surprise and pleasure, as if they had met someone from afar with whom they can share their particular and even esoteric interests. To welcome such a " discovered distant cousin" is a natural and spontaneous attitude, and the Japanese historians appreciated the existence of Needham. They also discovered that this " discovered cousin" was a renowned biochemist from Cambridge, which lended greater authority to his work.

After the Kyoto school discovered Needham, they appreciated and enjoyed scholarly exchange. It is rather a surprise for historians of science who are familiar with stories of betrayal and controversy, and whose research subjects are accompanied by gossip against competing groups, that the relationship between the Kyoto school and Needham and his collaborators was so cordial. Contrary to the assumed conflicts between the two " research communities", or "paradigms" of Needham and Kyoto, this case may be able to provide an example of " a peaceful exchange between two scientific societies". Their exchange and co-operation were substantiated by a series of letters exchanged between Yabuuti and Needham kept in the latter archive in the Needham Research Institute, Cambridge. They paint a picture of cooperation and the offering of mutual support, despite the facts that Needham was once surrounded by Japanese troops and that the Kyoto school is a legacy of Japanese colonial science. In due course, the work force for the translation of Needham's voluminous works into Japanese was mostly supplied 
from the stock of Yabuuti's students ; in addition to Nakayama Shigeru's particular contribution. The translation of Science Outpost was undertaken by Yamada Keiji, and that of The Grand Titration was completed by Hashimoto Keizo. Moreover, Needham visited Japan several times and enjoyed his stay and research in Japan, these were mainly facilitated and supported by Yabuuti's group. They also exchanged their students : for instance, one of our authors Keizo Hashimoto received his Ph.D. degree in Cambridge under the supervision of Needham. Hashimoto was formerly a student of Yabuuti, and then became his assistant at the Research Institute of the Humanities. During this period, Yabuuti arranged for him to go to Cambridge and to study for his Ph.D. with Needham. Their exchange was extended to more personal affairs: the author, Tsukahara, has witnessed some very personal exchanges between them during the mourning of Needham's late wife Lu Gwei-Djen.

One last recent case exemplifies this co-operation. In the recent reconstruction project of Su Song's Giant Water-clock at the Museum of Clockworks in Nagano, Japan, directed and supervised by Yamada Keiji, we can point to the stimuli received from the standard work in English on this issue, Heavenly Clockwork by Needham and others. Needless to mention, the stimuli given by Needham is surviving and continuous in Japan mainly through the scientific activities carried out by the still active members of the Kyoto school.

Next, let us discuss the history of Japanese science and Needham. Needham's interest in China was not limited to the area of China as a nation-state, but went beyond the sphere of influence of her traditional culture. In his works, the Japanese and Korean contributions to science and technology were not simply dismissed as peripheral, and he shed new light on these areas. In this sense, his geographical perspective can rightly be seen as East Asian rather than Chinese per se.

On the Japanese side, while history of Chinese science had a school centered in Kyoto, research on history of Japanese science were more widespread and part of general historical research. For such contact with Needham, we should look at his specific exchange with Nakayama Shigeru. Unlike some other Japanese historians of their own culture, Nakayama was outstanding for his approach of placing that particular local history within the wider East Asian and international historical context. As the title of his Ph.D. thesis, A History of Japanese Astronomy: Chinese Background and Western Impact, show, he discussed Japanese science as a development caught in the conflict between its traditional Chinese background and ideas newly imported from the West. No wonder that Nakayama's approach corresponded 
with the research carried out by Needham. Since the time when Nakayama was a Ph.D. student at Harvard in the late fifties, they communicated with each other, and Nakayama actually visited Needham. When Tsukahara interviewed Needham, he said that the discussion with Nakayama was certainly a stimulation, because of what the particular position of being a Japanese meant for the study of China. Different from Chinese scholars, for whom the " object" is equal to the "subject" of study, the Japanese are outsiders of China. Yet, the Japanese are different from European or other observers of China, because they share a greater cultural heritage with China, particularly the written language. In order to describe the scientific view on nature of a specific culture from the objective eyes of historians, being an outsider is certainly considered to be of merit. On this point, Needham and Nakayama are also in agreement. But again, even though both were educated in a modern science, biochemistry and astronomy respectively, Nakayama is an outsider of the Western cultural context or European modernity as such. Needham remarked and also admired that this doubleoutside-ness of Japanese intellectuals such as Nakayama could be turned into the possibility of a double objectivity towards both China and the West. A similar remark was also made by Nathan Sivin, whose friendship with Nakayama is almost as long as that of Nakayama's with Needham. For Needham, through personal contact with Nakayama and actual guidance during his several trips to Japan, he was able to acquire wider access to the historical material kept in Japan. Some of the early works of Needham have sometimes been criticized as being rather ignorant of Japanese achievements, but his works were gradually enriched by the constant supply of information from Japan.

Thereafter, for the Japanese side, Needham's work became a kind of model of research. The local histories of Japanese science seek to include such a wide context as Needham has amply provided in his Science and Civilisation in China, even to the extent that some Japanese historians of science are proposing a research programme modelled after Needham's, naming it "Science and Civilisation in Japan".

By all means, we should continue our discussion on the issue of the demarcation between Japan, Korea and China, or not only of Japan and Korea, but also of China and its peripheral cultures. It is now more than obvious that the stimuli given by Needham were not limited to factual findings from historical documentation, but spread to the renewal of the whole historiographical and regional perspective of the Japanese history of science.

Owing to the limitation of space, the third and fourth points will be discussed briefly. For most Japanese members of academia during the Cold War, Needham seemed to represent the concerned intellectuals of the West. 
These were the days when interest in China or Russia was automatically associated with leftist activities. Moreover, the Japanese scholarly community of the history of science was known for its left wing tendency and liberal-minded orientation. As has been pointed out several times, the generation of historians of science in the period were the outcome of discontent and criticism relating to natural science and engineering majors. There prevailed a general sentiment that historical and ethical studies on science and technology may lead to liberate us from alienation in advanced industrial societies and the militarization which seemed to culminate in the Vietnam war. As a whole, historians of science were thought to be the representatives of antitechno-science parties, and they were generally regarded as forming a social opposition against the establishment. It was a time when Marxist historiography was most appreciated in the Japanese history of Science Society. Even those who stayed away from Marxism were seen as mild left sympathizers.

The reason why Needham was welcomed and appreciated partly derived from his association with leftism. This certainly appealed to the Japanese academia to a considerable extent. However, a point of dispute is whether Needham stood on the opposite side to what the Japanese intellectuals assumed. Needham's position appealed to the Japanese not because he was from Cambridge, but because he was not very well accepted in the institutional framework of Cambridge University. For the Japanese, the authority of Ox-bridge was often misunderstood. Cambridge is by all means an elite University, but at the same time, it has been associated with leftist activities. Needham's image was that of a radical intellectual struggling within an old, obstinate, and conservative university. The "flower age" of this imagery produced dozens of similar figures in Japanese Universities.

Actually, Needham did not always fit into such an image. He was more complex. He always kept a firm position in one of the most powerful colleges in Cambridge, and was even appointed Master of it. It is true that he made leftist and liberal remarks in public, but the politics in Cambridge was not simply divided into two different camps. Needham's place was, different from the Japanese assumption, at the heart of the establishment, while he explored and encouraged radical social reforms and carried out research on history of Chinese science which was not accepted by either History of Science or Oriental Studies Faculties of Cambridge. One-sided understanding of this Needham's double-sidedness by the Japanese is most likely caused by the different social status of universities in Japan and England, particularly Ox-bridge, so powerful and politically manoeuvrable in English context.

Whenever we deal with the examination of the controversial issue of the Cultural Revolution in China, we have to be very careful of wording and 
conception. The point we should note is that quite a few Japanese historians of science were involved in this ideological battle and they openly expressed sympathy for Needham's view. On this issue replayed, Nakaoka Tetsuro the most important role, attracting a wide readership at the time. Nakaoka is one of the leading historians/theoreticians of science and technology, and his critique on industrial society appealed to the Japanese audience at the cult level, so he was referred to as a "Japanese Marcuse". In various works, he discussed and examined some independent efforts using an alternative local technology during the Chinese Cultural Revolution. The curious point was that when he later went to Cambridge to spend one year sabbatical with Needham, he wondered at his position in Cambridge: Needham was at the same time the Master of the powerful college and a radical social reformer. For Japanese academics, it was impossible to be like him².

Yamada Keiji was also known for his sympathy for Needham's view on this issue. Citations from Needham are quite often found in his writings. Yamada's commitment to these political issues were somehow more direct, and he was also regarded as one of the intellectuals sympathetic to the leftist movement of those days. We are now able to point out that the combination of studying history of science and interest in China and Chinese sociopolitical issues culminated in the expression of concern with Chinese current political issues'. In this sense, not only for Nakaoka and Yamada, but also wider Japanese audience, Needham was surely a symbol of a "friend comrade " in England.

Lastly, the impact of the linguistic aspect of Needham's work should not be dismissed. The publications his successive volumes are received with wonder and surprise because of his polyglotism and breadth, particularly so for the Japanese who are usually proud of their command of Chinese characters. To this pride, the surprising thing was that Needham's books are full of difficult characters from a variety of Chinese classics and, most of all, that this Needham was an Englishman. No wonder his discussion on Chinese classics in terms of English showed some new aspects of meaning and different interpretations to the Japanese. For instance it had not been necessary to translate such concepts from Chinese natural philosophy as $q i$ and $l i$ into Japanese, because the Japanese understand the Chinese characters as they are. It is certainly a benefit to understand them without rephrasing the concept, but it may have resulted in further misunderstandings caused by different cultural contexts and syntax. It is therefore considered that Needham's

2. Nakaoka Tetsuro, "Cambridge de kangaeta koto", Igirisu to Nihon no Hida.

3. See Yamada's various works in 70 s. 
ingenuity in examining Chinese natural philosophical classics using English, had the effect of refreshing the meanings and sheding new light on the different aspects of the conventional meanings of the characters. For the Japanese, translation of Needham's texts from English to Japanese could rightly characterised as having a "mirror effect" : namely, the Japanese saw a different image of themselves in the mirror of Needham reflecting Chinese classics. No wonder such an image was not only enjoyed, but also encouraged the Japanese scholar to envision these texts in a new light.

We should add one more remark : the interaction of translations of Needham's works among Japan, China, Taiwan, Hongkong and Korea could provide us with interesting examples of intertextuality in East Asian cultural exchange. Creating a work based on the Chinese classics, interpreted and translated into English, then returning to East Asian languages and citing it is a complicated cultural process. Further examination of this process will no doubt reveal some interesting discourses and exchanges between participating cultures.

As we have pointed out, Needham's impact on Japan can be analysed from several different aspects through ranging from the cultural to the linguistic, through the political context. The remark we should make finally is that Needham's impact can rightly be considered as on-going in Japan. The discussion we presented today can only propose a preliminary framework through which Needham's work will be better understood. We hope our further research will be able to contribute to the bridging of scholarship between cultures and civilisations initiated by Joseph Needham. 

Cognitive Homologies IN THE Studies of SCIENCE IN INDIAN ANTIQUITY : A HISTORIOGRAPHIC AXIS OF THE INDIIA.JOUIRNAL OF HISTORY OF SCIENC'E

\author{
Dhruv RaINA*
}

This paper follows closely on the heels of a series of papers on the historiography of the sciences of India - and it deals with the publications of just one journal called the Indian Journal of History of Scrences founded in 1966. The decade commencing 1950 witnessed an exponential growth of scientific institutions in India ; and by 1959 attempts were underway to organise researches into the history of sciences, though the tradition of research dated back to the first half of the nineteenth century. The Indian National Science Academy constituted a board that would address the task of producing an authoritative history of sciences of India. In 1964, at the behest of the Ministry for Scientific Research and Cultural Affairs, a meeting of interested scholars was organised, where it was decided that the Academy would take on the responsibility of constituting a National Commission for the Compilation of History of Sciences along the lines of the UNESCO Commission for Mankind.

The Commission in turn delegated the responsibility of the disbursal of research funds for the history of science to the Science Academy. The immedi-

* An earlier version of this paper was presented at the $20^{\text {th }}$ International congress of the History of Science. Liege in July 1997. A more detailed versıon entıled " Midnight 's Children as a Mirror of Politics and Science: A Science Studies Analysis of the official History of Science in India ". was presented at a Seminar at the Department of the Iheory of Science and Research. University of Gothenburg in September 1997 
ate task was the creation of professorial positions and a cadre of researchers. With the passage of time university departments were to recruit faculty into departments of history of science, drawn from the reservoir of scholars trained by the Commission. Thirty years later this process has still to take place. In any case these researchers would produce monographs, bibliographies and research articles that were to appear in the Indian Journal of the History of Sciences, (hereafter IJHS) and it is to these publications that we now turn.

\section{A PRofILE OF THE $I J H S$ PUBLICATIONS}

Let me begin with a brief profile of the publications appearing in this journal over the past thirty years, before providing an overview of three representative scholars in the field. Most of the papers appearing in this volume fall within a certain genre of the history of science writing - this is simultaneously an exaggerated claim as it is trivial for the sociologists of knowledge. A more reasonable claim, certainly demonstrable, is that Indians author most of the papers published in the journal, and that a significant number of Indians researching the history of science publish in the journal. However, scholars of a different analytical or historiographic focus have been publishing in other journals as well. This dispersal is evidently not a random phenomenon, since journals not merely embody concerns of research networks, but also methodological approaches, a domain of investigation and within the domain a shared conception of the central problematic. However, one of the peripheral outcomes of the professionalisation of science in modern India is the attempt to professionalise the history of science. The paradox is this : professionalisation is not evident in a distinct cognitive or institutional identity. Identity, if any, is best embodied in the precepts of what Russel calls dotage theory'.

The first assumption of this part of the study is that the view of science that distinguishes the Indian scientific community re-emerges in the IJHS account of the history of sciences and shapes the public image of science. The historian, in turn, legitimates this image of the scientist as generator of truths about the natural world. The scientific community draws capital from the resource base so created and social status so obtained. A second assumption, almost a consequence of the first, is that the cause of the absence of professionalisation of the history of science resides in its institutionalisation

1. C. Russel, "Rude and Disgraceful Beginnings : A View of the History of Chemistry from the Nineteenth Century ", British Journal of History of Science, 21 (1988), 272-294. 
and cognitive dependence on the scientific community. The IJHS archive thus provides the soft garnishing for Indian science.

Between 1966 and 1994, 568 research papers appeared in the IJHS, roughly about 21 papers per year, and one look at the variance and we observe that the discipline has grown marginally, if we are to go by the number of publications. Close to $40 \%$ of these papers are on the history of mathematics and astronomy, while the history of technology accounts for less than $5 \%$; the history of medicine accounts for about $16 \%$. Taking another slice, the historical period addressed by more than $50 \%$ of these papers is that of the ancient and medieval periods of Indian history, roughly $20 \%$ cover the history of science in modern India and contemporary history. This leaves a very narrow middle spanning more than a thousand years of history covered by about $27 \%$ of the publications. In the early stages of a discipline there is likely to be a greater focus on the early periods of history and questions of foundations. But thirty years on we notice a marginal displacement of focus towards contemporary history almost at the expense of interest in the medieval period. Of the total number of papers on the history of astronomy and mathematics in ancient India, more than $61 \%$ are on the astronomy and mathematics of the ancient and early medieval periods. This corresponds to the epoch of the Vedanga Jyotisha, and the astronomers Varahamihira, Aryabhatta and Brahmagupta - iconic presences in the pantheon of Indian science.

This conflation of history with antiquarian studies is a symptom of the historian bogged down in nationalist historiography, seeking vindication for the end of the golden age of science and culture in India. The Middle Ages thus appear as the dark ages, wherein science from the Indian past goes into a state of neglect. The explication of the onset of the dark ages provided a modality for deliberating upon the current state of science in India.

\section{PHILOSOPHICAL APPROACHES : THE SEARCH FOR COGNITIVE HOMOLOGIES}

In epistemological terms, some of the articles appearing here aim at teasing out homologies between the epistemology of modern science and the knowledge systems and practices of ancient and medieval India ${ }^{2}$. These papers could be seen as responses to two stimuli. In the early years when sci-

2. I use the term homology in the sense employed by the Japanese scholar Kaneko, although it is a usage which is circular. Cognitive homologies refer to cases where ${ }^{*}$ an isomorphic state of mind or similar mentality can also be found in the semantic sphere of another culture " (T. Kaneko. " Einstein's Impact on Japanese Intellectuals". in F Glick (ed ). The Comparative Reception of Relativity. 351-379. especially 359). 
ence still reaped the cream of the idea that it was ratified of a radical world order, there was an attempt to visualise science as the eventual victory in the battle between progressive ideas and the forces of obscurantism. However, Eurocentrism in the international domain, as well as the retreat of the socialist ideal in the 1980 s prompted a reverse commentary. The methodological imperative or the attempt to translate the methodology of the knowledge systems of ancient India in terms of the precepts of modern science delimited the ongoing dialogue between modern science and other knowledge systems.

One of the relics of the Orientalist tradition was the predisposition of the IJHS historians to direct their gaze to the Indian philosophical systems in order to divulge the origins of science in the Indian tradition. The internalist tradition, guided by a philosophical conception of science, thus was led onto the question of the foundations of science in ancient India. Six principal philosophical schools defined their discourse: Purva Mimamsa, Uttara Mimamsa, Samkhya, Yoga, Nyaya and the Vaisesika. The historian of science Subbarayappa interpreted the Vaisesika as a pluralist realist system, considered as the school of Indian atomism ${ }^{3}$. Let us examine this construction a little more closely.

The question that needs to be asked is how historians of science recuperate the Vaisesika. From the British Indologist A.B. Keith's Indian Atomism to contemporary readings of the history of sciences in India, cognitive homologies between several strains of Greek atomism and Vaisesika atomism have been proposed by a number of historians of science. Historians of science from the mid-nineteenth to the mid-twentieth century had celebrated the rapid evolution of modern atomic theory as a theory of physics : this celebration must be situated against the backdrop of the polemic between field theoretic descriptions of physics and the corpuscular description. In much of this historical narrative the evolution of atomism is presented as the victory of materialist thought. From the perspective of origins, a lineage, however complex, was drawn from Greek philosophical atomism to modern day atomic theory as a sub-discipline of physics.

Now if the Vaisesika system was ontologically committed to atomistic realism, then it became important to ask why it failed to blossom into a theory of the physical sciences or to stimulate the growth and elaboration of the

3. B.V. Subbarayappa, "An Estimate of the Vaisesika Sutra in the History of Science", Indian Journal of History of Sciences, 2, 1 (1967), 22-24, especially 22. Most redactions of the' Indian philosophical systems interpret the Vasesika as a school of realist atomism. 
sciences in India ${ }^{4}$. Subbarayappa proposes that there was a conceptual transformation of the school from a heterodox one into an orthodoxy, and this had to do with the synthesis of Vedic ideas that were integrated into the Vaisesika opposite. And though the Vaisesika was subsumed within the orthodoxy by the ninth century A.D., its epistemology required that perception and inference were important instruments for the acquisition of knowledge, that in turn furthered ideas both "naturalistic and rational" ". An overdeterminationist framework prompted numerous responses to this core interrogation ${ }^{6}$. If Subbarayappa and other contributors to the IJHS history were seeking answers in terms of the cognitive or epistemological transformations of philosophical systems themselves, the Marxists were attempting to reveal the socio-political basis of orthodox thought, and the "legend of suppression" provided ${ }^{7}$ them with an appropriate explanatory device.

It is important to note that while overdeterminationist history restricted both the kinds of questions that could be asked and the responses proposed, it did further important insights through the perspective of cross-cultural history. With the benefit of hindsight it may be remarked that the cross-cultural studies of science reckoned with the limitations of overdeterminationist history.

Subbarayappa comparative reconstruction of the Vaisesika takes recourse to diachronic maps or tables listing conceptual landmarks in the history of four major civilisations across time. These maps or tables served two related purposes. On the one hand, of establishing priority, of who did what first, and once this had been demonstrated to chart out possible channels for the transmission of ideas. Thus for Subbarayappa the significance of the Vaisesika resides in the fact that its theory of the elements and atomism were inte-

4. The question as posed by Subbarayappa was: " Why was it that the Vaisesika school with its presumed heterodox beginnings and owing allegiance not only to the reality of the external world but also the relationship between cause and effect was not able to gather momentum and establish a scientific tradition as we understand it now ?" (Subbarayappa, 31). As is evident, the question is entangled in a maze of historiographical wrangles, the most amazing feature of which is the triumphalist vision of modern science more or less dictating the question posed by the historian.

5. B.V. Subbarayappa, "An Estimate of the Vaisesika Sutra in the History of Science", op. cit., 23.

6. According to the overdeterminationist perspective of history, Fuller writes: " there is only one world order, which consists of certain nodal events through which all possible histories would have had to have passed". On the other hand in the underdeterminationist view " a given event need not have occurred, but once it did occur, everything that followed did so by necessity" (Fuller, 1993, 210-211).

7. D. Raina and S.I. Habib, "The Moral Legitimation of Science : Bhadralok Reflections on Theories of Evolution ", Social Studies of Science, 26 (1996), 9-42. 
gral parts of a larger philosophical system, thereby proposing that the system had developed autochthonously or internally. Further, the school is supposed to have come on to its own well before pre-Socratic ideas had taken on definite shape ${ }^{8}$ : in which case, the theory of atomism could not have been developed as a consequence of transmission from Greek sources. These narratives from the 1950s and 1960s argued from a singular epistemic conception of science and thus Subbarayappa writes : " ... if the Greek view is rational so is that of the Vaisesika for there is a theory of causation running through the latter" ". In non-Western nations then, particularly those that have had a colonial past, there is a perceptible subterranean discourse that seeks to reverse the amnesia that characterised the history of science prior to the 1950s - however, this reversal was framed in the very same mould of the history of science that characterised the former; namely the empirical-mechanist scientism of the era.

This genre of the comparative history of science was structured by two propositions in turn founded on the ideal of science as a cultural universal: (1) that the so-called scientific method had remained more or less constant over the centuries, (2) that the structure of pre-modern knowledge systems were unproblematically discernible in terms of the categories of modern science. This rendered it possible to compare knowledge systems of distinct culture areas across time and space - in other words constitutive of modern science was an objective and neutral translation machine or epistemic engine. This translational scheme came without any ethical injunctions that prevented the inverted reproduction of the chauvinism underlying Eurocentric history of science. Subbarayappa himself has never been open to the charge of Indocentrism ; but the bug of priority, so foundational to the nationalist historiography of science as much in the West as in the East, rendered it difficult if not impossible to decipher when it was cognitive justice ${ }^{10}$ that was being meted out, and when the narrative was lapsing into chauvinism.

Taking up another dimension of the philosophical reconstruction of science founded on the script of science as a cultural universal. I consider a paper written by a well-known philosopher, who is hardly a historian of science, T.M.P. Mahadevan". Mahadevan shares a programmatic stance with

8. B.V. Subbarayappa, "An Estimate of the Vaisesıka Sutra in the History of Scrence", Indian Journal of History of Sciences, 2, 1 (1967), 30.

9. Idem.

10. S. Viswanathan, "Strange Quest of Joseph Needham", in S.I. Habib, D. Raina (eds), Situating the History of Science. Dialogues with Joseph Needham, New Delhi, 1998, 198-219.

11. T.M.P. Mahadevan, "Philosophical Trends vs History of Sciences in India-Orthodox Systems ", Indian Journal of History of Sciences, 1 and 2 (1969), 27-41. 
the founders of the discipline of the history of science in India such as B.N. Seal ${ }^{12}$, and which runs through the discourse on science and culture during the first decades of the twentieth century. During this period the advocates of science adopted a diverse range of strategies in order to ensure the successful gestation of modern science within Indian society - a colleague and I have elsewhere have called this the programme of critical assimila$\operatorname{tion}^{13}$ - which in turn spawned of a number of historical investigations on the sciences of India.

These reconstructions bear a close affinity with those of the logical positivists. The most conclusive of these histories contend that of the knowledge forms of India, the disciplines of medicine and linguistics were the only ones that shared a methodological affinity with that of modern science. Furthermore, irrespective of the contributions made to science in areas such as astronomy and mathematics, in the present context, it was Indian philosophy that could contribute to modern science. This, it could be conjectured, was a spin-off of the quantum revolution in physics, wherein physicists such as Schrödinger and Pauli had attempted to guide their deliberations on the nature of quantum reality based on their appreciation of Vedantic and Buddhist philosophy. Thus Mahadevan argued that Indian philosophy could intervene in the production of modern scientific knowledge particularly within the domain of logic and methodology, the analysis of language and meaning, in elaborating upon the relationship between branches of knowledge and their unification and in highlighting the place of experience in the generation of knowledge $^{14}$. The last was introduced to disidentify with the ascription of the Weberians and the German Romantics that Indian philosophy was otherworldly.

A feature of this positivist reconstruction, as different from the Marxist scientism, for which even in antiquity there was a one way arrow leading from atheism to materialism to science, was that it never shied away from the circumstance that in antiquity scientific notions could have emerged in a

12. B.N. Seal, The Positive Sciences of the Ancient Hindus, reprunt Motilal Banarsidas, Delhi, 1985.

13. D. Raina and S.I. Habib, "The Moral Legitımation of Science : Bhadralok Reflections on Theories of Evolution ", Social Studies of Science, 26 (1996), 9-42 ; D. Raina, " Evolving Perspectives on Science and History: A Chronicle of Modern India's Scientific Enchantment and Disenchantment (1850-1950) ", Social Epistemology, 11, 1 (1997), 3-24 : D. Raina, "A Bibliometric Inference of the Historiographic Concerns Underlying the Indian Journal of the History of Science and a Preliminary Sociology of the Discipline in Indaa ". Economic and Political Weekly (1988).

14. T.M.P. Mahadevan. "Philosophical Trends vs History of Sciences in India-Orthodox Systems ". Indian Journal of History of Sciences, 1 and 2 (1969), 27. 
sacred cosmos. Mahadevan's metaphysical pragmatism bears much in common with seventeenth and eighteenth century naturphilosophie - the investigation of nature, as an Indian sage Aurobindo put it, was a preparatory stage to learning of the higher spiritual truths ${ }^{15}$. Similarly, the need to improve the precision in measurements of distance and time was driven by the doctrinal need to secure the efficacy of ritual incantation - this was first pointed out by Thibaut in his work on the Sulbasutras.

Within the same context, there was much concern, whether the Indians knew about the Pythagorean theorem. Western scholarship had deified the notion of "geometric proof" amongst the Greek mathematicians, and then projected it as one of the central elements of Greek science that was later to become a constitutive element of modern science. Nineteenth century history of mathematics had branded the mathematics produced in India and China as algorithmic or algebraic, a variety of mathematics inferior to Western mathematics. In order to neutralise the judgmental intent of this reading, historians of science in India and other parts of the world sought to show that equivalents of the Pythagorean theorem were to be found elsewhere. However, what has been settled with certainty is that the property of Pythagorean triples were known amongst several ancient peoples long before this theorem was proved on Euclidean lines.

Thus while working out of the thesis that the sciences of antiquity were situated in a sacred cosmos, or a scientia sacra, even the study of language and meaning or the science of linguistics in antiquity served as a sadhanaor a penance - in order to ensure the realisation of Brahman ${ }^{10}$. Further, in the case of medical practice in antiquity, it was educed that the discipline couldn't decouple the self (the mind would be a Cartesian category) from the body. The self was primary, and this self was situated and united in a mindbody complex (samyoga-purusa) $)^{17}$. The efficacy of a cure or a curative regimen was dictated as well by the practice of an ethics that bound both patient and doctor ${ }^{18}$. In this writing of the 1960s and early 1970s, we encounter as subterranean texts anxiety concerning the moral vacuity of science, the pan-

15. T.M.P. Mahadevan, "Philosophical Trends vs History of Sciences in India-Orthodox Systems". Indian Journal of History of Sciences, 1 and 2 (1969), 28 ; D. Raina and S.I. Habib, "The Moral Legitimation of Science : Bhadralok Reflections on Theories of Evolution ", Social Studies of Science, 26 (1996), 9-42.

16. Ibid., 29 ; Thus the renowned medieval poet and grammarian Bhartrharı's work, the Vakyapadiya, was not just a work on grammar but on the philosophy of language (ibid., 30).

17. Ibid., 30.

18. Idem, 30. 
demic condition of industrial civilisations - and these anxieties figured in different ways in the constructions of the imaginary past.

As mentioned earlier, even in the more formal logical disquisition there was an attempt to retranslate the methodological precepts of Indian philosophical systems on lines homologous to that of modern science ${ }^{19}$. Such interpretative exercises were obviously founded on the postulate of the methodological unity of the sciences across time - and this is possibly the most central presupposition of the philosophical approaches. Slightly beyond the ken of the $I J H S$ there lingered the chauvinist reading that all of modern science prefigured in Indian antiquity. In the 1970s, when the arch of scientific knowledge began to crumble, in India revivalism intersected with relativism in maintaining that each culture had its own science endowed with the ethos of that culture, and that there was little scope for a dialogue across cultures.

The philosophical tradition ran its course throughout the 1960s and 1970s, quite oblivious of the Kuhnian revolution that had produced a reconceptualisation of science and its dynamics. The philosophical approaches were enabled by a tradition initiated by the five volumes of $A$ History of Indian Philosophy authored by Surendranath Dasgupta ${ }^{20}$. Dasgupta himself while trained " traditionally", sought to translate the Indian philosophical tradition in terms of the concerns of Western philosophy. He adopted as his exemplar, the German scholar, Windelband's $A$ History of Philosophy ${ }^{21}$. Radhakrishnan's two volume Indian Philosophy could be seen to belong to this very tradition. However, by the 1960 s colonial rule, one hundred and fifty years of Oriental scholarship, as well as the efforts of Indians embarking on these projects of translation were to transform these philosophical texts from the past in a manner in which it was no longer possible to recuperate their original sense, if there was one, again. In any case, the primary purpose of these philosophical excursions into the history of science were threefold: Indian philosophy was to provide a meta-theory for the sciences - possibly inspired by the Vienna circle; this would in turn facilitate the redrawing of

19. Ibid., 31. An important point raised in these studies was that amongst the various instruments essential for obtaining valid knowledge (pramana) that included perception, reasoning, inference, analogy etc., was an equally important one called sabda, or the testimony of a trustworthy person. It is interesting to note that in the recent literature on the sociological history of science in the Western tradition, it is recognised that the merit of a scientufic argument did not merely depend on the scientific evidence mustered in tts favour but was as dependent on the social station of the Individual making the knowledge claum (Shapin).

20. S. Dasgupta, A History of Indian Philosophy, 5 vols, Delli, 1980.

21. W. Windelband, A History of Philosophy, 2 vols, New York, 1958, (First Published, in 1893). Actually, it would be an interestmng exercise to figure how the structure of Windelband's book provides a template for the structure of Dasgupta's marvellous work. 
disciplinary boundaries; and finally, philosophical excursions into the history of sciences would contribute to the development of an ethics for a science that may have lost its soul ${ }^{22}$.

\section{A LOST OPPORTUNITY FOR THE HISTORY OF SCIENCE}

Shifting our focus within the same tradition, we turn to the other end of the temporal and conceptual spectrum. This relates to the history of the modern sciences in India, inaugurated during the period of the East India Company, and subsequently with direct British Rule. S.N. Sen, one of the coauthors with Subbarayappa of $A$ Concise History of Science in India ${ }^{23}$, was actively involved, albeit unsuccessfully, in giving the discipline an institutional identity. Sen began by studying the introduction of modern sciences in India that commenced in the late sixteenth century with a trickle of medical men from Europe, naturalists, Jesuit missionaries and adventurers. What began as a trickle became a steady flow of scientists, doctors and military engineers. Sen went onto pose the question, I should like to call Sen's question, why despite close and long contacts with European science, was the introduction of modern science in India so slow till the closing years of the nineteenth and early decades of the twentieth century ${ }^{24}$ ? The question becomes significant because this was the century characterised by the most expeditious expansion of European colonialism, as well as by the diffusion of European science.

What Sen found intriguing was the fact that between the trickling in of modern scientific knowledge and the first publications of Indians on the socalled modern sciences almost a hundred years were to lapse. And so he proceeds to examine (1) internally: the character of science transplanted in India, and the motivations behind this programme ; and (2) externally: the social and psychological preparation necessary for the assimilation of the new knowledge. Such an investigation necessitated a sensitivity to the difference in emphasis accorded by Europeans and Indian to scientific progress ${ }^{25}$. On this count Sen mustered more than adequate historical evidence to estab-

22. T.M.P. Mahadevan, "Philosophical Trends vs History of Sciences in India-Orthodox Systems ". Indian Journal of History of Sciences, 1 and 2 (1969), 40.

23. D.M. Bose, B.V. Subbarayappa, S.N. Sen, A Concise History of Science in India, Delhı, 1970.

24. S.N. Sen, "The Character of the Introduction of Western Sctence in India during the Eighteenth and the Nineteenth Centuries ", Indian Journal of the History of Science, 1 and 2 (1988), 112-122, especially 112 .

25. Ibid., 113. 
lish the thesis that European efforts during this period were restricted to what he calls the field sciences: geography, geodesy, geomagnetism, geology, botany, agriculture, and astronomy. The principal agenda was that of charting the resources of the Indian subcontinent, in the hope that the appropriation of resources be rendered more efficient. The circulation of this knowledge was also tardy on account of the fact that these sciences and their findings were shrouded in secrecy, since scientific information so obtained was essential to the competition between the colonising nations of the time ${ }^{20}$.

The activity of the Jesuits in India, as Sen was to observe " was particularly barren and abortive ... there is nothing to show that the Jesuit contacts facilitated in any way the transmission of European science to India "27. Within the perspective of comparative history, the history of the transmission of European science in India was entirely at variance with the Chinese one. Sen's reading was premised upon his conception of science, and his conception of what was a scientific contribution. On the one hand, like most historians of science of his generation, physics was the exemplar of the sciences. And surely the Jesuits in India did little physics. But what the Jesuits did do was undertake a monumental task of preparing dictionaries of some of the regional languages of India, such as Kannada, Telugu and Tamil - while Sen was cognisant of this work, he doesn't address the importance of this enormous compendium - possibly leaving it for the historians of " culture". Secondly, in the later half of the nineteenth century the Jesuits in India contributed no papers to scientific journals, but their contribution to the cause of education and science education in India is undeniable.

Since the British put off the introduction of research as part of the university charter for almost fifty years, Sen and subsequent generations of historians of science in India examined the development of the scientific research system, particularly in domains distant from the field sciences in the concerted efforts of scientists trained in India and abroad. These scientists, driven on by a nationalist agenda pressurised the imperial administration into including post-graduate teaching and research into the agenda of university education ${ }^{28}$.

Gradually Sen turned to the study of the history of education in India, commencing from antiquity down to the period of British rule. But the focus was to acquire an understanding of how the legacy of educational institutions was transformed, erased, substituted with the onset of colonial rule - and

26. Ibid., 118.

27. Ibid., 114.

28. Ibid.. 119. 
this would possibly open up the black box of assimilation. I say black box, because at the time, history of science still in its scientistic mode, could not have seen assimilation in terms of the dialectic of the traditional and the modern. The historiography of transmission could best be exemplified in the metaphor of percolation models. But the core hypothesis around which Sen's research was organised was that the British educational experiment was grafted upon a culture possessing educational institutions for roughly two thousand and five hundred years ${ }^{29}$.

Sen chronicles how most institutions for the dissemination of scientific knowledge were associated with temples of various denominational orders. This reading was founded on the assumption that all such educational institutions on the Indian sub-continent were organised and managed along similar lines as those of centres of learning located around the temple cities of medieval South India. In fact, these institutions were thus seen as (1) continuing in a tradition from hoary antiquity, that in turn, (2) were uniformly distributed throughout the country, and (3) and their fossil remnants were still to be found frozen at the time of the onset of colonial rule. Two historiographic obstacles more or less impelled this reconstruction. The first had to do with the greater quantum of physically inscripted historical evidence be it artefactual or in the form of monuments in Southern India as opposed to the North ${ }^{30}$. Secondly, in the just turned sovereign republic India, national identity could be constructed around the idea of the unity of cultural institutions, since the nation was a jigsaw of linguistic and racial entities, and educational institutions were just one of the many ${ }^{3}$. Furthermore, his reconstruction of these institutions of higher learning bears many affinities with that other medieval institution now distributed all over the world, namely the medieval European university. Sen elucidates that the focus of pedagogy at these temple-associated state-supported institutions qua universities was on formal knowledge, rhetoric and aesthetics. And as has happened so often when writing Indian history, the reconstruction is often based on foreign sources, this time Sen indicated that the textual evidence for the reconstruction was from entirely Tibetan and Chinese sources ${ }^{32}$.

29. S.N. Sen, "Education in Ancient and Medieval India ", Indian Journal of the History of Science, 23, 2 (1988), 1-32, especially 1.

30. Ibid., 8

31. Nehru's two most marvellous contributions to civilizational studies: The Discovery of India and Glimpses of World History. contain very fine apcrcus regarding the unity of the Indian nation. and nationhood in a broader sense. However, even though contemporary researchers on Indian history often turn to Nehru's Discovery for a nuanced insight.

32. S.N. Sen, " Education in Ancient and Medieval India ", op. cit., 9. 
As distinct from the formal disciplines, technical education and the system for imparting training in the arts and crafts, came with contractual obligations binding on both master and the apprentice. That Sen himself was situated on the trajectory of the history of science and technology of his times is reflected in his conclusion that for all the virtues of the system, " twas beset with drawbacks inasmuch as it was not conducive for the industrial revolution, and the rhetoric of innovation " "33, so important in subsequent history of technology studies figures there albeit in a preliminary form.

Further, Sen discusses the educational institutions that appeared during the medieval period, these being the maktabs, madrasas and the karkhanas - in the case of the former two, in addition to a religious education a scientific education was also imparted. The Arab synthesis of several scientific traditions, and its equally important role in the emergence of scientific revolution, led historians of science studying the medieval period, Sen and Rahman included, to place special emphasis on scientific learning during this period ${ }^{34}$. However, this overlooked certain facticities. Firstly, that during the medieval period science was not at the centre of culture, a place it did move to in until the twentieth century. Secondly, science in the contemporary context is in a very different relationship with other branches of learning that must be explicitly recognised. Hence any past recuperation of science that foregrounds it overlooks the complex encystment of different knowledge domains.

One aspect of Sen's studies into educational institutions by far outweighs those relating to say the history of astronomy or that of the introduction of modern science. This has to do with the proliferation of educational institutions throughout the Indian sub-continent from the medieval ages. This runs counter to the picture created by British historians that provided one of the legitimatory tropes of British rule : that it was the British Imperial Government that lit the lamp of enlightening knowledge on a dark continent plagued by superstition and ignorance. Officials of the East India Company ${ }^{34}$ noticed the broad expanse of educational institutions just before the onset of British rule. The importance of this historical feature in rejecting many of the claims of imperial history, that were foundational for Eurocentric history of science, was not picked up by Sen's generation of historians, obsessed as they were with priority disputes. However, historians of science working on Egypt and

33. Ibid., 19.

34. Ibid. 23.

35. W. Adam, Adam's Report on Vernacular Education in Bengal and Behar, Submitted to Government in 1835, 1836, and 1838, With a Brief View of its Past and Present Conditions, Calcutta, 1865. 
the Arab world today are coming up with very similar conclusions ${ }^{36}$ in their respective contexts. And this has meant that educational practices in turn have to be situated culturally. This takes us back to the dialectic of tradition and modernity. The new dialectic would have to disavow itself of the notion of tradition being both burden and obstacle to the development of knowledge. It still remained for Sen to explain why this educational system either failed to evolve or was replaced. Situated on the horizon of modern science, Sen writes that for some decades prior to the institution of British rule, the traditional institutions had fallen into decline, and this decline followed in the wake of the disintegration of the Mughal empire ${ }^{37}$.

In a paper he wrote in the mid 1960s Sen recognised that the history of sciences were undergoing a tremendous change, and this change was of the nature wherein the social determinants of science were going to become more important ${ }^{38}$. But the brand of externalism Sen practised during these years was none other than internalism. It would not be stretching a point too far in suggesting that in an environment where historians were nested within the community of scientists there was a neat correspondence between the scientists' conception of science and the growth of scientific knowledge, and the perception of the very same object and processes by the community of historians of science. This was a product of the institutional dependence of the history of science on the world of science. Hence certain institutional and cognitive barriers hindered the development of a critical theory of science and society.

\section{THE END OF THE GOI.DEN AGE OF SCIENTISM}

While the $I J H S$ accounts owed much to the Orientalist archive in terms of recreating the high traditions of Indian civilisation, they were at variance with the colonial one. In fact the IJHS project was, metaphorically speaking, an archaeological undertaking to bring forth the buried traditions, knowledge, and nuggets of culture that had been ignored by the scrutinising gaze of the colonial historian. The $I J H S$ history was thus part of a cultural project that emerged in the $1950 \mathrm{~s}$. The project itself acquired a station during that

36. P. Crozet, "Modernization of Science and its History Outside European Boundaries : The Case of the Egyptuan Projects for Modern Science in the $19^{\text {il }}$ Century ", in S.I. Habib and D. Raina (eds), Situating the History of Science. Dialogues wth Joseph Needham. New Delhi, $1999,245-259$.

37. S.N. Sen, "Educatıon in Ancient and Medieval India ", op. cit., 26.

38. S.N. Sen, "Changing Patterns of the History of Sciences", Science and Culture, 31,5 (1965), 214-219. 
period of the Nehruvian era when there was a proliferation of scientific institutions.

The scientistic frame was adopted for the history of science studies by the IJHS. In this era the two cultures debate drove a deep wedge into academia : wherein the culture of science masqueraded as a "priestly culture " 39 , and the scientist was seen as the generator of truth. The History of Science project was led by a Commission supported by a scientific academy on whose governing council there had and has never been little or token representation by a social scientist of repute, or for that matter any social scientist at all.

There were serious research attempts undertaken to respond to the Needham question. But given the accepted terms of the internal-external divide, society provided a backdrop within which science might fruitfully evolve or decline. If science was a cultural universal, without qualification, the social merely was an arena for the staging of science. The social was rendered active when the need to explain the non-performance of science, or its inability to reach out to new audiences arose, or finally when science failed to live up to its rhetorical promise to usher in the millennium. The highly limited horizon of the social so constituted posed impediments for the theoretical development of the history of science within the framework of the IJHS.

This view of history was overdeterminationist, as the scientist's history of science tends to be. This brings us to the paradox, that while these historians professed inspiration from Needham, they remained within the overdeterminationist frame. As Fuller ${ }^{40}$ points out in a recent paper, Needham challenged the existing historiography of his time, by insisting that history mattered not for the sake of the past or for the sake of history, but history mattered for science itself ${ }^{41}$. This possibility could not have been appreciated for those situated on the frame of triumphalist science - though one may well ask whether the locus of these Indian historians as former colonial subjects may not have sensitised them to this possibility.

Nevertheless, this internalist framework did indicate how treaties on Indian philosophy and linguistics could inform modern science - but even that was an idea that could have achieved realisation had somebody from the scientific community decided to take it up. A narrow shift in focus from the

39. M. Wertheim, Pythagoras' Trousers : God Physics and the Gender Wars, Fourth Estate, London, 1997.

40. S. Fuller, Philosophy, Rhetoric \& the End of Knowledge: The Coming of Science \& Technology Studies, 1993.

41. S. Fuller, "Towards a Prologemena for a Global History of Science ", in S.I. Habib and D. Raina (eds), Situating the History of Science. Dialogues with Joseph Needham, New Delhi, 1999, 114-151. 
history of science to the history of education momentarily opened the window that might have altered the picture of the history of science by questioning its foundations. However, so prevalent was the evangelical ideology of science that the importance of some of these findings weren't picked up either by the historians themselves or their audience. Only when science came to be decentred from its privileged place in culture were the implications of some of these findings picked up within the framework of the critiques of modernisation. The school remained fairly restricted, and the Marxist historians of the time such as D.D. Kosambi and Debiprasad Chattopadhyaya ${ }^{42}$ toiled outside this framework. As the Nehruvian era gradually closed towards the end of the 1970s, the crisis in development became more acute : the three signifiers of the age - modernity, science and industrialisation had delivered but not as they promised they would. The sociologists and varying shades of Marxist scholarship would subsequently take on the mantle of science studies from the $I J H S$ generation.

42. D. Chattopadhyaya, Science and Society in Ancient India, Calcutta, 1979. 


\title{
Why THE ClaSSIC OF MountaINS AND SEAS (THE SHAN HaI JING) CONTAINS TOPOGRAPHICALLY INACCURATE DATA
}

\author{
Véra V. DOROFEEVA-LICHTMANN'
}

The Classic of Mountains and Seas (the Shan hat jing, hereafter SHJ), compiled probably early in the $\left.\right|^{\text {st }}$ century B.C., occupies a special place among terrestrial descriptions surviving from ancient China. It is distinguished by the extent of the geographical area encompassed, the multiplicity of detail provided, and by a remarkably systematic arrangement of locations and associated data.

The arrangement of locations is especially consistent in the first part of the text, entitled The Classic of Mountains (the Shan jing, hereafter SJ). This part constitutes the core of the text and contains the earliest material ${ }^{2}$. The $S J$ consists of 26 lists of mountains. Each list delineates a route. The location of each mountain is given with respect to the preceding one along the route 3 . These respective locations are supplied with cardinally-oriented directions and precise distances between each two mountains on a route, and, therefore, give an impression of rigid topographical accuracy ${ }^{4}$.

1. This research was started under the auspices of the Maison des Sciences de l'Homme Foundation (1993-1995) and developed thanks to an Alexander von Humboldt Stipendium (1996-1997).

2. The Classic of Seas (the Hat Jing. hereafter HJ). the second part of the text. is less than half the size of the $S J$ and comprises of later layers which differ considerably from the $S J$ in subject matter. It is mainly devoted to often fabulous peoples and peculiarities of faraway countries.

3. With the exception of the initial mountains of the lists.

4. The precise distances between locations are never in evidence in the $H J$. Though routes may still be traced in the first four chapters of the $H J$, they are no longer found in subsequent ones. 
It is not surprising, therefore, that interest in the geographical background of the $S H J$ in general, and the $S J$ in particular, can be traced from its earliest extant commentary dating from the beginning of the $4^{\text {th }}$ century A.D by Guo $\mathrm{Pu}$ (276-324). It became most clearly articulated in late commentarial tradition (that of the Qing dynasty, 1644-1911), and since then has become a central concern in its study, especially by Chinese researchers ${ }^{\circ}$.

These studies aim to identify and locate the listed features of relief on the earth's surface, determining how precisely their respective locations, as given in the text, correspond to the actual topography of described terrain. In other words, these studies are primarily concerned with the " degree of topographical accuracy" of data provided in the $S H . J$.

However, despite the seemingly precise definitions of locations found in the $S J$, the results of such extensive studies are rather disappointing and sometimes puzzling. Thus, only a rough approximation of the described territories may be derived from their analysis. As far as the majority of specific features of relief are concerned, there are different and often contradictory points of view on their identification and actual location. Yet, no matter which of these identifications and actual locations are preferred, they produce a similar effect with respect to the system of respective locations given in the text. Namely, these locations " fail to match" with actual topography.

It is of central importance here that we are not dealing with some minor discrepancies?. On the contrary, there is an almost absolute discrepancy. This may be clearly seen from representing the locations as geographical maps.

5 Especially significant in this respect is the commentary by Bi Yuan of the Qing dynasty in his edition of the text SHJ xinjraozheng (New Corrected Edition of the SHJ).

6 For surveys of identifications of places mentioned in the SHJ. see the annotated translations of the SHJ by EM Yanshina (trans.). Katalog gor i more (Shan hat tsan) (The Catalogue of Mountains and Seas (Shan hal jing)), Moscow. 1977. R. Mathieu. Elude sur la mythologie et l'ethnologie de la Chine ancienne. Tome I Traduction annotée du Shanhai jing. Tome II. Index du Shanhai jing. (Mémoires de I'Institut des Hautes Etudes Chinoises. Paris, Collège de France - Institut des Hautes Etudes Chinoises. 1983. vol. 22) For the seminal works on the subject see Wu Chengzhi. SHJ drli. Inshi (New Interpretation of the SH.rs Geography). 1922, Wei Tingsheng and Xu Shengmo, Shanjing dili rukao (A Modern Gengraphical Study of Shanching with maps), Taipei. 1974. Tan Qixiang. " Lun $W_{u}$ zang Shan $/ 1 n g$ de diyu fanwei " (Discussion of the Geographical Area Encompassed by the Wizang Shanjung), in Li Guohao et al (eds). Explorations in the History of Science and Technology in ('hina. Shanghai. 1982. For more examples, see Section F (Geography and Ethnology) of the bibliography of the $S H J$ by R. Fracasso." The Shan hat Jing : a Bibliography by Subject ". Cina. 23 (1991). 80-92. As an example of relatively recent research of this kind, see Fu Yongta, Shenzhou de fa xian. Shanhai jing dilt kao, (Discovery of the Shenzhou : Exploration of the SHJ's Geography). 1992.

7. As could have resulted, for example, from partial corruption of the text. 
For example, in Map 1 (by Wang Chengzu) an attempt has been made to keep to the directions and distances of the lines of mountains, as defined in the text. This has resulted in their schematic superimposition on a rough and considerably distorted physical map. The lines of mountains, in their turn, have become slightly distorted when compared to their delineation in the text.

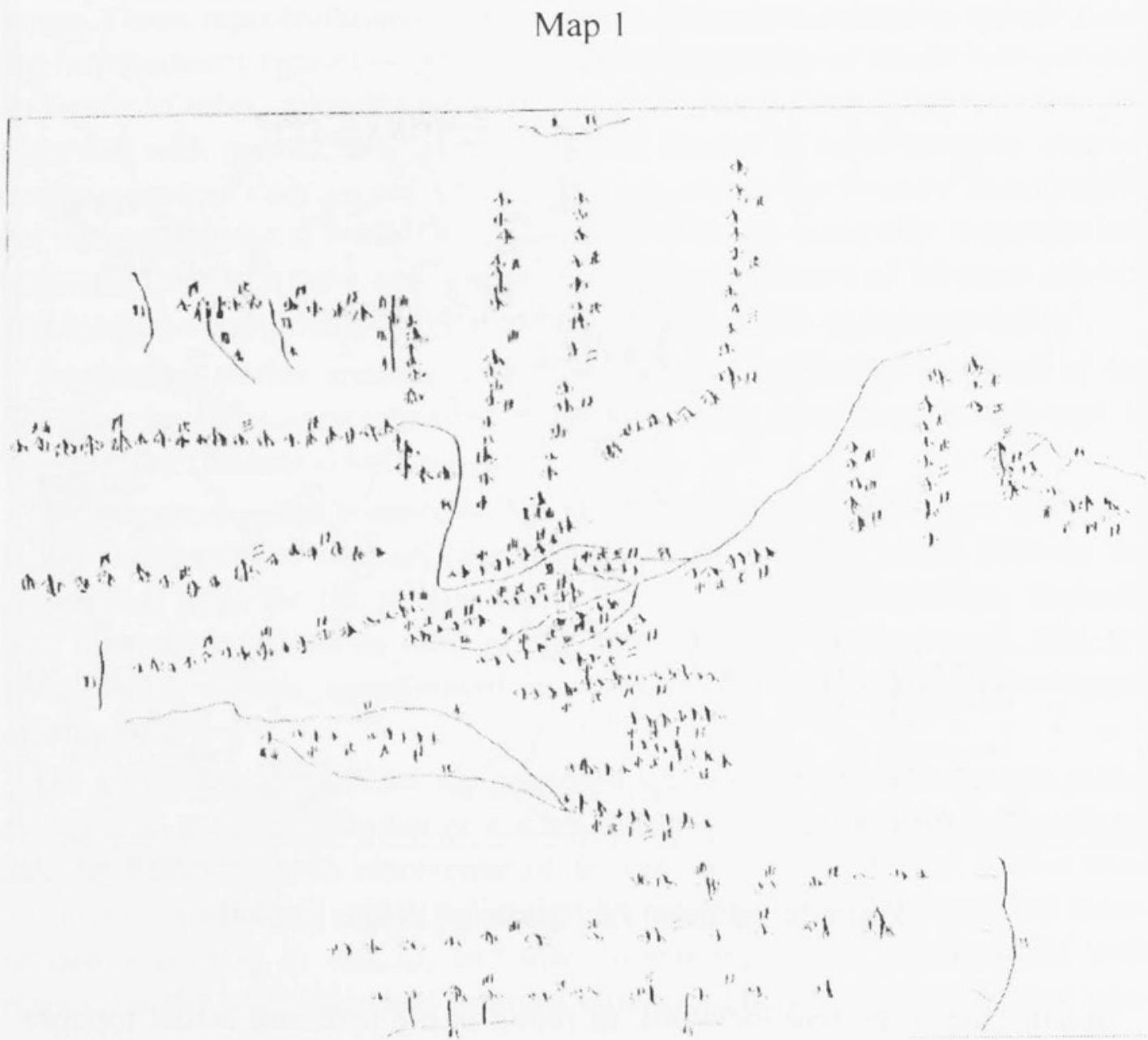

Reproduced from Wang Chengzu [1988, p. 19] 
By contrast, in Map 2 (by Liu Siyuan) the lines of mountains are conformed to a modern map. As a result, the given directions of the lines are violated, and the continuity of certain lines is even broken up ${ }^{8}$.

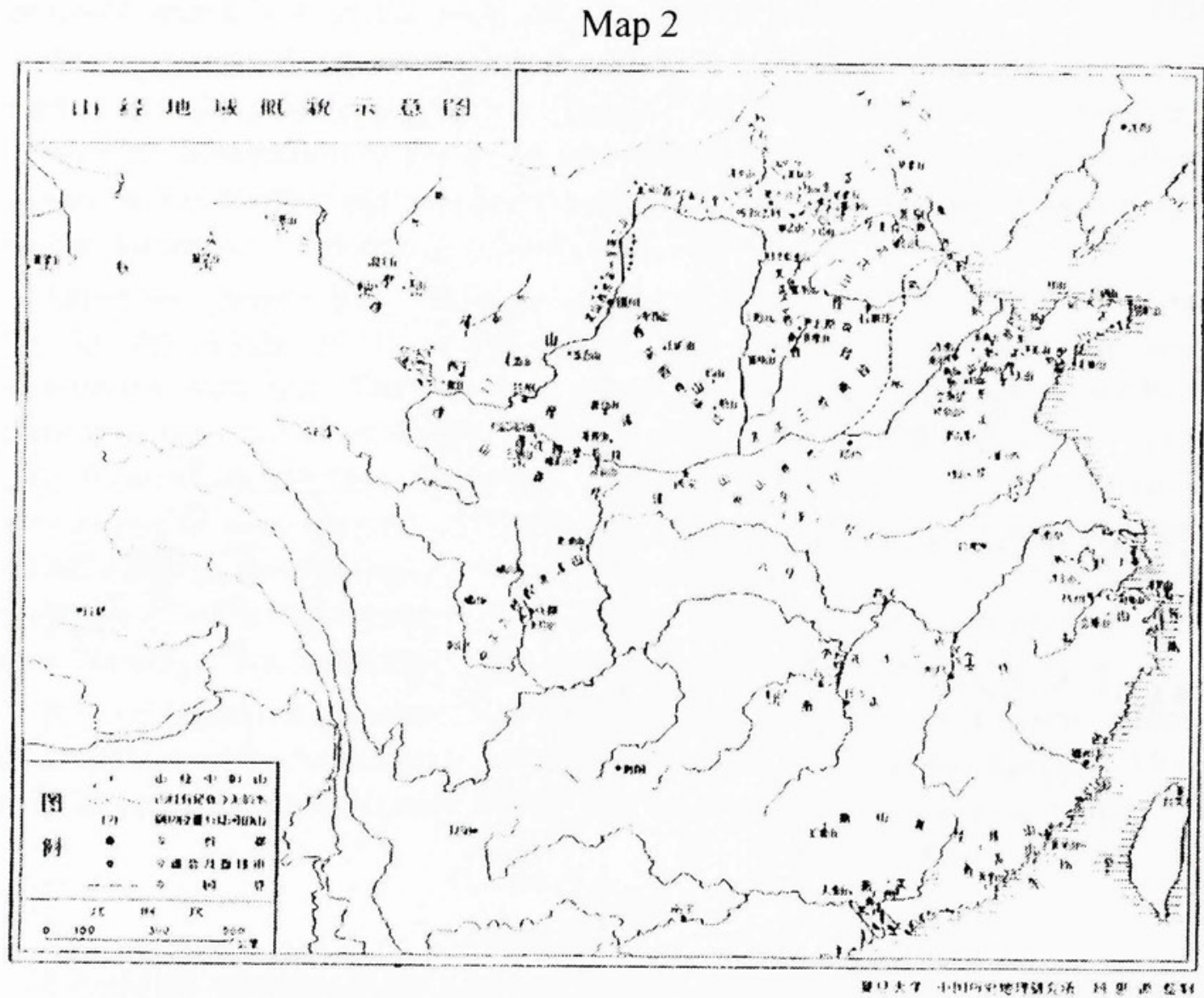

Reproduced from Tan Qixiang [1982a, p. 294]

In sum, the respective locations, as round in the text, and actual topography of featured terrain are not compatible unless the cohesion of respective locations is broken up (as found in Map 2) or actual topography is distorted (as found in Map 1).

8. The same approach is applied by Wei Tingsheng and Xu Shengmo, op. cit., in detailed maps appended to their fundamental study of the geographical background of the $S J$ and reproduced in the translation of the $S H J$ by R. Mathieu, op. cit. These maps show localities of specific features of relief referred to in the text. Needless to say. the lines of mountains are no longer in evidence on these maps. Occasional features of relief registered in the $S H J$ are found on the maps of Western Zhou - Warring States China by Tan Qixiang (ed.). Zhongguo lishi dituji (The Atlas of Chinese Historical Geography), vol. 1, Shanghai, 1982. 17-46. 
The discrepancy between the respective locations given in the $S H J$ and actual topography might give the impression that the $S H J$ conveys strikingly inaccurate topographical knowledge of the represented territories.

This conclusion rests on the implicit assumption that the $S H J$ was aimed at conveying topographical reality. I question this assumption in general, and, in particular, I would like to point to the methodological shortcomings of representating the respective locations found in the $S H J$ as geographical maps. These representations imply that the respective locations should meet the requirements typical of geography and cartography of much later periods and even of other cultural traditions. For example, in Map 2 the locations are regarded with respect to the principles and format of representation characterizing modern cartography and worked out within the Western cartographical and geographical tradition. This seems to be an especially inappropriate approach, since Chinese cartography before the influence of Western science and modern cartography differed markedly in its codes of representation?

In contrast to this approach, I believe that the respective locations of the $S H J$ can be fully comprehended only when they have been scrutinized in terms of the Chinese cosmological tradition.

This cosmological perspective implies that these locations are part of a larger framework of cultural presuppositions and notions which provide the conceptual basis for the arrangement of these locations. From this perspective their arrangement is seen as the translation of a cosmology, and the components of this arrangement as vehicles for expressing cosmological meanings ${ }^{10}$.

As a first step in pursuing the proposed approach, 1 have tried to put aside, as much as possible, whether or not actual topography of terrain is described, and especially from its representation as a modern map. Instead, I have tried to determine how the routes delineated by mountains are arranged and interrelated according to the $S J$, and then to represent their arrangement with respect to the principles and patterns characteristic of ancient Chinese cosmography.

Now let us take a look at the scheme of routes produced by this approach (see Fig. 1).

9. See. e.g., J.B. Harley and D. Woodward (eds), " Cartography in the Traditional East and Southeast Asian Societies". The Histony of Cartography. vol. 2.2. Chicago. London. 1994 ; R. Smith, Chinese Maps 'Images of 'All Under Heaven; Hong Kong. London. 1996.

10. The first assumption that the $S H J$ might convey a sort of "esoteric topography " and that its locations might be "positions" of a cosmogram $(\mathrm{k} u)$ was advanced by $\mathrm{M}$. Lackner. "Die Verplanung des Denkens am Beispiel der $t u$ ", in H. Schmidt-(ilintzer (cd.), Lebenswelt und Weltanschauung in frihneuzettlichen China. Stuttgart. 1990. 139. 
Figure 1

"Southern Mounteins"

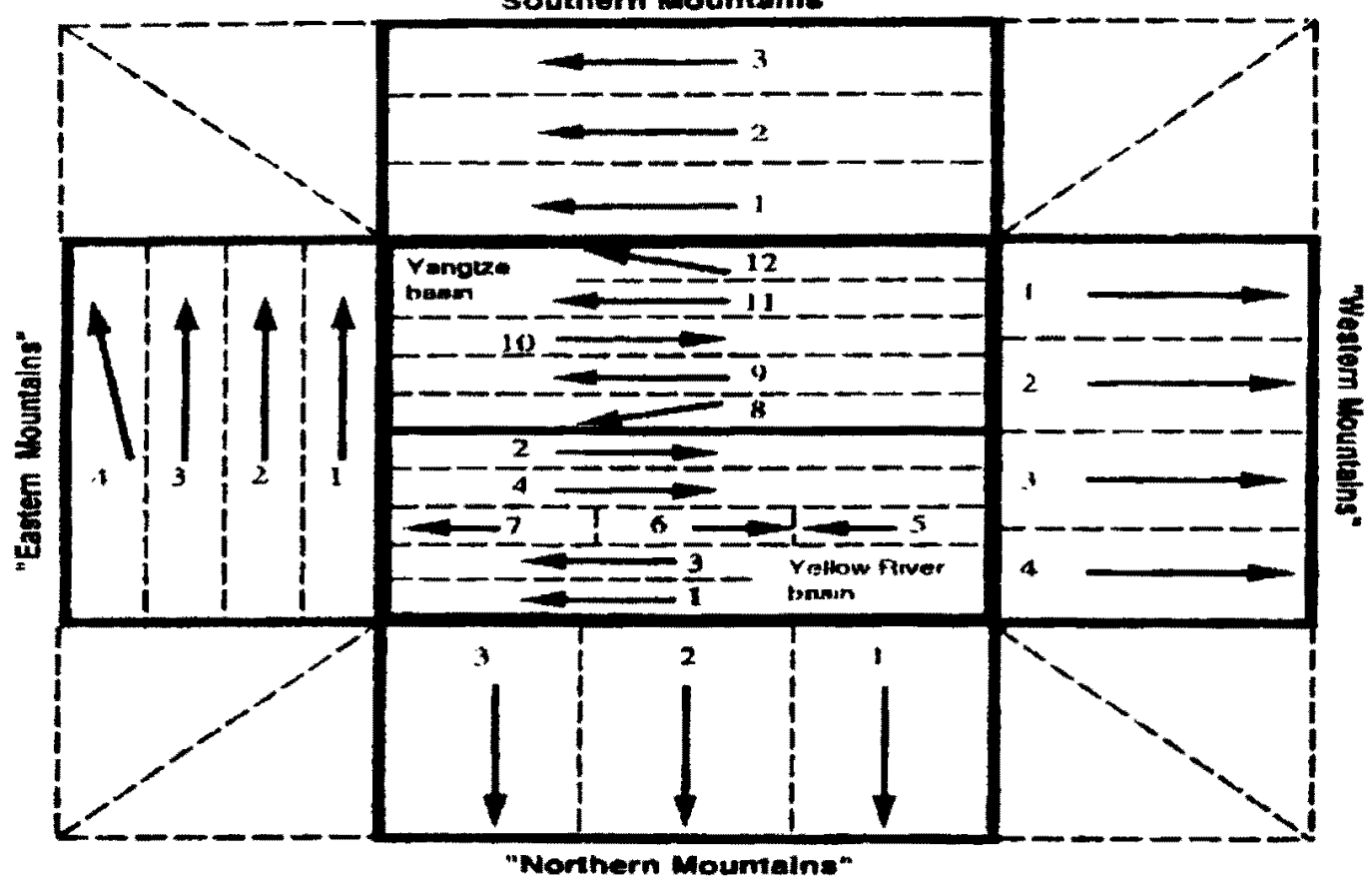

System of routes in The Classic of Mountains

Figure la

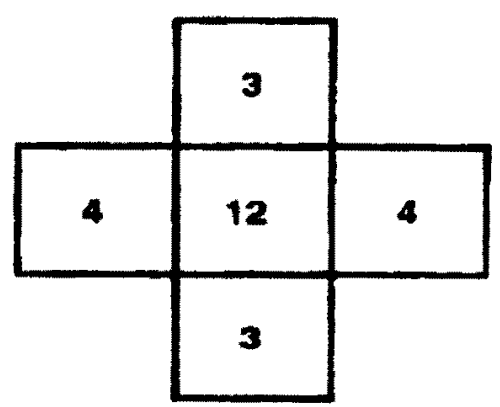

Number of routes 
Figure $1 b$

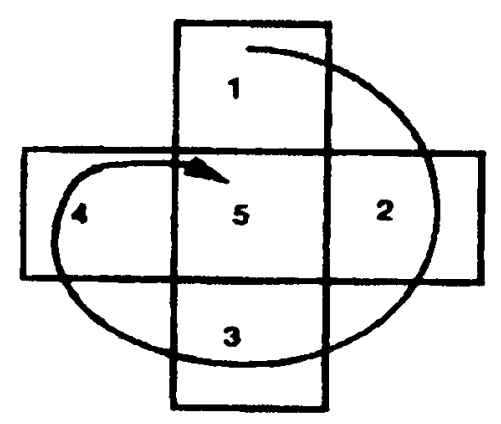

Sequence of sections

The scheme shows:

- the dominating directions of the routes,

- their sequence,

- their dispersion over a general quinary framework oriented according to the cardinal points and the center.

The quinary framework, and all these characteristics of the routes are clearly defined in the text.

The scheme also proposes a tentative reconstruction of the arrangement of routes within each of the five main sections. This arrangement, on the contrary, is done on the basis of approximated respective locations of territories delineated by the routes (as given in Map 1), as the text does not specify respective locations of the routes in their sections. Even if this arrangement is tentative and a possible subject for correction in the course of further research, it still enables us to draw important conclusions on the general nature of the received scheme.

A detailed analysis of this scheme and the principles and patterns of Chinese cosmography is far beyond the scope of this paper, and I have already discussed them elsewhere"l.

11. It is elucidated in my articles " Conception of Terrestrial Organization in the Shanhat jing ". Bulletin de l'Ecole Françaıse d'Extrème Orient, 82 (1995). 57-110. and "La production de l'espace sacré ", Géographie et cultures, 18 (été 1996), 3-30. The principles and patterns of Chinese cosmography are discussed in my " Topographical Accuracy or Conceptual Organization of Space? Some Remarks on the System of Locations Found in the Shanhat Ing ", in Yung Sik Kim and F. Bray (eds). Current Perspectives in the History of Science in East Asia. Seoul. 1999. 165-179. 
Here I would only like to point to the main property of this scheme, its regularity.

For example, it is remarkably balanced from the point of view of the number of routes in the terrestrial sections (see Fig. Ia).

The lines within the four peripheral sections go in the same direction :

- in the Northern section - to the North,

- in the Western to the West,

- in the Southern to the East,

- in the Eastern to the South ${ }^{12}$.

The lines in the Central section are arranged in a more sophisticated way, constituting two apparently regular sets, especially from the point of view of the order of their alteration".

In sum, the reconstructed system of routes expresses the idea of terrestrial order rather than maps actual topography, or, in other words, conveys a conception of spatial organization ${ }^{14}$.

From this perspective, the attempt to conform the system of routes to topographical reality does not seem to be a fruitful way to approach the text. It seems more reasonable to explore what cosmological meanings are conveyed through this system.

One of the main aims of this exploration is to determine by what criteria the mountains are assigned to a definite route.

The main criterion is explicitly given in the " summaries" appended to the description of each route. The "summaries" specify the patron deities associated with the mountains, and detail sacrifices to be performed to these deities $^{15}$. A route apparently comprises those mountains which have similar deities and rites. This observation is of central importance for understanding the system of routes, as it pinpoints the sacred nature of space mapped by this system.

12. One imperfection. the last route of the eastern section declines to the East.

13 These sets represent the Yellow River and Yangtze River basins Including the Yangtze basin into the center is of considerable interest from the point of view of its " political " meaning. as these territories were qualified as southern periphery according to the most authoritative ancient Chinese terrestrial description, the $Y_{u}$ gong. and related texts

14. This conforms to the association of the $S H J$ by the Chinese cultural tradition with the activities of the last mythical emperor $\mathrm{Yu}$ the Great, who is famed for overcoming the Flood and restoring world order

15. There is one route (the $4^{\text {th }}$ route of " The Eastern Mountains " . $14^{\text {in }}$ in the overall order of the $S /$ ) whose summary is partly lost. and the section describing the deities is missing ( $S H J$ juanshu, 4/9a) 
As illustration, let us take a look at the reconstructed system of routes from the point of view of the appearance of their deities (Fig. 2), the appearance being given in the majority of cases.

Figure 2

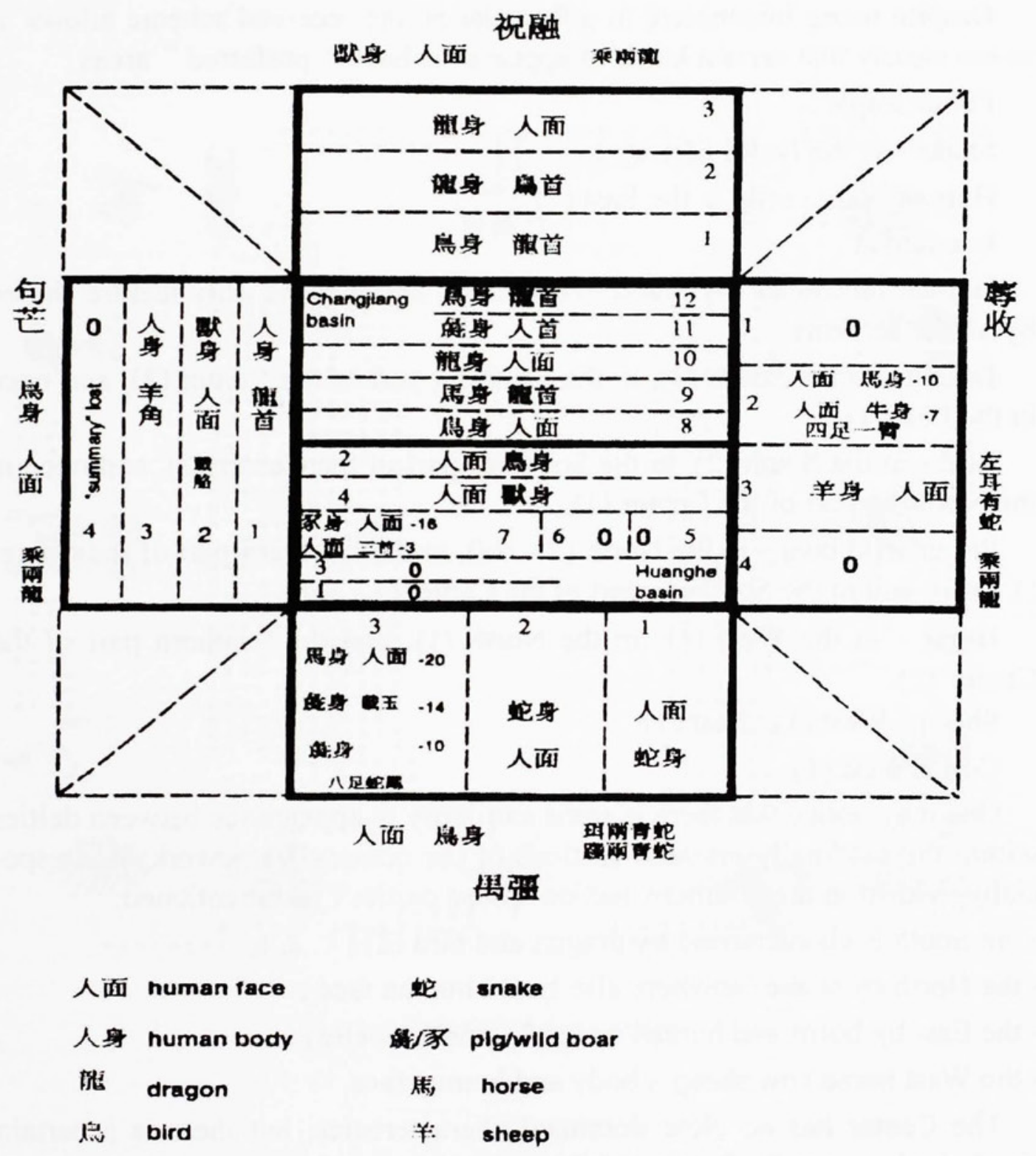

System of spirits in The Classic of Mountains and the Outside the Seas

It is missing in 7 routes of a total of 26 , and there are 3 routes which consist of parts with deities of differing appearance. The appearance of 
deities is given in a rather uniform way, as hybrids of different animals, or animals and human beings. For example, the deities of the Southern section are as follows :

(Route 1) " bird's body - dragon's head";

(Route 2) " dragon's body - bird's head ";

(Route 3) " dragon's body - human face".

Despite being incomplete in a few places, the received scheme allows us to see clearly that certain kinds of appearance have " preferred" areas :

For example :

Snake - in the North $(2+1)$.

Human body - only in the East (2)

In contrast :

Human face/head - is found everywhere, and it is the only feature shared by all the sections.

Dragon- in the South (3), in the Southern part of the Center (3), and once in the East (1).

Bird - in the South (2), in the Southern part of the Center (2), and once in the Northern part of the Center (1).

Pig or wild boar - in the North $(2-z h i)$, in the Northern part of the Center $(1-s h i)$, and in the Southern part of the Center $(1-z h i)$.

Horse - in the West (1), in the North (1), and the Southern part of the Center (1).

Sheep - West (1); East (1).

Cow - West (1).

One may notice that there is some similarity in appearance between deities within the cardinally-oriented sections of the quinary framework. It is especially evident in the Southern section whose deities I just mentioned.

- the South is characterised by dragon and bird (2);

- the North by snake (nowhere else !) and human face :

- the East by horns and human body (2, nowhere, else) ;

- the West horse/cow/sheep's body and human face.

The Center has no clear dominant characteristics, but there is a certain similarity between the South and the Southern part of the Center.

In brief, the provided scheme enables us to see that the routes are delineated with respect to a certain idea of how the divine powers were dispersed over the terrestrial surface. The imposed differentiation of the terrestrial 
surface then maps a sort of " spiritual landscape" 16 . The spiritual landscape is conceived of as a set of regularly arranged and cardinally-oriented units of terrestrial division submitting to differing deities.

If we imagine pictures behind the characters, the spatial distribution of deities immediately reminds us of the famous Chu Silk Manuscript (Fig. 3).

Figure 3

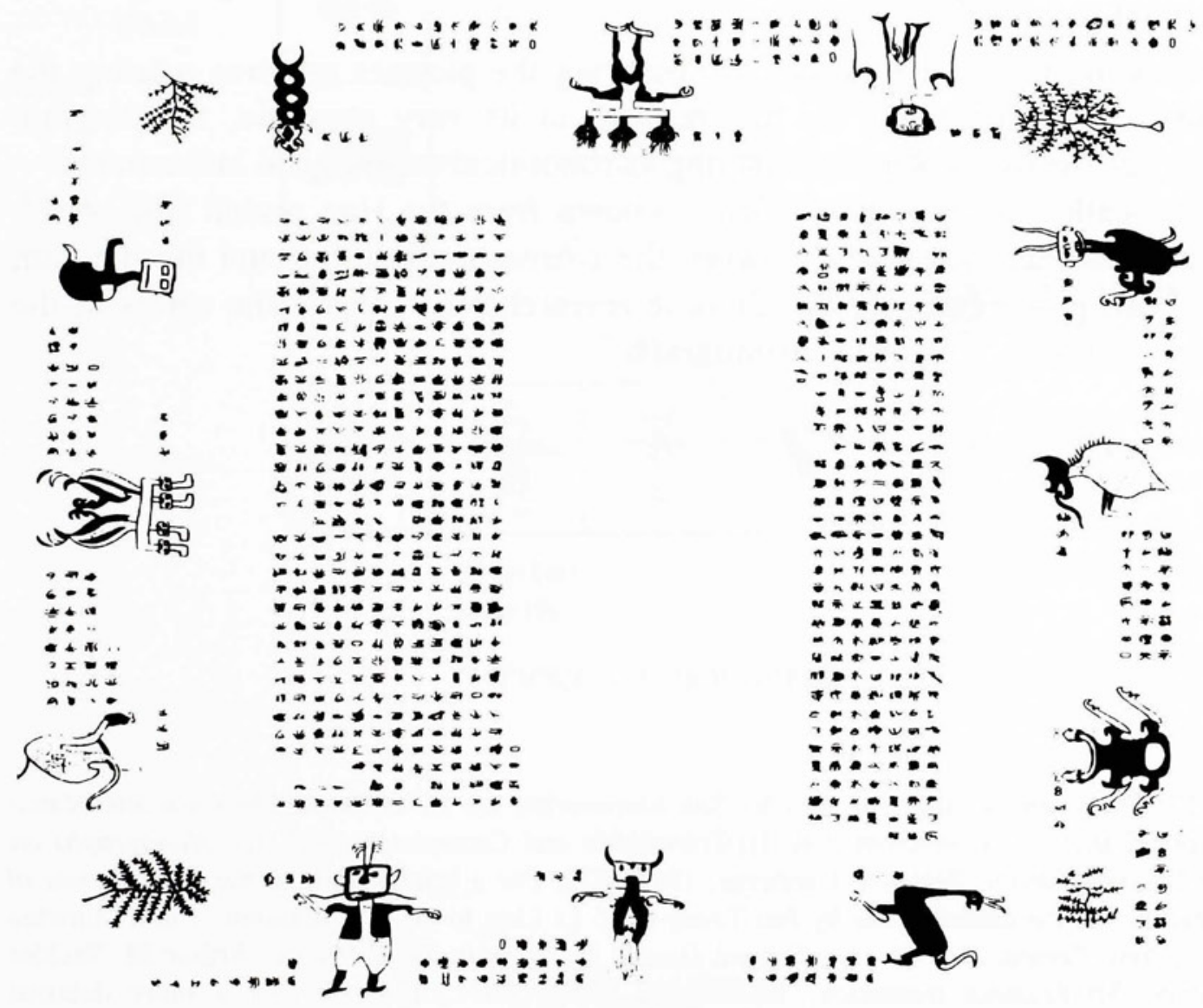

The Chu Silk Manuscript

16. It is necessary to note here that the $S J$ in general focuses on the divine attributes of mountains. The listed mountains are perceived as " homes " of various supernatural creatures, plants, magical objects, and deities, and spirits. The creatures, plants and other things are mostly so-called " anomalies" and can hardly be distinguished clearly from divinities. It then seems very likely that the $S J$ features only those mountains which possess divine attributes, in other words, it provides an account of " sacred spatial points ". 
The Chu Silk Manuscript dates back to the $4^{\text {th }}$ century B.C., and is considered to deal with matters of astronomy and astrology ${ }^{17}$.

The manuscript provides a diagram which has textual and pictorial parts. The center is occupied by two relatively long textual passages placed upside down with respect to each other. They are framed by an alteration of pictures and short textual passages elucidating these pictures. The pictures show 12 supernatural creatures or deities - three on each side of the manuscript. These deities constitute a tempo-spatial structure (Fig. 3) : the deity to the left of each side is in charge of one of the four seasons, and, hence, of one of the cardinal points.

Reading the textual parts and observing the pictures requires rotating the manuscript (clockwise). In this respect, in its very structure, the diagram (Fig. 4a) strongly resembles rotating astronomical/astrological instruments the so-called cosmographs (shi) - known from the Han period (Fig. 4b) ${ }^{18}$. The typological similarity between the cosmograph design and the diagram has been pointed out by the Chinese researcher $\mathrm{Li}$ Ling $^{19}$ who refers to the diagram as to a " pictorial cosmograph".

17. For a seminal sndy of the Chu Silk Manuscript, see N. Barnard, The Ch'u Silk Manuscript : Scientific Examination (vol. I), Translation and Commentary (vol. II). Monographs on Far Eastern History, Series 5, Canberra, 1972-1973. For a brief review of the current state of research, see the contributions by Jao Tsung-i and Li Ling to the "Discussion ", in T. Lawton (ed.). New Perspectives on Chu Culture During the Eastern Zhou Period, Arthur M. Sackler Gallery, Smithsonian Institution, Washington, D.C., 1991, 176-183. For a more detailed analysis of specific research problems referred to in the "Discussion". see e.g., Jao Tsung-i and Zeng Xiantong, Chu boshu (Cliu Silk Manuscript), Hong Kong, 1985 ; L1 Ling, Changsha Zitanku Chu boshu yanjiu (Exploration of the Chu Silk Manuscript Discovered at the Zitanku, Chang-sha), Beijing, 1985 ; Li Xueqin, Jianbo yiji yu xueshu shi (Lost Texts on Bamboo and Silk and the History of Scholarship), Tarbei, 1994, 37-91.

18. See e.g.. D.J. Harper, "The Han Cosmic Board (Shi)". Early China, 4 (1978), 1-10 : C. Cullen, "Some Further Points on the Shih ", Early China, 6 (1980-1981), 31-46 ; S. Field, "Cosmos, Cosmograph, and the Inquiring Poet : New Answers to the 'Heaven Questions'", Early China, 17 (1992), 83-110.

19. See Li Ling, "Chuboshu yu 'shitu'" (The Chu Silk Manuscript and Cosmograph Design), Jiang Han kaogu, $\mathrm{n}^{\circ} 1$ (1991), 25-43 ; Zhongguo fangshu kao (A Study of Chinese Magıcal Techniques), Beijing, 1993, 180. 
Figure 4a

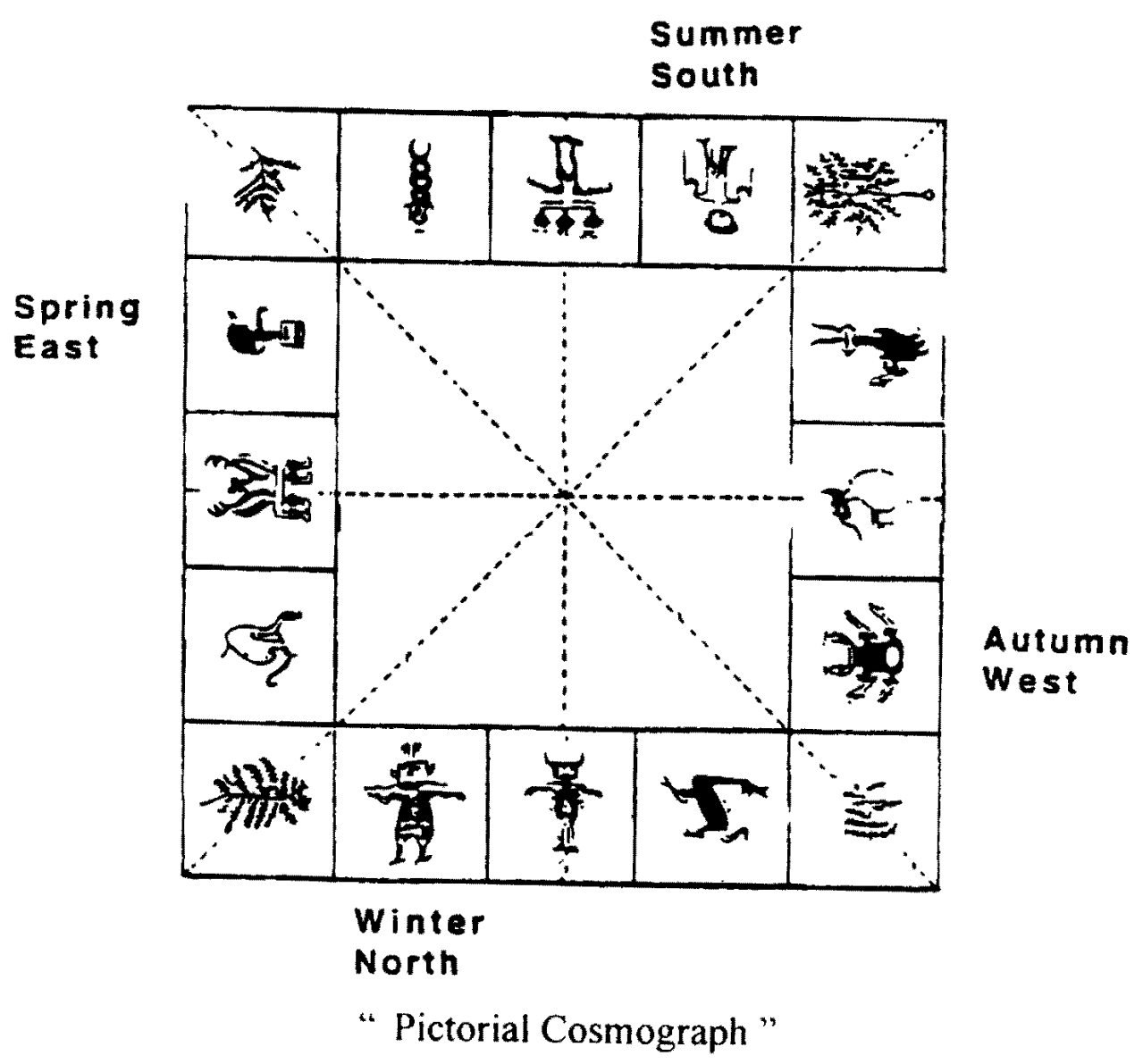

Figure $4 b$

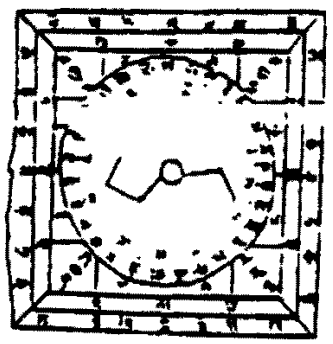

Cosmograph design 
Both the "pictorial cosmograph" and the scheme of spiritual landscape of the $S J$ are designed to convey " sacred cosmography". There is serious evidence to suggest that such structures in general, and these two in particular, served as instruments (or were conceived of as instrumental) for ritual world-making.

This problematic, is, however, the topic of a special study. 


\title{
PENSÉE CORRÉlative ET ARITHMOLOGIE EN CHINE LE CAS DE SHAO YONG 邵雍 (1012-1077)
}

\author{
Alain ARRAULT
}

Je ne voudrais pas me montrer entièrement en désaccord avec l'idée selon laquelle les Chinois auraient été des gens essentiellement pratiques, portés à se méfier de toutes théories. On doit cependant se garder d'aller trop loin dans ce sens: l'école néo-confucéenne des $\mathrm{XI}^{\mathrm{e}}, \mathrm{XII}^{\mathrm{e}}$ et XIIIe siècles réalisa une étonnante synthèse philosophique, curieusement contemporaine de la synthèse scolastique en Europe.

Joseph Needham

\section{PENSÉE CORRÉLATIVE}

La pensée chinoise, qui a très tôt suscité des questions chez ceux qui l'ont approchée de près, s'est vue qualifiée, dans les dernières décennies, de corrélative ou d'analogique. Le verdict des spécialistes fut de reconnaître, du point de vue de ses modes de fonctionnement, sa spécificité par rapport à la pensée dite axiomatico-déductive ou hypothético-déductive, propre au monde occidental au moins à partir de Descartes, à l'aube de l'époque moderne.

Ces premiers pas ont conduit au fond à donner de la pensée chinoise une définition négative : elle $n$ 'est pas axiomatico-déductive. L'absence de cau- 
salité, dans le même ordre d'idée, devient le point saillant de cette pseudo définition'.

On ne pouvait néanmoins en rester là : plusieurs sinologues tentèrent d'approfondir cette première approche. Jacques Gernet a montré de manière convaincante que la pensée des Chinois a pour horizon téléologique, non pas l'immuable, comme c'est le cas chez les Grecs, mais le changement ${ }^{2}$. Là où la pensée hellénistique recherche derrière les phénomènes (le désordre de l'apparence) une réalité stable, régie par des lois universelles et connaissables, la pensée chinoise ne s'intéresse qu'aux mutations et aux transformations des choses. Il s'agit dès lors de décrire, - et souvent d'anticiper -, le passage d'un état " $x$ " à un état " $y$ ".

Angus J.Graham, en se basant essentiellement sur les écrits cosmologiques de l'époque des Han $(-206,+220)$, consacre une partie d'un chapitre de son Disputers of the Tao aux modes de fonctionnement de la corrélativité ${ }^{3}$. Selon lui, le rapport qui existe entre les diverses analogies se résume à des relations de contiguïté et de similarité, concepts empruntés au linguiste Roman Jackobson ${ }^{4}$. Posons comme exemple les correspondances des deux instances yang et $y$ in :

$\begin{array}{cc}\text { YANG } & \text { YIN } \\ \text { ciel } & \text { terre } \\ \text { chaud } & \text { froid } \\ \text { feu } & \text { eau } \\ \text { soleil } & \text { lune } \\ \text { cercle } & \text { carré } \\ \text { etc. } & \text { etc. }\end{array}$

Le rapport entre le yang et le yin est similaire à celui qui existe entre le ciel et la terre (relation horizontale). Quant à la corrélation entre, d'une part,

1. A. Gighlione, La pensée chinoise et l'abstraction. Paris. 1993 (thèse), a apporté quelques nuances à cette absence en montrant qu'il existait cependant dans la pensée chinoise des " métaphores de la causalité".

2 J. Gernet, "Sur la notion de changement ", L'intelligence de la Chine. Paris, 1994, 323334.

3. A.C Graham, " The Reunification of the Empire and of Heaven and Man ", Disputers of the Tao, Illinois, 1989.

4. A. Graham, op cit., 320 et ss. Ces notions font étrangement penser à ce que Michel Foucault appelle " le savoir de la ressemblance" qui, selon lui. constitue l'épistémè de la culture occidentale au XVI" siècle Voir M Foucault, " La prose du monde" " Les mots et les choses, Paris, 1966. 
le yang et le ciel et d'autre part le yin et la terre, elle se caractérise par un rapport de contiguiité (relation verticale).

$$
\begin{aligned}
& \text { yang } \rightarrow \text { yin } \\
& \text { ciel } \rightarrow \text { terre }
\end{aligned}
$$

Relation paradigmatique de la similarité

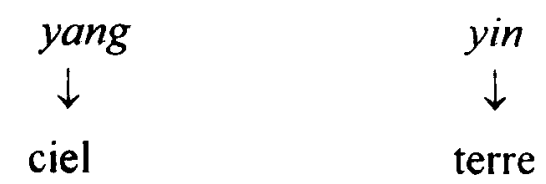

Relation paradigmatique de la contiguiité

Et Graham d'ajouter que “ ...beaucoup de la vie ordinaire et pratique relève irrévocablement de la pensée corrélative ; de même pour la pensée en oeuvre dans les arts. Toute cosmologie corrélative est poétiquement stimulée avec ce en quoi elle est en sympathie, un trésor de métaphores et de métonymies" $"$. Cela signifie-t-il que la pensée corrélative, à la différence de la logique scientifique, occupe tout un pan de notre manière de penser, celle, oserions-nous le dire —, de la spontanéité et de l'immédiateté ?

Cependant, bien que les associations en soi, - pourquoi tel élément est en relation avec tel autre -, demeurent en Chine rarement réfléchies et explicitées, les systèmes cosmologiques qui en découlent, la manière d'ordonner ces associations entre elles, la logique qui les sous-tend, les disciplines et les champs de savoir où elles sont opérantes, sont complexes et le sont devenus de plus en plus au fil du temps.

Enfin, la dernière caractéristique, - qui devrait probablement être du point de vue chronologique la première - , unanimement partagée en ce qui concerne le système de pensée chinoise, est que ce dernier, selon Marcel Granet, " a pour fonction non la connaissance pure, mais une action civilisatrice : son rôle est de sécréter un ordre agissant et total ". Joseph Needham renchérit en voyant dans cette pensée proto-scientifique, qu'il ne cesse de faire valoir par la qualité de ses inventions, un matérialisme organique où chaque phénomène est lié à tous les autres suivant un ordre hiérarchique ${ }^{7}$. C'est donc l'aspect pratique au sens aristotélicien du terme, une pensée tournée vers l'action, qui a le plus retenu l'attention.

5. Ibid.. 350 .

6. M. Granet, La pensée chinoise, Paris, 1968.

7. J. Needham, La science chinoise et l'Occident. Paris, 1973, 14 (Points). 
Pourtant, un penseur du $\mathrm{XI}^{\mathrm{e}}$ siècle, Shao Yong 邵雍(1012-1077), dément la validité de certains des aspects de " la" pensée chinoise. Il a en effet, dans le domaine de l'arithmologie - un domaine dont je vais définir les contours ci-dessous - , approché la notion de modèle et rendu possible son application sur des faits d'expérience, nous emmenant ainsi très loin de l'aspect strictement pratique et analogique de " la" pensée chinoise.

\section{LES NOMBRES ET L'ARITHMOLOGIE}

En Chine, comme ailleurs, la numération écrite a d'abord servi au dénombrement. Compter les objets, les animaux, etc., a été, d'après les inscriptions sur os et carapaces, une des premières préoccupations des Chinois ${ }^{8}$. A cette numération qui est décimale se sont juxtaposés des indices séxagésimaux non numériques pour marquer le temps (ce fut d'abord le cas pour les jours, puis pour les années et enfin pour les mois et les heures).

Mais, comme dans bien d'autres cultures, "l'aspect quantitatif du nombre fut très rapidement pressenti comme un événement proprement qualitatif, c'est-à-dire appartenant à un ordre de pensée structuré par le réseau des correspondances analogiques " 9 . On ne s'étonnera plus dès lors que, même un champ de savoir qui a priori paraît " innocent" comme la métrologie, est investi de la dimension qualitative ${ }^{10}$. Cependant, l'usage strictement symbolique, - emblématique disait Marcel Granet en parlant de la Chine -, des nombres dans les savoirs traditionnels, qu'ils soient occidentaux ou orientaux, joue un rôle de premier plan, souvent plus important que leur usage mathématique. Pour définir ce vaste domaine, Jean-Pierre Brach parle d'arithmologie ou d'arithmosophie" rique d'ordre symbolique qui, éventuellement, informe des disciplines aussi diversifiées que l'architecture, la musique, l'astrologie, etc. Enumérer les

8 Al sujet des plus anciennes numérations liées à la quantification. voir $\mathrm{R}$ Djamouri, "L'emploi des signes numériques dans les inscriptions Shang". Extrême-Orient ExtrêmeOccident, 16 (1994), 12-42. G. Guitel, Histoire comparée des numérations écrites. Paris, 1975, 467-545, distingue trois étapes dans la numération chinoise. La première correspond à l'écriture sur os et carapaces : la seconde est un système hybride qui allie multiplication et addition et la troisième celle que les Chinois utilisent pour les tables à calcul, une numération dite de position. Pour une présentation succincte mais efficace des diffèrentes numérations chinoises, voir J.-C. Martzloff. “ Les nombres et la numération ", Histoire des mathématıques chinotses, Paris. 1988, 169-174.

9. Cf. J -P. Brach, La symbolıque des nombres, Paris, 1994, 5 (Que sais-je ?; $\mathbf{n}^{\circ} 2898$ ).

10. Voir J.-C. Hocquet. entrée “ Métrologie ”, Encyclopedıa Universalıs (1992), 237-245, qui parle au sujet des mesures antérieures au système métrique décimal de mesures anthropométriques, " calculées sur les hommes".

11. Cf. J.-P. Brach, op cit., 3. 
systèmes arithmologiques que les Chinois ont mis en oeuvre demanderait plus qu'un article.

Je retiendrai seulement qu'aux alentours de notre ère le phénomène prit une telle ampleur que le traité bibliographique de l'Histoire des Han, sous le vocable très suggestif de shushu 術數 ${ }^{12}$ (techniques et nombres), lui confère une place de choix et parfaitement délimitée. Les titres réunis sous cette rubrique comportent toutes les techniques qui ont, peu ou prou, un rapport avec la divination, que ce soit l'achilléomancie, la chélionomancie, la géomancie, l'astronomie, la physiognomonie, etc. Il est vrai qu'en Chine la symbolique numérale fût très tôt orientée vers le monde de la mancie. Ainsi, le Livre des mutations, un des plus anciens classiques, associe aux lignes des hexagrammes obtenus par le tirage de l'achillée les nombres 6 ou 9. De récentes découvertes laissent même subodorer qu'à l'origine les lignes continues ou brisées des hexagrammes étaient en fait des chiffres ${ }^{\prime 3}$. Un des commentateurs du Yijing 易經, Gu Huan 顧懽, au $\mathrm{V}^{\mathrm{e}}$ siècle de notre ère, étaie le rapport nombre-divination en soulignant que, bien que les êtres divins (shen 神), les puissances omniscientes qui détiennent les clés de notre destin, ne soient pas des nombres, c'est pourtant par l'entremise des nombres qu'ils se manifestent ${ }^{14}$. Le nombre est doté d'un pouvoir magique de manifestation $^{15}$.

Il est cependant curieux de remarquer que toutes les techniques divinatoires comprises dans la catégorie shushu n'ont pas forcément recours aux nombres, y compris dans leur système de correspondances. Et si nous avions à éliminer toutes les pratiques qui ne sont pas, stricto sensu, de la divination par les nombres ${ }^{16}$, la catégorie se réduirait comme une peau de chagrin.

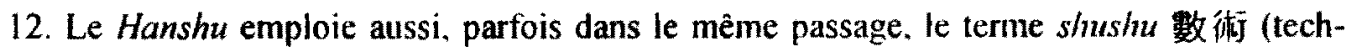
niques numériques). Les deux expressions ont été à la suite de l'Hıstorre des Han employés l'une pour l'autre.

13. Voir J.-P. Diény, "Les inscriptions sur os et écailles de lépoque des Zhou " Journal asiatique, 3-4 (1986), 455-466. Ces inscriptions numériques datent de la fin des Yin (XIII'-XIc siècles avant notre ère) et des Zhou (à partir du $\mathrm{XI}^{\circ}$ siècle avant notre ère)

14 “Shen sui fei shu, yin shu er xian” 神雖非數因數而影 Cité dans le Zhou Yı zhushu 周易注䟽, Stku quanshu. 7.536

15. On pourrait se demander à ce sujet si ce sont les nombres seuls qui ont cette dimension " magique " ou le fait qu'ils soient obtenus par le jeu du hasard.

16. M. Kalinowski, " La divination par les nombres dans les manuscrits de Dunhuang", Nombres, astres, plantes et viscères, IHEC, vol. XXXV (1994). 37-78. souligne que les procédés de tirage emploie trois méthodes pour obtenir des figures mantiques : le décompte pour les tiges de calcul, l'extraction pour les fiches numérotées et le jet pour les pions. les pièces de monnaie et les dés. 


\section{MODÈLE NUMÉRIQUE}

Don J. Wyatt a montré avec pertinence que Shao Yong avait mis au premier plan de ses préoccupations la notion de shu (nombre), contre la tendance générale de son temps qui privilégiait les principes $(/ i \text { 理 })^{17}$.

Dans ses "Chapitres sur l'observation des choses" (Guanwu pian 觀物篇), notre homme des Song du Nord a développé une arithmologie dont les caractéristiques en font une spéculation originale. Une série de notions numériques ${ }^{18}$ sont articulées à l'intérieur d'un système qui, de bout en bout, demeure cohérent. Censé refléter, - ou symboliser-, le cosmos, ce système n'intervient pourtant pas comme une simple symbolique de type pythagoricien ou mystique. Sa logique et ses applications, en particulier sur la phonologie, lui confèrent le statut de modèle, un modèle à prétention exhaustive, capable de refléter fidèlement l'univers. La démarche pour élaborer un tel modèle s'articule en trois étapes correspondant à trois notions numériques découlant l'une de l'autre : 1) les nombres substantiels (tishu 體數);2) les nombres fonctionnels (yongshu 用數)；3) les nombres généraux (tongshu 通數).

\section{LES NOMBRES SUBSTANTIELS}

Ce sont les nombres attribués aux figures du ciel et de la terre. Les quatre figures célestes (yang majeur, yang mineur, yin majeur, yin mineur) et terrestres (fermeté extrême, fermeté relative, souplesse extrême, souplesse relative) ${ }^{19}$ sont empruntées aux commentaires du Livre des mutations (Yijing). Mais là s'arrête le rapport avec le célèbre classique puisque les nombres employés (10 et 12$)$ ne sont pas ceux que la tradition revendique $(6,7,8,9)$. La distribution des deux nombres 10 et 12 , dont il n'est pas anodin de remar-

17. D.J. Wyatt, The recluse of Loyang. Shao Yung and the Moral Evolution of Early Sung Thought. Honolulu, 1996, 120-122, 192-195. D.J. Wyatt n'est resté qu'au niveau des pétitions de principe, sans entrer dans le détail des spéculations numériques de Shao.

18. Il existe dans l'oeuvre de Shao Yong bien d'autres notions numériques. Il s'agit notamment des nombres de la conformité et de l'inversion qui sont étroitement liés avec les diagrammes des trigrammes et des hexagrammes du Livre des mutations ( $Y_{I J I n g}$ 易經). Les prendre en compte demanderait plus de place qu'il n'est permis ici Voir A. Arrault. Shao Yong (1012-1077) Un phllosophe poète dans la Chıne prémoderne. Paris, 1995, $481-517$ (thèse, à paraître).

19. Ces huit figures constituent autant de phases décrivant un cycle allant. par exemple. du yın mineur au yang majeur en passant par le yin majeur et le yang mineur (cycle de la croissance). 
quer qu'ils correspondent aux séries dénaires et duodénaires usitées comme marqueurs du temps, s'opère de la manière suivante :

\begin{tabular}{|l|l|l|c|}
\hline \multicolumn{2}{|c|}{ Ciel } & \multicolumn{2}{c|}{ Terre } \\
\hline yang majeur 太陽 & 10 & fermeté extrême 太岡 & 10 \\
\hline yin majeur 太陰 & 12 & souplesse extrême 太柔 & 12 \\
\hline yang mineur 少陽 & 10 & fermeté relative 少剛 & 10 \\
\hline yin mineur 少陰 & 12 & souplesse relative 少柔 & 12 \\
\hline
\end{tabular}

\section{NOMBRES DES QUATRE FIGURES CÉLESTES ET TERRESTRES}

Le nombre substantiel de la série yang s'obtient par l'addition des chiffres 10 dont la somme est multipliée par 4 :

NSyl: $10+10+10+10=40 \times 4=160$

le même procédé est appliqué à la série yin :

NSy $2: 12+12+12+12=48 \times 4=192^{20}$

Les chiffres additionnés dans chaque série opèrent numériquement la fusion du ciel et de la terre. L'usage du multiplicateur 4 tient probablement au fait que nous sommes en présence de quatre entités. Le recours à la multiplication s'explique, selon Shao Yong, par le fait que cette opération arithmétique signifie génération, alors que la division symbolise la destruction.

\section{LES NOMBRES FONCTIONNELS}

A partir des nombres substantiels, les nombres fonctionnels (NF) s'obtiennent selon la procédure exposée ci-dessous :

NFyl : $160-48=112$

NFy2 : $192-40=152$

Les nombres soustraits le sont par croisement : on enlève à la série yang le nombre yin (48) et inversement pour la série yin, comme s'il s'agissait de séparer les deux phases, opposées mais complémentaires, du yin et du yang. Le passage des nombres substantiels aux nombres fonctionnels représente la transition qui conduit de l'état d'immobilité à l'état de changement. L'idée que les choses ne deviennent opérationnelles et changeantes qu'à partir d'une soustraction transparaît déjà dans le Livre des mutations où, pour faire un tirage, on doit retirer une tige aux cinquante tiges d'achillée. Cette unique

20. NS signifie " nombre substantiel" ; y1 et y2 respectivement pour (série) yang et (série) yin. 
tige, la tige inutilisable, représente paradoxalement la plus haute instance de la cosmologie et prend, suivant les commentateurs et les époques, divers noms : l'Un suprême (Taiyi 太-), le Faîte suprême (Taiji 太極), etc.

\section{LES NOMBRES GÉNÉRAIX}

Le nombre général (NG) est tout simplement issu de la multiplication du nombre substantiel par le nombre fonctionnel : NG : $112 \times 152=17024$

Ce nombre est mis en corrélation, de manière similaire, avec diverses strates :

a. nombre du changement (bianshu 變數) des quatre figures célestes ;

b. nombre du changement des êtres mouvants (les animaux, dongwu 動物);

c. nombre de la transformation (huashu 化數) des quatre agents (eau, feu, terre, pierre $\left.{ }^{21}\right)$;

d. nombre de la transformation des choses immobiles (les plantes, zhiwu 值物).

D'où il s'ensuit que le nombre général du changement et de la transformation (bianhua shu 變化數) des quatre figures célestes et des quatre agents est 289816576 , soit $17024 \times 17024$; le même nombre identifie le nombre général du changement et de la transformation des animaux et des plantes ${ }^{22}$.

À ce stade, quelques remarques s'imposent. Le mode de raisonnement, la cohérence du système et les nombres obtenus n'ont rien de commun avec la tradition chinoise de l'arithmologie. Il est dès lors légitime de s'interroger sur la portée et la signification de tels procédés. Nous sommes de fait face à un véritable modèle, c'est-à-dire un cadre de pensée dans lequel un ensemble de notions reflète ou tente d'expliciter le fonctionnement de l'univers. De ce point de vue, on peut aussi parler de modèle de la physique classique, de la relativité, etc. Chaque modèle suppose un certain nombre d'axiomes, ou d'a priori, desquels découle une série de conséquences. Il est cependant exact que le modèle numérique de Shao Yong, bien que supposant certains principes (passage de l'immobilité au changement par procession de l'univers), ne procède pas par axiomes mais de manière analogique, tout en maintenant entre les diverses notions le principe de déduction : les nombres généraux

21. Une des particularités de Shao Yong est de constamment s’appuyer sur des ensembles à quatre éléments. Certains, comme ceux des figures célestes et terrestres. appartiennent à la tradition mais d'autres. comme ici les quatre phases, sont une invention de son cru : une exception notable dans une civilisation qui s'est toujours référée à cinq phases (eau. feu, bois, métal, terre).

22. Pour la présentation des notions numériques exposées cı-dessus. voir " Guanwu pian ", 11, éd. du Daozang. 705-718 n ${ }^{\circ} 1040,11$ a-12a. 
sont déduits des nombres fonctionnels qui, à leur tour, le sont des nombres substantiels. Comme tout modèle, il est non seulement destiné à être confronté avec les faits empiriques, mais aussi déplacé sur des objets de savoir divers; c'est l'aspect générationnel d'un modèle ou sa capacité à pouvoir englober un maximum d'objets.

Le premier et le seul domaine qui va être confronté à ce modèle est celui de la phonologie. II serait ici trop fastidieux de rappeler l'histoire et les principes d'analyses de la phonologie chinoise. Retenons seulement que cette discipline connut, bien avant Shao Yong, un développement remarquable grâce aux apports du bouddhisme, qui introduisit en Chine des éléments d'analyses phonologiques de la culture indienne, et à l'adaptation aux besoins autochtones de cet outil très performant. D'une manière générale, les documents ayant trait à la phonologie sont des dictionnaires de rimes. Ces dictionnaires se basent sur la langue jugée standard d'une époque donnée. Au changement dynastique, et donc dans la majorité des cas de changement de capitale, et à l'évolution diachronique de la langue ${ }^{23}$ correspondait la nécessité de corriger la prononciation devenue obsolète des caractères chinois.

$\mathrm{Si}$, dans les catégories employées (les quatre divisions des initiales, les quatre tons des finales, etc.), Shao Yong perpétue cette tradition qu'il a héritée de son père, qui lui-même la tenait d'un bouddhiste, le but de ses analyses phonologiques n'est pas d'élaborer un dictionnaire de rimes, ou un tableau des rimes qui permettaient de convertir les anciennes prononciations, mais à rendre compte, de manière exhaustive, de l'ensemble des sons possibles. Autrement dit, l'aspect utilitaire de la phonologie, - connaitre la bonne prononciation pour pouvoir lire correctement à haute voix et écrire des poésies prosodiquement justes -, disparait $t^{24}$. La démarche qu'il suit nous est maintenant familière. Deux séries de quatre figures, célestes et terrestres, se voient attribuer alternativement les nombres 10 et 12 (voir Schéma 1 cidessous).

23. Les phonologues chinois n'ont jamais reconnu que leur langue avait pu évoluer mais ont considéré que l'écart de prononciation qu'ils pouvaient constater avec les dictionnaires précédents était dù à un défaut de notation de ces derniers.

24. Le père de Shao Yong. Shao Gu, dont malheureusement nous n'avons conservé qu'une préface, y reprend l'argument traditionnel en faveur de la rectitication des sons . une mauvaise prononciation engendre de mauvais discours, des doctrines lallacieuses. la perversion du vrai et du faux et le désordre de l'empire, d'où la nécessité de corriger les initiales et les finales. Cf. $Y_{l}$ tong bian 易通變, “Zhengyin xulu”正音敘錄, 19. 1a-5b. SKQS 804.452-454. Pour l'analyse de ce texte et ce qu'en a retenu Shao Yong. voir Hirata Shôji 平田昌司, “"Huangii jingshi shengyin changhe tu yu Qieyun zhizhang $t u$ "皇極經世唱和圖與切音指掌圖, Tôhò Gaku-hö, n 56 (1984). 
Schéma 1

\begin{tabular}{|l|l|l|l|}
\hline \multicolumn{2}{|c|}{ Ciel } & \multicolumn{2}{c|}{ Terre } \\
\hline soleil 日 & 10 & eau 水 & 10 \\
\hline lune 月 & 12 & feu 火 & 12 \\
\hline astres 星 & 10 & terre 土 & 10 \\
\hline marqueurs sidéraux 辰 & 12 & pierre 石 & 12 \\
\hline
\end{tabular}

Nombres des figures célestes et terrestres

On obtient à nouveaux deux nombres substantiels, 160 et 192, mais, cette fois-ci, ces nombres désignent des faits empiriques de la langue : les initiales et les finales. Cette intrusion du réel dans le modèle va provoquer des vagues qu'il faudra endiguer.

\section{MODĖLE NUMÉRIQUE ET AMÉNAGEMENTS}

Nous sommes donc en présence de 192 initiales et 160 finales qui sont agencées comme suit : 1) Les initiales sont réparties sur 12 catégories. Chaque catégorie, comprenant deux types de sourdes et de sonores (qing 清 et zhuo 濁) qui chacune sont à leur tour distinguées selon quatre divisions ( $s i$ deng 四等, kai fa shou bi 開發收閉), contient donc $16(2 \times 2 \times 4)$ initiales. Mais il va de soi que, de facto, il n'existe pas 192 types d'initiales. Par exemple, la catégorie qui comprend les nasales est dépourvue de nasales à la quatrième division. D'après Shao Yong, ce sont des initiales sans son et sans caractère. Cet exemple n'étant pas unique, il faut finalement retrancher 40 types d'initiales au nombre total, d'où le chiffre de 152 qui devient le nombre fonctionnel des initiales ; 2) Les finales sont distribuées sur 10 catégories qui chacune comprenne 16 types de finales, subdivisées en deux types de labialisées et de non labialisées ( $x i$ 拿 et $p i$ 闢) et distinguées selon les quatre tons : plat, ascendant, partant, rentrant (ping, shang, $q u, r u$ 平上去入). Pour des raisons similaires au cas des initiales, il y a 48 finales sans son et sans caractère $^{25}$. Le nombre fonctionnel de finales se monte donc à 112 .

A partir des nombres fonctionnels, on retombe à nouveau sur le nombre général de $17024(152 \times 112)$. Ce nombre correspond au nombre total de syllabes obtenues grâce à la combinaison de chaque initiale avec chaque finale. C'est sous forme de tables (voir ci-dessous Tables 1 et 2), dans

25. Shao Yong se sert de l'analogie du soleil qu'on ne peut percevoir lorsqu'il occupe les

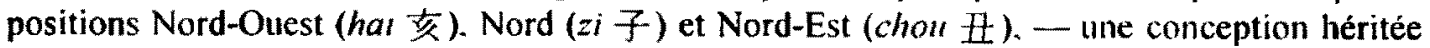
de l'époque Han - pour préciser que les tinales absentes existent bel et bien mais que nous ne pouvons pas les " percevoir". Cf. "Guanwu pian" 12x. éd. du Daozang. 705-718 n 1040. $19 \mathrm{~b}$. 
lesquelles les initiales et les finales manquantes sont respectivement notées par des carrés et des cercle noirs, que Shao Yong présente toutes les permutations possibles, soit $30720(192 \times 160)$ combinaisons.

Table 1

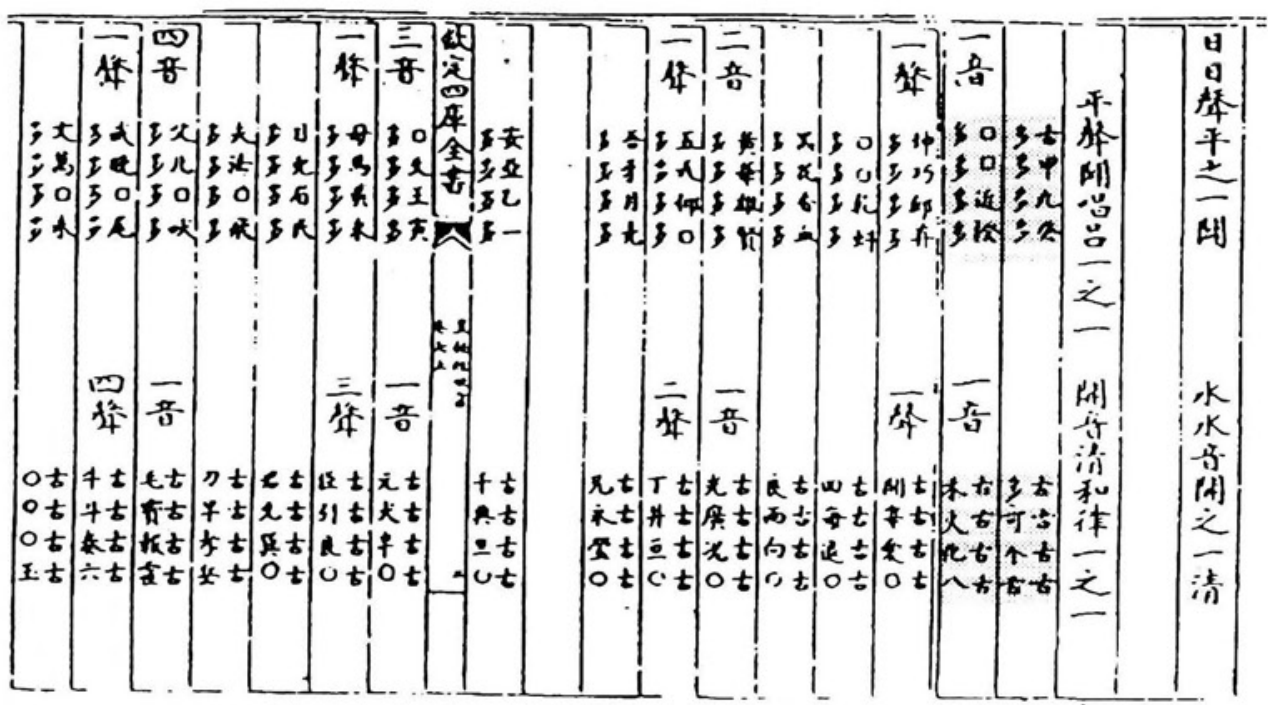

Extrait du Huangji jingshi 皇極經世, Daozang, 1040, 7, 2a-b.

\begin{tabular}{|c|c|}
\hline il & \\
\hline $\mathrm{fl}$ & \\
\hline $\mathrm{fl}$ is & \\
\hline flis is & \\
\hline 15 il & \\
\hline foil & \\
\hline (7) il & \\
\hline 18 il & \\
\hline
\end{tabular}

Légende : " $i$ " : initiale ; $f$ " : finale

Hélas, la langue, retorse, exige encore un nouvel aménagement pour pouvoir s'inscrire dans le modèle car, en dehors de celles déjà notées comme inexistantes, il faut bien admettre qu'il y a des initiales et des finales qui n'apparaissent pas dans la langue. Par exemple, il n'existe pas de finale " im " au ton rentrant. Shao Yong résout ce problème, qui risquerait de rendre caduc son modèle, en parlant d'initiales et de finales qui ont un son mais pas de caractère et qu'il note par des carrés et des cercles blancs (voir ci-dessous Table 2). Derrière ces petits arrangements, le nombre effectif d'initiales est de 131 et de 83 pour les finales, avec un total de 10873 syllabes $(131 \times 83)$. 
Table 2

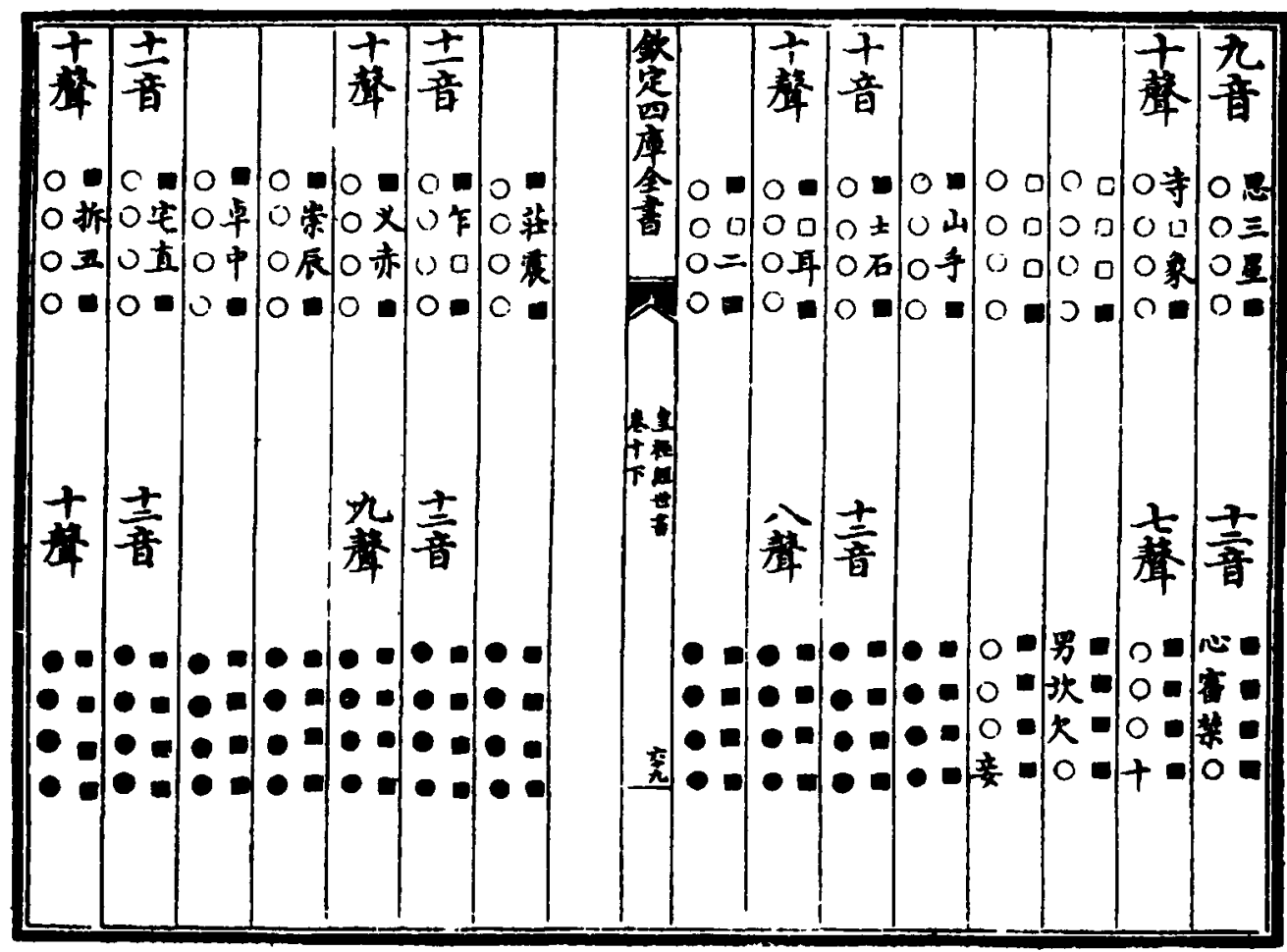

initiale avec son mais sans caractère

$O$ finale avec son mais sans caractère

initiale sans son et sans caractère

finale sans son et sans caractère

Extrait du Huangji jingshi, SKQS, 803, 10, 1029.

Par ailleurs, ce nombre devrait être encore réduit puisque inévitablement, à cause du mode d'exposition choisi, certains composés sont amenés à se répéter (voir par exemple ci-dessus les deux premières lignes [il $\mathrm{fl}$ ] des parties inférieure et supérieure de la Table 1) et que, - désavantage d'une combinaison formelle - certains composés ne peuvent se lire dans la langue chinoise de l'époque des Song ${ }^{26}$. Ces défauts sont les conséquences d'un système qui se veut exhaustif, non utilitaire, presque un jeu de l'esprit destiné à présenter tous les sons possibles, oublieux de sa langue de référence ${ }^{27}$. Les tables qui sont le reflet d'un projet à visée exhaustive, fondé sur un système 
de combinaisons, ne peuvent, ce me semble, que recevoir le nom de " tables des sons".

\section{CONCLUSION}

L'exemple que je viens d'évoquer permet de tirer un certain nombre de conclusions :

1) La spéculation sur les nombres que propose Shao Yong renouvelle par bien des aspects l'arithmologie chinoise. Elle rompt définitivement le lien, plus ou moins lâche, qui existait entre arithmologie et pratiques mantiques et n'est plus la répétition ou l'agglomération de ce qui a précédé. Ce n'est plus une simple symbolique mais un véritable modèle.

2) Un modèle, d'abord du point de vue de la cosmologie, qui est censé expliciter le passage de l'immobilité au changement et qui, ensuite, s'applique à la phonologie, dans laquelle intervient un système de combinaisons formelles rendant compte de tous les sons possibles, une innovation dans le domaine de la phonologie.

3) Les faits tangibles, comme ceux de la langue, ne peuvent qu'imparfaitement se couler dans le moule du modèle ; aussi est-il impérieux d'imaginer quelques astuces, de tordre les faits au profit de la validité du modèle : une démarche qui n'est pas sans rappeler les petits aménagements que certains modèles scientifiques peuvent subir, jusqu'à ce que les faits, trop têtus, rendent le modèle inopérant.

4) Tous les points que je viens de relever montrent que les particularités de la pensée corrélative chinoise, - en particulier son aspect pratique dénué d'abstraction -, ne sont pas valables de toute éternité. La pensée corrélative a elle aussi une histoire. 



\title{
The ARgument Between Right-Rotation THEORY AND LEFT-Rotation THEORY OF THE SUN, THE MOON AND THE Five Planets in ANCIENT ChINA
}

\author{
CHEN Meidong
}

That the sky rotates from east to west is the intuition of ancient people all over the world which they believe to be true. In the Spring and Autumn and the Warring States periods at the latest, the Chinese found that while rotating from east to west with the stars, the sun, the moon and the five planets move from west to east with different speeds, representing more complicated motions than stars do, among which the five planets, sometimes in direct motions (from east to west in comparison with the stars), sometimes keeping stationary (moving in pace with the stars), and sometimes in retrograde motions (from east to west in comparison with the stars), showing much more complex motions. The Gaitian 蓋天 School gave the phenomena stated above a vivid metaphor ${ }^{1}$ : the sky in which the stars are located is like a large millstone which completes one circling rotation from east to west everyday; the sun, the moon, and the five planets are like ants on the millstone which, besides moving with the stone, crawl from west to east with different speeds, and in the case of the five planets, the crawl is sometimes from west to east (direct motion), sometimes stops, and is sometimes from east to west (retrograde motion). While replacing the millstone with a large globe, the Huntian 渾天 School which emerged a little later made the same point as the Gaitian School did. This is the initial theory of right-rotation of the sun, the moon

1, Li Chunfeng 李淳風(602-670), Jinshu晉書, 11, Tianwen zh 天文志. 1. Beijing. 1974. 278-279. 
and the five planets, the primitive and intuitive theoretical explanation for the motions of the sun, the moon, and the five planets.

Probably in late Western Han ( ${ }^{\text {st }}$ century $\left.\mathrm{BC}\right)$, accompanying the emergence of the theory that solar eclipse is caused by the moon covering the sun, the ideas that the distances from the sun and the moon to the celestial sphere are different, and that they are not linked to the sky were formed naturally, which challenged the right-rotation theory of the sun, the moon and the five planets. At this time it was suggested that, like stars, the sun and the moon both move from east to west, with the stars moving fastest, the sun next to them, and the moon still next. This is the original left-rotation theory of the sun and the moon which is as effective as the right-rotation theory of the sun and the moon in explaining the phenomena concerning relative motions of the sun and the moon, for from the view of relative motion, the two theories can both explain the eastward motion of the sun and the moon in comparison with the stars. Not long after its appearance, the left-rotation theory of the sun and the moon was fiercely criticized by Liu Xiang 劉向 (77 ?-6 BC.), a great Confucianist of the time. Negating the left-rotation theory with the reason that it violates the teaching of ancient sages and official theory, Liu Xiang's criticism is not convincingly based ${ }^{2}$, but because of Liu Xiang's high intellectual position, and the prevailing custom of believing in teaching of ancient sages, as well as the lack of self-perfecting mechanism in itself, the left-rotation theory of the sun and the moon was almost forgotten for more than one thousand years afterwards.

It was not until early Northern Song $\left(11^{\text {th }}\right.$ century) that Zhang Zai張載 (1020-1077), a famous thinker, brought up the old question again. He argued that both the sky and the stars move from east to west, which brings the $q i$ 氣 to move in the same direction, and also brings the sun, the moon and the five planets, which all link to $q i$, to move from east to west. Because the sun, the moon and the five planets move slower than the sky and the stars do, they seem to move from west to east. As for the different speeds of the motions of the sun, the moon and each of the five planets, Zhang Zai managed to explain with the yin-yang theory ${ }^{3}$. In Southern Song $\left(13^{\text {th }}\right.$ century), Zhu Xi 朱喜 (1130-1200), another famous thinker, stated repeatedly and supplemented this theory, arguing that the stars move a circle and one $d u\left(365.25 d u=360^{\circ}\right)$ everyday, and the sun moves a little more slowly, covering one circle a day, while the moon is slower, moving $13 d u$ less than one circle, etc. ${ }^{4}$

2. Shen Yue 沈約 (441-513), Songshu 宋書, 23、Tianwen 天文. 1. Beijing. 1974、679.

3 Zhang Zai, Zhengmeng 正蒙. “Canliang pian”參兩篇. in Zhang Zai / 張載集. Beijing. 1985, 10-13.

4. Zhu Xi. Zhuzı quanshu 朱子全書, 50 . 
Because of the great influence of Zhang Zai, and even more of Zhu Xi, on thinking and academic circles, the theory of left-rotation of the sun, the moon and the five planets prevailed among Confucianists then, and even replaced the right-rotation theory as an officially recognized standard theory. But most of the astronomers, calendar makers as well as a part of scholars still adhered to the right-rotation theory. Zhu Yuanzhang 朱元璋(r. 1368-1398), the first emperor of the Ming dynasty, maintained the right-rotation theory, and explicitly ordered his government to treat it as an official theorys. This is an interesting example of political intervention in astronomical theory. Such as it was, from Southern Song to early Qing, arguments among scholars kept going on.

Those who held the right-rotation theory launched their attack mainly from four aspects : (1) according to the left-rotation theory, the sun moves faster than the moon, which does not conform with the ethics that the sun is the monarch who should move with slow pace and be leisurely, and the moon is the subject who should move with rapid pace and be laborious; (2) according to the left-rotation theory, when the five planets retrograde, they move faster than the sky, which violates the basic Confucian theory that the sky should move the fastest ; (3) the left-rotation theory upheld by Zhang Zai and Zhu Xi wasn't able to give necessary explanation to the annual variation of the sun's rising and setting azimuth and of the vertical angle ; (4) the leftrotation theory avoided, or even denied the uneven motion of the sun, the moon, and the five planets, which had long been an undoubted fact to astronomers and calendar makers ${ }^{6}$.

During the argument, the up holders of the left-rotation theory also revised and supplemented their theory. For example, Yu Yan 俞琰 (ca 1253-1258) of late Song and early Yuan pointed out that the sun's orbit is like the threads twining the spindle; at winter solstice twines the most southern point; at summer solstice twines the most northern point, and at the two equinoxes coincides with the equator, and such motions are continuously going on? Another example is Wu Cheng 吳澄 (1249-1333) of the Yuan Dynasty who admitted the uneven motion of the sun, the moon, and the five planets, which he inserted in the left-rotation theory; he gave an explicit account on the order of the moving speeds of the stars, the sun, the moon, and the five plan648.

5. Zhu Yunming 祝九明, Zhishan qian wen 枝山前聞. Shuofu說预. vol 9. 13. Shanghai,

6. Xu Qian 許謙, Dushu congshuo 請書蒜說, 2, Siku quanshu, vol. 61. 461-462, Wang Yinglin, Liujıng tianwen bian 六經天文編, 1, Siku quanshu. vol 786.134-135.

7. Yu Yan. Shuzhai yehua 書齊夜話, 3, Siku quanshu, vol. 865, 625-626. 
ets $^{8}$. A third case is that of Huang Runyu 黄潤玉(1389-1477) of the Ming Dynasty he illustrated more explicitly the sequence of the moving speeds of the sun, the moon, and the five planets, in organic relation with their distances to people, and established a model for motions of heavenly bodies, using the left-rotation theory of multilayers of $q i$ proposed by $\mathrm{Zhu} \mathrm{Xi}$ as mechanic of the motions of these heavenly bodies?.

The most convincing arguments supporting the right-rotation theory and negating the left rotation theory came from Huang Zhencheng 黃鎭成 of Yuan and Wang Xichan 王錫闇 (1628-1682) of early Qing ${ }^{\prime 0}$. They confirmed the reliability of right-rotation theory and the unreliability of the leftrotation theory mainly on the basis that the sun orbits around the ecliptic. They pointed out that the theory of the sun's orbit set out by the left-rotation school fell into difficulty in explaining why the sun's orbit must be confined in the region about $48 d u$ from extreme north to extreme south. The left rotation theory also runs into difficulty in explaining why the distances between two neighboring twining threads of the sun's orbit change with such regularity that it becomes larger from the extreme south to the middle, becomes smaller from the middle to the extreme north, and again becomes larger from the extreme north to the middle, becomes smaller from the middle to the extreme south. They also pointed out that according to the theory that the sun orbits on the ecliptic set out by the right-rotation theory, the first question can be explained by the fact that the ecliptic obliquity is about $24 d u$, and the sun's diurnal westward movement is about $1 d u$ along the ecliptic, at the point of winter and summer solstices the sun reaches its extreme southern and northern points of the ecliptic respectively, and at the points of two equinoxes, the sun is at the ecliptic obliquity. And also according to the rightrotation theory the regular phenomena set out by the second question can also be calculated accurately with a mathematical method, i.e., the regular variation is the natural result of the theory of the sun orbiting on the ecliptic. The accounts by Wang Xichan, more explicit and more detailed than those of Huang Zhencheng, may be regarded as a good summation for the long-term debate between the left-rotation theory and the right-rotation theory about the movements of the sun, the moon, and the five planets in ancient China.

Both the left-rotation theory and the right-rotation theory regarded the left rotation of the sky and the stars, as well as the apparent motion of the sun,

8. Wu Cheng. Wu Wenzheng J 吳文正集, 2, Siku quanshu. vol 1197.33

9 Huang Runyu. Haihan wanxiang lu 海涵萬象錄. Congshu /icheng chubian. vol. 604. 1 2 .

10. Huang Zhencheng. Shangshu tongkao 尚書通考. 1. Siku quanshu. vol. 62、19, Wang Xichan, Xiao an yishu 曉庵遺書. “Zazhu”雜著. 
the moon, and the five planets as real motions, which is the very historical condition and knowledge background under which the debate between leftrotation theory and right-rotation theory carried on. By comparing between the two, the right-rotation theory is more mature and more conform to reality. But in insisting on the idea that the sun, the moon and the five planets are not linked to the crystal, and developing a theory of multi-layer dynamic and mechanical mechanisms for heavenly bodies, which is unattainable by the right-rotation theory, the left-rotation theory was not totally wrong. 



\title{
The ACCEPTANCE Of Proportional EXPRESSION IN JAPAN
}

\author{
Ken'ichi SATO
}

My aim in this paper is to discuss the transfer of scientific knowledge in pre-modern Japan. The discussion will however be limited to the case of traditional Japanese mathematics from the beginning of the $17^{\text {th }}$ century to the beginning of the $19^{\text {th }}$ century. I will begin with a brief observation on how traditional Japanese mathematicians accepted extraneous mathematical knowledge. For traditional Japanese mathematicians who lived in the first half of the Edo period (1063-1868), the "other culture " meant that of China. For example, the proportional expression, which they imported from China, is very elementary from the viewpoint of mathematics. We are commonly acquainted with using the expression like " $a$ is to $b$ as $c$ is to $d$ ". In this expression, we can easily deduct that a.d = b.c holds (as is well-known in the history of mathematics, the solution using this expression is called "the rule of three "). But we historians will be attracted enough as to the following points.

Firstly, the notion of proportional expression was familiar to Chinese mathematicians since they came into contact with Jesuit missionaries at the very end of the $16^{\text {th }}$ century. Although this was imported into Japan in the first half of the $18^{\text {th }}$ century, traditional Japanese mathematicians did not assume that the proportional expression from China could be used for almost all arithmetical problems. That was only to the calculation of calendar that they limited the use of the expression. The reason of the limitation should be discussed.

Secondly, in order to answer the previous question, we must inquire into the conditions of traditional Japanese mathematics relating to the propor- 
tional expression. Later I shall suggest that not only was their own proportional expression independent from the Chinese one, but also that some social factors prevented them from accepting the Chinese style. In the process, a relationship between mathematics and astronomy in the context of traditional Japanese mathematics will come to the forefront.

Before entering into the main themes of Japanese mathematics, let us have a brief look at the history of Chinese mathematics.

In the $17^{\text {th }}$ century, traditional Chinese mathematicians came to know the word proportion, bili 比例, in Chinese, through the translation the six first books of Euclid's Elements (1607) by Matteo Ricci (1551-1610) and his disciple Xu Guangqi 徐光啓(1562-1633). But the theory of proportion never took root in the world of Chinese mathematics. Rather, this word bili was more circulated in the area of arithmetic in using the rule of three. The Chinese translation of the rule of three was found on Li Zhizao's 李之藻 (1565-1630) book, the Tongwen Suanzhi 同文算指 (the Treatise on European Arithmetic, literally the Combined Languages Mathematical Indicator, 1614). Li Zhizao, who was another disciple of Matteo Ricci, gave it a new name, sanlü 三率 (method of three terms), to this calculation. This method is as follows. The expression " $a$ is to $b$ as $c$ is to $d$ " is written down in the sanlu-method as shown below (See Fig. 1):

Figure I
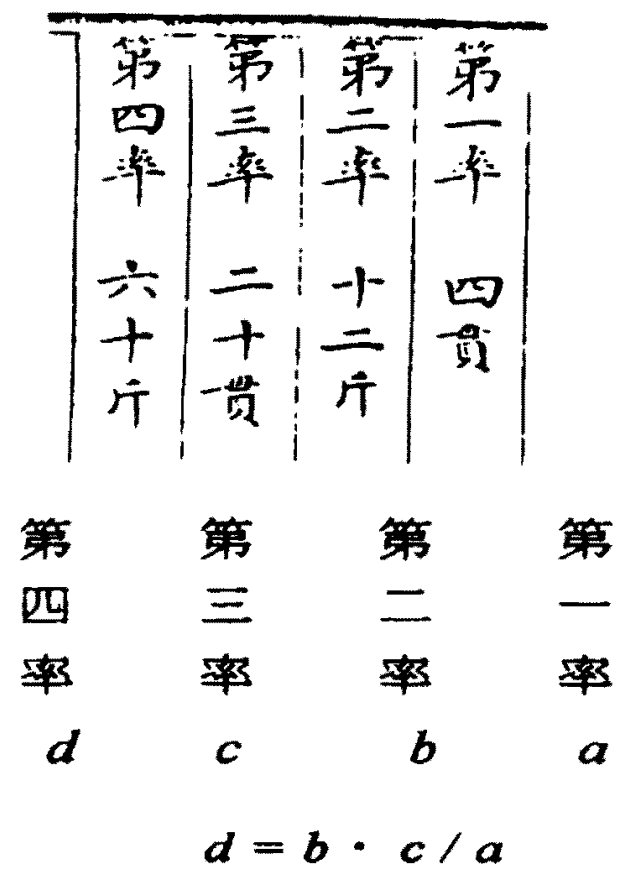

A passage from the Tongwen suanzhi and the system of sanlü-method 
Four columns are used to express the proportional expression. From the right column, the first means term $a$, the second $b$, the third $c$, and the fourth $d$. Only this juxtaposition indicates that this is a proportional expression. If one did not know the value of $d$, one would calculate : $d=b$.c /a.

After Li Zhizao, this calculation became very popular in the world of Chinese mathematics. It was found especially useful within calendar-making, where the rule of three was frequently used for the explanation of spherical trigonometry. For example, one Chinese mathematician, Mei Wending 梅文 鼎 (1632-1721), skilfully used the rule of three to explain the series of formulae of spherical trigonometry in his Lisuan quanshu 曆算全書 (Complete Work on Calendar Mathematics, 1723), which was afterwards imported into Japan in the 1730s. Therefore Chinese traditional mathematics found an appropriate position for the proportional expression within the most important work for them, namely, calendar-making.

Here we will turn our eyes to Japan. After the Tokugawa government rigorously imposed the banishment and purge of Jesuit missionaries and ordinary Christians from the 1630s onwards, the policy of seclusion in Japan was strictly enforced. As a result, the first generation of traditional Japanese mathematicians, who were shut from new Chinese information, had to explore mathematics with their own innovations. In those days, as a new trend of Chinese mathematics was led by Jesuit knowledge, the books written by them were on the list of forbidden books. Thus, their available sources were inevitably limited mainly within very old Chinese textbooks like the Suanxue qimeng 算學啓蒙(Introduction to Mathematics, 1299), and the Yanghui suanfa 楊輝算法 (Yanghui's Mathematical Methods, 1274-1275).

With regard to the history of the proportional expression, the founders of Japanese mathematics, including Seki Takakazu 關孝和(?-1708), were familiar with proportional problems using the solution by the rule of three. Moreover, they could enlarge upon the scope of the technique not only for arithmetical problems, but for those of the similarity of figures. In particular, they made every effort to solve the problems of the similarity of right triangles. This enlargement had been completed by the time of Seki. Furthermore, they expressed their results with their own notation system founded by Seki, named ijo-hô 維乘法 (literally cross-multiplication method). At least we can observe that this system was used on the materials in the 1680s (e.g. Takebe Katahiro's Hatsubi sanpò endan genkai 發微算法演段哜解, 1685).

In order to express the formula, " $a$ is to $b$ as $c$ is to $d "$, we arrange these terms as a matrix. (See Fig. 2) 
Figure 2

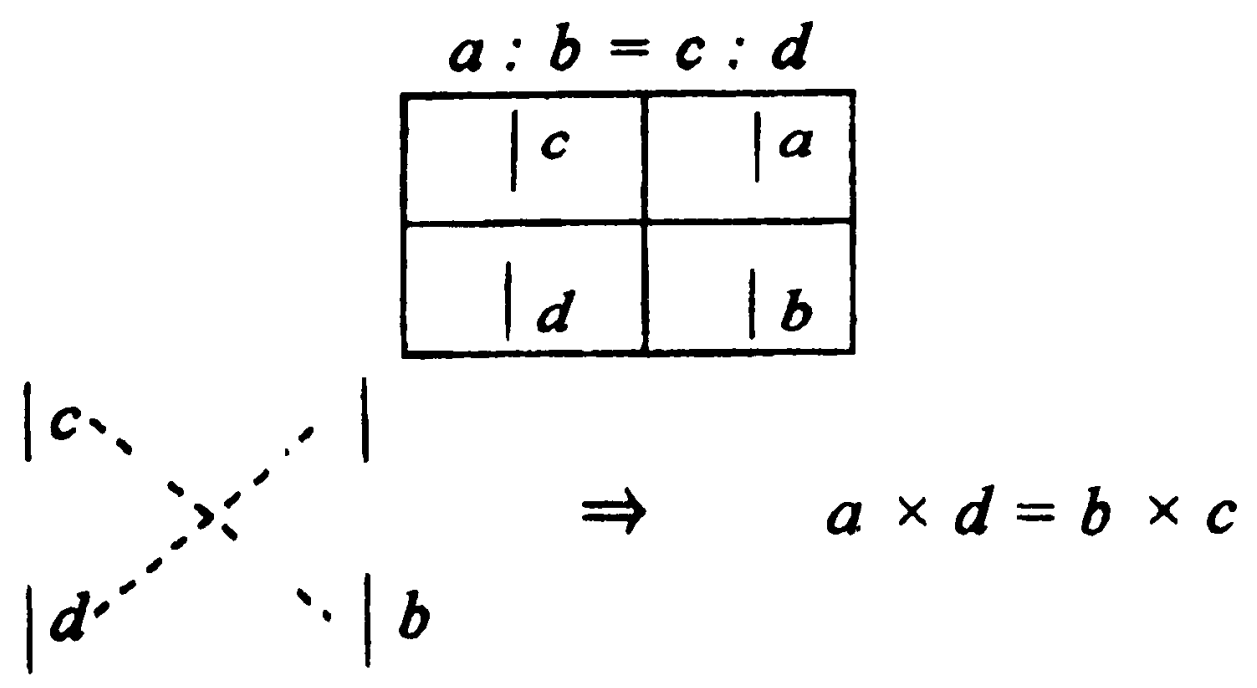

The System of $l j \hat{o}-h \hat{o}$

The sign "I" means that the numerical coefficient of each term is number 1 .

In reality, it is doubtful whether Japanese mathematicians recognised this expression as our modern expression " $a$ is to $b$ as $c$ is to $d$ " because this expression implicitly indicates a.d $=b$.c (this was the reason why they called it ijô-hô, cross-multiplication method).

Rather, they took it for granted that the essence of this expression was revealed by this multiplication. We should notice that they had already founded their own method of expressing proportion or its equivalent before the Lisuan quanshu was imported in Japan.

The Tokugawa government decided to lift the ban on prohibited books from China in 1720. That decision was made by shogun Tokugawa Yoshimune 德川吉宗(1684-1751), whose aim was to renew the Japanese calendar system. After the lift, first of all, the Lisuan quanshu was imported from China. Takebe Katahiro 建部賢弘(1664-1739), who was a disciple of Seki, interpreted this treatise with Japanese punctuation, and presented it to the government in 1733. After this, the book was circulated among Japanese mathematicians.

The Lisuan quanshu contains many passages mentioning the rule of three used for the interpretation of spherical trigonometry. Japanese mathematicians very honestly imitated this style. Namely, they used the rule of three as a special instrument for spherical trigonometry. Needless to say, we know this method could be used for various types of problems. As a result, the proportional expression of Chinese style, that is, the sanlu-method, was used only for spherical trigonometry in Japanese mathematics. Thus there were 
two notation systems to express one formula, the rule of three. I shall discuss possible reasons for this below.

However, in the course of their history, Japanese mathematicians did not immediately accept the Chinese style of the rule of three as explained in the Lisuan quanshu. At least we can find neither this expression, nor the word bili, hirei in Japanese, in Takebe's works. As far as we know, the first mathematician who consciously used the word hirei was Ajima Naonobu (1732-1798). But he wrote only a commentary on one passage of the Lisuan quansh $u$ where the rule of three was used. His scholia expressed the correspondence between the traditional $i j \hat{o}-h \hat{o}$ style and the Chinese rule of three with the aid of the word hirei. In his commentary text, we can easily observe that for Ajima the Chinese rule of three should be reinterpreted by ijo-ho which might have been more familiar to him.

But Ajima's able disciple, Sakabe Kouhan 坡部廣胖(1759-1824), did not use his master's attempt. Boldly he gave the traditional ijo-ho system a new name, hirei-shiki 比例式, which is used today as the translation of " proportional expression". Moreover, it is interesting that he kept two notation systems in his book, the Sanpô tenzan shinanroku 算法點窗指南錄

(The Instruction of Tenzan Method, 1810). One was hirei-shiki of traditional Japanese style, and the other, the rule of three written in Chinese style. The former was used to solve quite elementary arithmetical problems, and the latter those of spherical trigonometry (See Fig. 3 and Fig. 4).

Figure 3

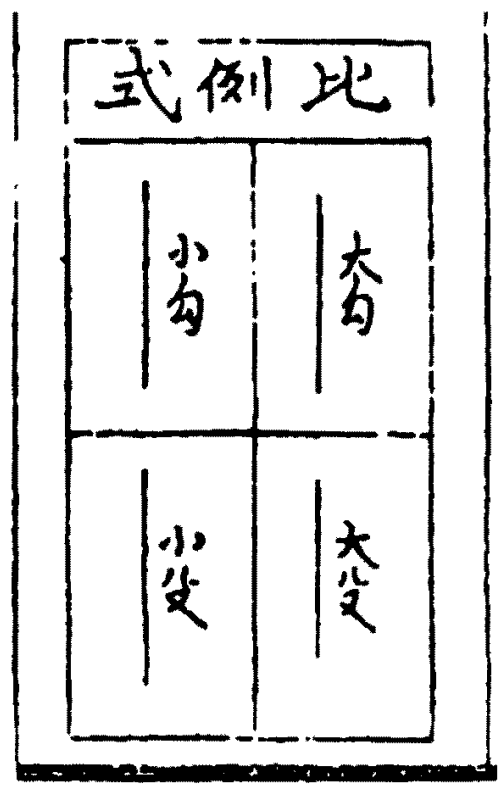

Sakabe's hirei-shikı 
Figure 4
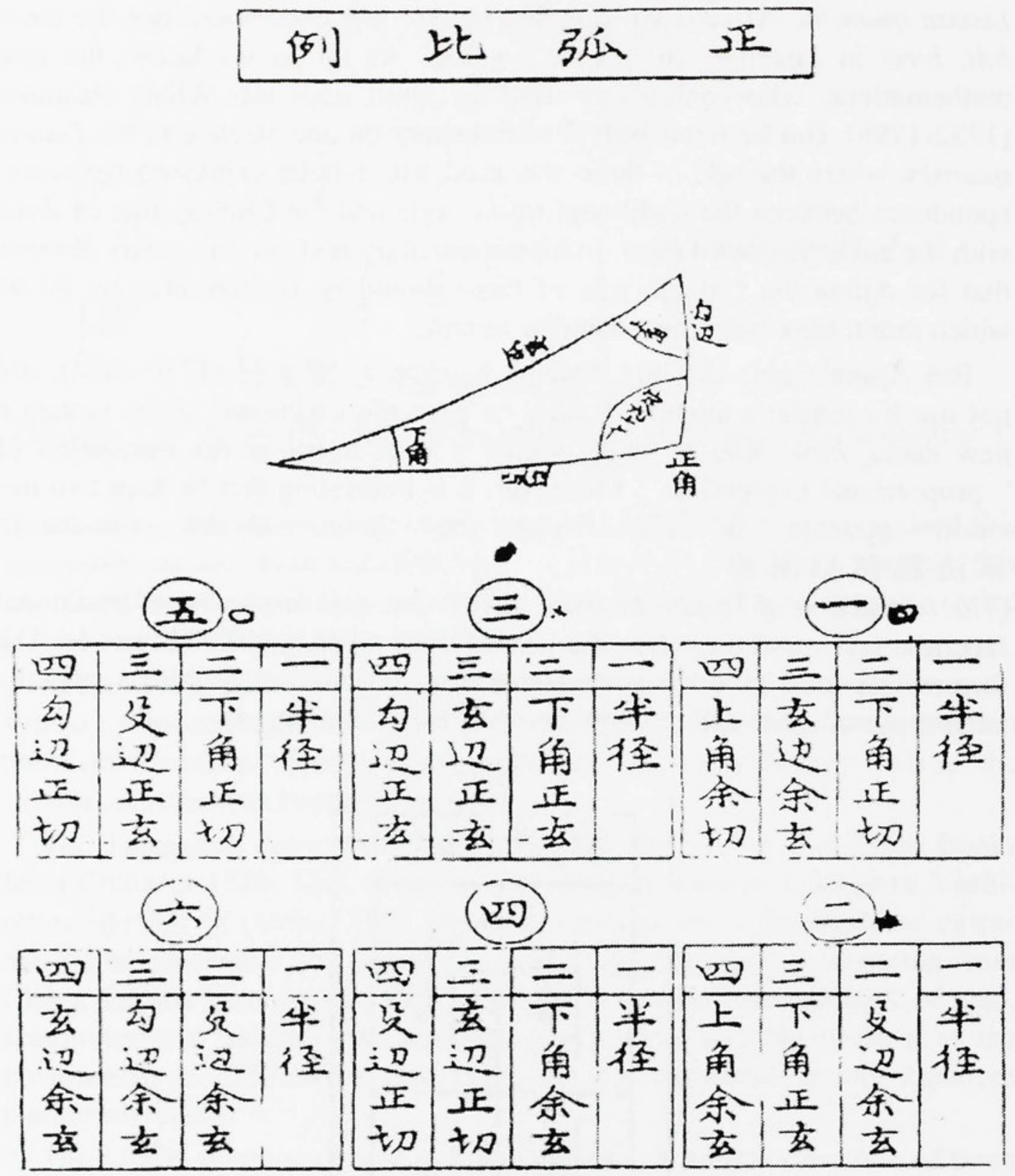

The Formulae of Spherical Trigonometry Introduced by Sakabe

The system of the rule of three expressing a series of formulae for a spherical triangle. 
Strangely enough, Sakabe wrote his commentary on spherical trigonometry in an appendix or more precisely in an "Extra” (Bangai 番外). This means that calculation of this subject was not taken into account as a major item for mathematicians. As he wrote in the same place, this calculation was mainly used for calendar-making.

Sakabe's treatment of the calculation of trigonometry, i.e. the fact that he put it aside into the "Extra" evokes a natural question. That is, did he not recognise spherical trigonometry as a proper object for mathematicians? And if not, why? Here we must discuss these problems from another viewpoint relating to the duality of the notation system expressing the rule of three. There are three key words to answer them : the conservativeness, the " newfangledness", and the " professionalization" of mathematicians at his time.

It was precisely at this time that Sakabe discovered that the rapid augmentation of the number of amateur mathematicians was due to the emergence of cultural popularization in the $18^{\text {th }}$ century. Such an increase in the number of amateur mathematicians needed some principle to control their own activity under a hierarchical system. Thus, they adopted the so-called iemoto 家元 system, which characterised the mass-culture in those days, and which nowadays survives (iemoto refers to the presidential master of this hierarchy). This organisation and sectarianism inevitably resulted in conservativeness and toadyism. In the course of that, the name of Seki came to be

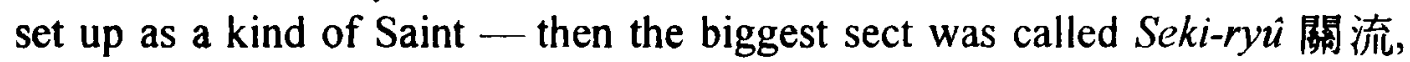
that is, Seki school. Sakabe also acted there as one of the leaders. Their conservativeness prevented them from changing Seki's notation system into Chinese style. In other words, they were so accustomed to their traditional system that they did not feel the necessity to change the system at all - we have only to see the case of Ajima.

Moreover, from the viewpoint of the constituents of mathematics, their style of making the problems and solutions was suitably configured to use the traditional system - they made every effort to inquire the very complicated and nonsense problems. These amateur mathematicians without any exception studied such " sophisticated" mathematics as a kind of hobby or entertainment. Their interest was projected not to the minute and boring numerical computations of trigonometry, but to the aesthetic and attracting problems of figures solvable by the traditional system, $i j \hat{o}-h \hat{o}$.

Japanese mathematicians were, however, newfangled as well as conservative in a way. In fact, they were very sensitive to novelties from China, as they were searching new sources to create new types of problems. It did not seem that it was contradictory for them to accept the authority of both the 
Japanese master Seki Takakazu and Chinese new mathematics, perhaps because they recognised that their mathematics was a descendant of Chinese mathematics. Sakabe, though from hindsight, solved neatly a difficult problem, that is, the compatibility of tradition and innovation. His solution was to replace the traditional expression, $i j \hat{o}-h \hat{o}$, by a new Chinese name, hirei-shiki. He kept the tradition by the local using notation, and at the same time, he could satisfy the tendency to Sinophilia by borrowing Chinese names.

From our discussion, we can see another aspect relating to the history of Japanese mathematics. That is the existence of scholars or practitioners who used mainly the rule of three of the Chinese system in their work. They belonged to groups of astronomers or surveyors, whose vocation made them frequently use trigonometry. Paradoxically, from the viewpoint of traditional Japanese mathematicians' standard, such practitioners should have been classified as non-mathematicians who utilised mathematics. Most astronomers or surveyors were more or less associated with governmental or provincial official work. So they were completely separated from the greater part of amateur mathematicians. Of course some mathematicians worked in the national observatory as astronomers or in the office of civil engineering as surveyors. But it is worth noting that their activity was Janus-faced. As mathematicians, they would study very complicated geometrical problems as a hobby, and as astronomers, they would use an abacus to calculate trigonometry as his service. As most of them did not have to bind themselves with the authority of iemoto, they could be free from the traditional Japanese notation system. To begin with, their main purpose was to make a precise calendar or map relying on accurate calculations, not to be entertained by nonsense problems. This strange bi-polarization of scholars should be interpreted as the "professionalization" of Japanese mathematicians, though they had no social standing nor status. Their professionalization was attained by leaving behind the professors of astronomers and surveyors. Of course these scholars had never lived in the same world from the outset.

These are the reasons why Sakabe's book treated the material of spherical trigonometry as an extra rather than as a mainstream topic. After Sakabe's work, the name of hirei-shiki, that is, proportional expression, and its notation system by traditional $i j o \hat{o}-h \hat{o}$ were completely established in the world of Japanese mathematics. And nothing, neither the duality of their notation system, nor their style of social activity, changed for another half century, until the beginning of the Meiji period. Confronted with modernisation, the authority of iemoto was replaced by that of the new government, who ordered them to abolish traditional Japanese mathematics. 


\title{
CONTRIBUTORS
}

\author{
Alain ARRAULT \\ Catherine JAMI \\ Université de Liège \\ CNRS \\ Liège (Belgique) \\ Paris (France) \\ Gregory BLUE \\ University of Victoria \\ Victoria, B.C. (Canada) \\ Yung Sik KIM \\ Seoul National University \\ Seoul (Korea) \\ CHEN Meidong \\ Jacob KISTEMAKER \\ CAS Institute for the History \\ FOM Institute for Atomic and \\ of Natural Sciences \\ Beijing (China) \\ Molecular Physics \\ Amsterdam (The Netherlands) \\ H. Floris COHEN \\ Georges MéTAILIÉ \\ University of Twente \\ CNRS - MNHN \\ Enschede (The Netherlands) \\ Paris (France) \\ Véra DOROFEEVA-LichTMANN \\ Dhruv RaINA \\ University of Göttingen \\ National Institute of Science, \\ Göttingen (Germany) \\ Technology and Development Studies \\ New Delhi (India) \\ Peter J. Golas \\ University of Denver \\ Denver, co (USA) \\ Ken'ichi SATo \\ Saitama (Japan) \\ Keizo Hashimoto \\ Kansai University \\ Osaka (Japan) \\ Togo TsuKahara \\ National University of Kobe \\ SUN Xiaochun \\ University of Pennsylvania \\ Philadelphia (USA)
}



